\title{
ESSAYS ON INTERGENERATIONAL TRANSMISSION IN KOREA
}

\author{
A Dissertation \\ presented to \\ the Faculty of the Graduate School \\ at the University of Missouri-Columbia
}

In Partial Fulfillment

of the Requirements for the Degree

Doctor of Philosophy

by
JOONHONG AHN
Mueser, Dissertation Supervisor

JULY 2021 
The undersigned, appointed by the Dean of the Graduate School, have examined the dissertation entitled:

\section{ESSAYS ON INTERGENERATIONAL TRANSMISSION IN KOREA}

presented by Joonhong Ahn, a candidate for the degree of Doctor of Philosophy and hereby certify that, in their opinion, it is worthy of acceptance.

\begin{tabular}{c}
\hline Professor Peter Mueser \\
\hline Professor Shawn Ni \\
\hline Professor David M. Kaplan \\
Professor Brian Kisida
\end{tabular}




\section{ACKNOWLEDGMENTS}

I sincerely appreciate my advisor, Professor Peter Mueser, for his continuous support and guidance to become an economist during my Ph.D. course. He was always willing to listen to my academic and non-academic issues and advised me to have the right solutions. He also provided me great opportunities to work on two projects for him. While working with him for the past four years, I have learned priceless lessons to my professional career and personal life. Without his invaluable advice and overwhelming support, I could not have completed my degree with a satisfactory result.

I am indebted to a number of the faculty members in the Mizzou Department of Economics. Dr. Shawn Ni has always been interested in my research and provided significant guidance and comments on my papers. Dr. Kaplan always welcomed me anytime I asked questions on econometrics and provided ways to find solutions that helped to understand how to connect econometrics theories and applications. In addition, I would like to thank Dr. Loginova that she put her trust in me for more than two years while working for her as a teaching assistant. Also, I thank Drs. Wang and Haslag, as well as wonderful staff members (Lynne Owen, Pamela Gerth, and Sue Leutschaft) for their supports. I also thank my friends; Dr. Ingul Baek, Dr. Tai Lee, Dr. Sanha Noh, Dr. Sanguk Kwon, Mr. Heon Lee, and Mr. Dongho Kang, for their supports of my researches and valuable memories in Columbia. Lastly, I would like to express my gratitude to Dr. Kyung-Seong Jeon who always share his thoughts on discussions.

Last but not the least, I especially appreciate my wife, Hyunyoung Lee, for her unlimited support, trust and patience. I tremendously thank my parents for their supports to begin my academic journey in the U.S. Without my family's sacrifice, I cannot earn this dissertation and degree. 


\section{TABLE OF CONTENTS}

ACKNOWLEDGMENTS ................. ii

LIST OF TABLES ................... vi

LIST OF FIGURES $\ldots \ldots \ldots \ldots \ldots \ldots$ viii

ABSTRACT ................... ix

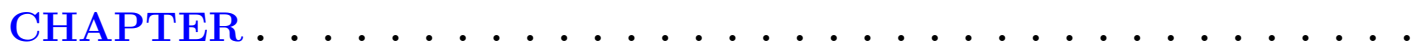

chapter1

Intergenerational Transmission of Earnings and Human Capital in Korea and the Role of Vocational Education1chapter.1

1.1 Introduction . . . . . . . . . . . . . . . . . 1

1.2 Literature Review . . . . . . . . . . . . . . . . . . . . 4

1.3 The Education System in Korea . . . . . . . . . . . . . . . 8

1.3.1 General Education Structure . . . . . . . . . . . . . 8

1.3.2 The Role of Vocational High School . . . . . . . . . . . . . 9

1.4 Data . . . . . . . . . . . . . . . . . . . . . . . 11

1.4.1 Korean Labor and Income Panel Study (KLIPS) . . . . . . . 11

1.4 .2 Sample Description . . . . . . . . . . . . . . . . . . 13

1.5 Empirical Strategies $\ldots \ldots \ldots \ldots \ldots$

1.5.1 The Effects of Parental Earnings on Children's Earnings _ . . 16

1.5.2 Total Education Effects . . . . . . . . . . . . . . 18

1.5.3 Intergenerational Transmission of Education . . . . . . . . 19

1.6 Empirical Results . . . . . . . . . . . . . . . . . . . . . . . . 21

1.6.1 Estimation of Intergenerational Earnings Relationships . . . . 21

1.6.2 Total Effects of Education . . . . . . . . . . . . 28 
1.6.3 Estimation of Intergenerational Transmission of Education and the Role of Vocational and Academic High School . . . . . . . 33

1.7 Robustness Checks . . . . . . . . . . . . . . . . . . . . 37

1.8 Conclusion . . . . . . . . . . . . . . . . . . . . . . . . . 43

2 Nonparametric Bounds on Intergenerational Transmission of Human Capital in Korea . . . . . . . . . . . . . 46

2.1 Introduction . . . . . . . . . . . . . . . . 46

2.2 Empirical Specification . . . . . . . . . . . . . . . 50

2.2 .1 No Assumption Bounds . . . . . . . . . . . . . . . . . 51

2.2.2 Monotone Treatment Response . . . . . . . . . . . . . 53

2.2.3 Monotone Treatment Selection . . . . . . . . . . . . . . . 55

2.2.4 Monotone Instrumental Variables _ . . . . . . . . . . . 57

2.3 Data: Korea Labor and Income Panel Study (KLIPS) . . . . . . . . 63

2.4 Results . . . . . . . . . . . . . . . . . . . . . 65

2.4.1 Treatment Effects on Child's Years of Schooling . . . . . . . 65

2.4.2 Treatment Effects on Child's College Completion . . . . . . 70

2.5 Discussion and Conclusion . . . . . . . . . . . . . . . . . 74

3 Effects of Parents' Health Problem on Children's Education Attainment ................... 77

3.1 Introduction . . . . . . . . . . . . . . . . 77

3.2 Empirical Strategy $\ldots \ldots \ldots \ldots$. . . . . . . . . . . . . . 81

3.3 Data . . . . . . . . . . . . . . . . . . 83

3.3.1 Korea Labor and Income Panel Study (KLIPS) _ . . . . . 83

3.3.2 Sample Description . . . . . . . . . . . . . . . . . 85

3.4 Empirical Results . . . . . . . . . . . . . . . . . . . . . 88

3.4.1 The Effects of Parental Illness on Children's College Attendance 90 
3.4.2 The Effects of Parental Illness on Children's Years of Schooling 97

3.4.3 The Effects of Parental Illness with Controlling for Parental Income . . . . . . . . . . . . . . . . . . . . . . 105

3.5 Discussion and Conclusion . . . . . . . . . . . . . . . . . . 108

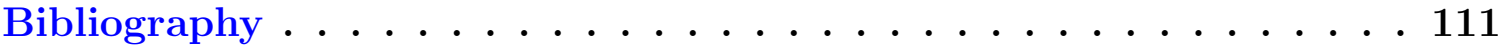

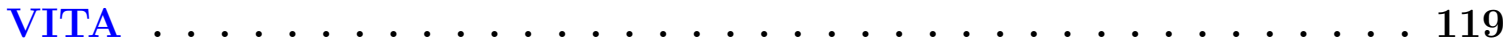




\section{LIST OF TABLES}

Table Page

1.1 Transition in vocational high school curriculum: 1998-2012 . . . . . . 10

1.2 Earnings distribution of parents and children . . . . . . . . . . . 14

1.3 Sample statistics of education . . . . . . . . . . . . 15

1.4 The effects of parental earnings on sons' earnings . . . . . . . . . 23

1.5 The effects of parental earnings on daughters' earnings . . . . . . . . 24

1.6 Effects of children's vocational high school degree on their earnings . 26

1.7 The effects of father's schooling on sons' educational achievement . . 34

1.8 The effects of father's schooling on daughters' educational achievement 35

1.9 The effects of family characteristics on children's vocational high school

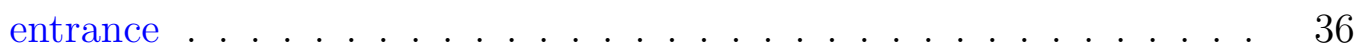

1.10 Intergenerational earnings association by parental earnings distribution 39

1.11 Robustness checks for sons . . . . . . . . . . . . . . . . . . . . 40

1.12 Robustness checks for daughters . . . . . . . . . . . . . . . . 41

1.13 Year fixed effect of the intergenerational earnings relationship . . . . 42

2.1 Summary Statistics . . . . . . . . . . . . . . . 64

2.2 Child's Schooling Outcomes by Parent's Education and Father's Oc-

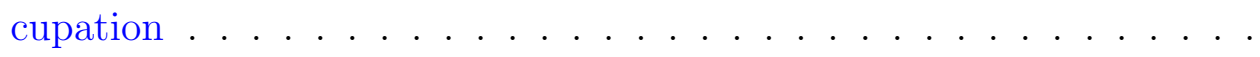


2.3 ETS Point Estimates and Bounds of A Parent's Education on Child's Years of Schooling . . . . . . . . . . . . . . . . 67

2.4 ETS Point Estimates and Bounds of A Parent's Education on Child's College Completion . . . . . . . . . . . . . . . . . . . . . 71

3.1 Sample Description . . . . . . . . . . . . . . . . . 86

3.2 Parents' Illness Identification Power . . . . . . . . . . . . . . . . . 89

3.3 Paternal Illness Effects on Children's College Attendance . . . . . . . 91

3.4 Maternal Illness Effects on Children's College Attendance . . . . . . . 92

3.5 Paternal Severe Illness Effects on Children's College Attendance . . . 95

3.6 Maternal Severe Illness Effects on Children's College Attendance . . . 96

3.7 Paternal Illness Effects on Children's Years of Schooling . . . . . . . . 99

3.8 Maternal Illness Effects on Children's Years of Schooling . . . . . . 100

3.9 Paternal Severe Illness Effects on Children's Years of Schooling . . . . 102

3.10 Maternal Severe Illness Effects on Children's Years of Schooling . . . 103

3.11 Correlation Between Father's Illness and Education . . . . . . . . . 105

3.12 The Effects of Parents' (Severe) Illness on College Admission with Controlling for Parents' Income . . . . . . . . . . . . . . . . 106

3.13 The Effects of Parents' (Severe) Illness on Years of Schooling with Controlling for Parents' Income . . . . . . . . . . . . . . . . 107 


\section{LIST OF FIGURES}

Figure

Page

1.1 Total educational effects of sons and fathers on sons' earnings: Son less

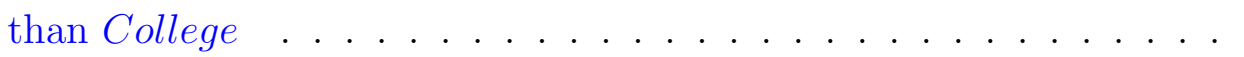

1.2 Total educational effects of sons and fathers on sons' earnings: Son at least College . . . . . . . . . . . . . . . . . . . . . . 30

1.3 Total educational effects of daughters and fathers on daughters' earnings: Daughter less than College . . . . . . . . . . . . . .

1.4 Total educational effects of daughters and fathers on daughters' earnings: Daughter at least College . . . . . . . . . . . . . 


\section{ABSTRACT}

This dissertation studies the effects of parents' resources on children's labor market outcomes in Korea. The educational structure in Korea has changed substantially with rapid economic growth over the last several decades. There is a substantial difference between parents and children's average educational attainment. Because of economic development and schooling difference between parents and children, the intergenerational transmission of economic status may show different patterns than in developed countries. In addition, parents' health problems may play a role to limit children's educational attainment by reducing parenting quality during early childhood or adolescent periods. The dissertation estimates various causal channels of parents' economic resources to children. The dissertation consists of three chapters.

In Chapter 1, I investigate the intergenerational relationship of earnings and education in Korea with particular attention to the trajectories of vocational and academic high school graduates. I estimate that the intergenerational earnings elasticity in Korea is 0.4 , which is consistent with previous studies. When educational attainment of fathers and child are controlled, parental earnings are positively associated with children's earnings, although the association decreases to 0.08 (0.10) for sons (daughters). Sons whose fathers completed only a vocational high school degree have a greater chance of attending college than sons whose fathers completed only an academic high school degree. A college degree of a father helps children to have higher earnings and to increase their chance of attending and graduating from college. Father's education has a stronger impact on children's earnings when children's educational attainment is higher. A vocational high school degree reduces a child's probability of attending and completing college compared to academic high school graduates. However, notwithstanding this educational disadvantage, vocational grad-

uates do not appear to suffer substantially in terms of expected earnings, relative to 
academic high school graduates.

In the second chapter, I estimate the average causal effects of parents' educational attainment on the educational attainment of children in Korea using a new method, the nonparametric bounds approach. This approach does not require the assumption of homogeneous and linear effects of parental schooling. It also uses relatively weaker assumptions, monotone treatment response and monotone treatment selection, than assumption underlying other methods and is more amenable to testing. With the additional assumption of monotone instrumental variables, it provides the tightest bounds on the average treatment effects (ATE) that an increase in parents' education increases children's educational success. It also shows the effects are overestimated in simple regression models.

The third chapter examines the effects of parental health on children's educational attainment. Parental illness changes parenting quality both by affecting family wealth and in other ways that influence children's labor market outcomes. Parental health problems can especially have relatively larger impacts on children's education when children are in either primary or secondary education than other periods. Longitudinal data from the Korean Labor Income Panel Survey, for the period 1998 2018, enables me to examine parental illness effects in the early childhood and adolescent period on ultimate educational achievement. Empirical application in this paper pays attention to situations that each parent's either unexpected or chronic health problems change children's human capital. 


\section{Chapter 1}

\section{The Intergenerational Transmission of Earnings and Human Capital in Korea and the Role of Vocational Education}

\section{$1.1 \quad$ Introduction}

A vast literature has studied inequality in a variety of economic outcomes to find out the important factors causing increases in economic inequality. While dispersion of the income distribution has increased substantially, interest in intergenerational mobility has grown as a factor influencing inequality. Because education is one of the most important variables in explaining earnings, an increase in the variance across educational attainment could be an important factor in rising earnings inequality. ${ }^{1}$ Education also plays a crucial role in the intergenerational mobility. Parental earnings and educational attainment can influence children's education, which affects children's earnings. Prior studies of the intergenerational mobility have focused on transmis-

\footnotetext{
${ }^{1}$ Lemieux (2006) finds that increases in the return to post-secondary education can explain some of wage inequality changes.
} 
sion of parental income (Mazumder and Levine (2002); Lee and Solon (2009); Corak (2013a, b); Chetty et al. (2014a,b)) and effects of parental education on children's economic outcomes, educational attainment and earnings (Restuccia and Urrutia (2004); de Haan (2011); Holmlund et al. (2011)).

While most of the prior studies of parental educational transmission focus on estimating the effects of parental education on children, this study allows us to show what effects parental background, including earnings and paternal education, have on children's educational attainment and earnings using detailed educational attainment. Although educational attainment is usually measured by years of schooling obtained, I also distinguish by type of high school: academic and vocational high school. Parental earnings and paternal schooling level can affect children's economic outcomes both directly and indirectly. Since a father's education is a key factor in explaining his own earnings, a father's education can indirectly affect children's outcomes through parental earnings. This study investigates the intergenerational transmission of earnings and education in Korea using detailed educational variables considering the effects of parental earnings and paternal educational level simultaneously.

Korea provides a particularly interesting case, as Korean economic growth during the last half century has been among the highest in the world, propelling the country from the bottom half of the income distribution to the rank of developed countries. The rate of growth in educational achievement was particularly fast during the last decades of the twentieth century. In 1980, the college attendance rate was only 27 percent, but by 2000 it had increased to 80 percent. $^{2}$ As a result, for those reporting educational attainment and income in our analysis in the period since the turn of the century, the average education of parents would be much lower than that of

\footnotetext{
${ }^{2}$ According to Ministry of Education \& Technology (2008), only $27 \%$ of high school graduates attended a college in 1980, but it increased over $85 \%$ in 2000. Almost $90 \%$ of academic high school graduates has enrolled a college since 2005.
} 
respondents. My analysis poses the question of whether such rapid change could disrupt the intergenerational status transmission process.

In Korea, there is a well-organized vocational education system at the secondary education level. Since the 1960s, with initiation of the National Curriculum Plan, secondary education has been provided by two types of high schools: academic high schools and vocational high schools. Students in vocational high schools learn specific vocational skills. After graduating from a vocational high school, they can enroll in college, like academic high school graduates, although most of them enter the labor market. In studies looking at U.S. data, Acemoglu (2002) and Autor et al. (2006) show that demand for tasks of middle-skilled workers has shrunk due to skill biased technology changes. Introduction of new technologies causes job polarization, by which the middle-skilled tasks are replaced with new technologies, but they cannot substitute for low- and high-skilled tasks. In this paper, I can use detailed parental educational attainment to estimate educational transmission to the successive generation. This paper investigates empirically how a father's vocational high school degree is related to his children's education and future earnings. It also examines the effect of a vocational high school degree of both fathers and children on children's labor income and compares this to labor market outcomes for academic high school graduates.

Using the Korean Labor and Income Panel Study (KLIPS), the first and the largest employment-focused data set in Korea, which provides a panel of respondents extending from 1998 to 2016, I calculate the intergenerational earnings elasticity. In particular, I measure the relationship between the log of parental labor income and the log of children's earnings using ordinary least squares (OLS) and quantile regression approaches. Then, I fit a model to predict the total effects of educational attainment of both fathers and children on children's earnings. I also estimate the effects of paternal education and other family background factors on children's educational 
achievement, predicting both college attendance and college completion. Based on detailed educational information of both fathers and children, this study is able to estimate the effects of paternal educational attainment on college attendance and completion and earnings of children. These analyses allow us to identify how various family background factors are related to the intergenerational correlation of earnings and transmission of education. I focus particular attention on the effects of vocational high school degrees of fathers on children's earnings and education.

The remainder of this study is organized as follows: Section 2 describes previous studies concerning intergenerational mobility. In section 3, I describe the educational system in Korea. Section 4 describes the Korean Labor and Income Panel Study (KLIPS) dataset that is used in this study and shows details of variables and basic data statistics. I present models to estimate the role of vocational high school in intergenerational effects in section 5 and discuss results in section 6 . Section 7 presents robustness checks that test the sensitivity of the intergenerational earnings relationships. Section 8 concludes this study.

\subsection{Literature Review}

Becker and Tomes $(1979,1986)$ develop models of parents' human capital investment in their children and identify the importance of credit constraints in educational investment models, particularly those affecting educational opportunity when children are in either primary or secondary school. Also, Becker et al. (2018) describe how increasing earnings inequality or an increasing education premium brings about endowment inequality among households, which decreases intergenerational mobility, as it induces a strong positive relationship between endowments and children's economic outcomes. Solon (1999) summarizes relevant theoretical and empirical studies. He gives an overview of empirical studies based on three topics: earnings correla- 
tions of siblings, intergenerational earnings elasticity, and neighborhood effects on intergenerational transmission of earnings. Mogstad (2017) reviews the theories of human capital investment of Becker and Tomes and related empirical studies, raising questions regarding the assumptions made by Becker and Tomes.

Recent empirical research on intergenerational mobility has been focused on measuring changes in economic status between parents and children based on the intergenerational earnings elasticity. Most studies of intergenerational mobility use data from European countries and the United States. For example, Dearden et al. (1997) Blanden et al. (2004), and Nicoletti and Ermisch (2008) analyze Britain, and Bjorklund and Jantti (1997) analyze Sweden; Bjorklund and Jantti (1997), Mazumder and Levine (2002), Mazumder (2005), Lee and Solon (2009), Corak (2006, 2013a, b), and Chetty et al. (2014a, b) estimate the intergenerational mobility in the U.S. The average estimated intergenerational earnings elasticity in the U.S. is around 0.4 but Lee and Solon (2009) point out that studies have yielded widely divergent estimates, varying from 0.20 to 0.45 . However, Lee and Solon suggest that the transmission effects of parental earnings in the U.S. have not changed significantly over two decades.

Corak (2013a) estimates what Alan Krueger calls as "The Great Gatsby Curve," which shows the positive relationship between changes in economic inequality and the intergenerational earnings elasticity. He shows that the equality of economic opportunity declines when income inequality and the college premium increases. Chetty et al. (2014a, b) also estimate the intergenerational mobility of income in the U.S. using the federal income tax records, but they use the income rank of parents and child as measures of mobility. They argue that the traditional log-log specification shows a nonlinear relationship between parents' and child's income because the intergenerational income elasticity is less in the bottom and top of the income distribution. They employ a rank-rank specification, which shows a linear relationship at all income levels. With the rank-based measure, Chetty et al. (2014a, b) indicates that 
mobility has not changed significantly in the 2000s, although inequality has grown due to a shift in the upper end of the income distribution. An increase of 10 percentage points of the parental income rank induces an increase of about 3.5 percentage points of children's income rank. Generally, recent studies show that the U.S. has lower intergenerational mobility of income than European countries.

Holmlund et al. (2011) review the empirical literature on the causal relationship between parental education and child's education, showing that the estimation results differ significantly across studies. They also employ three identification strategies to estimate the intergenerational association of education using Swedish register data: using families of twins, using adoptees, and using an instrument. Although parental schooling plays a substantial role in children's educational attainment in the reviewed previous studies, the causal effects of parental education represent a small part of the factors influencing a child's education in Sweden.

De Haan (2011) estimates the intergenerational educational association using a new identification strategy, the nonparametric bounds method, which gives bounds on the causal effects of parental educational attainment. She finds that an increase in education from high school to a college degree of either parent has positive impact on a child's education, but their magnitudes are lower than estimates based on OLS. Additionally, many studies investigate the intergenerational transmission of cognitive ability (Blanden et al. (2007); Gronqvist et al. (2017); Conti and Kopinska (2018)). Parental cognitive abilities are positively associated with children's cognitive abilities and educational attainment and so also indirectly influence the labor market outcomes of children through the educational attainment of children.

Several studies have estimated the intergenerational mobility of income in Korea (Kim (2009); Ueda (2013); Richey and Jeong (2014); Lee (2014); Kim (2017)). Ueda (2013) estimates the intergenerational elasticity of earnings in Korea using an ordinary least squares analysis with multiple-year average methods. This approach 
takes averaged annual parental earnings for two to five years as a proxy of permanent income in order to reduce measurement error relative to empirical studies that use observed annual earnings. He shows that the average intergenerational elasticity of earnings is relatively lower in Korea, around 0.25, than the U.S., which is around 0.4 (Solon (1992)), but the exact value depends on which multiple-year average method is used. Kim (2017) extends Ueda's analysis, using more accurate fathers' permanent earnings, imputing missing earnings of fathers using the information of the father's birth cohort. He points out that Ueda uses the fathers' information for incorrect years to impute missing fathers' annual earnings, which he argues reduces the estimates of the intergenerational earnings elasticity. By using a fathers' sample with appropriately matched years, Kim finds that an increase of 1 percent of a father's earnings increases children's earnings by 0.4 percent, which is similar to that of the developed countries.

Lee (2014) examines the effects of an educational reform on intergenerational income mobility in Korea. The reform considered is the change from exam-based admission into high school to district-based admission. Intergenerational economic mobility declines after this regime shift since it allows higher-income households to migrate selectively to allow their children to have a better quality of high school education. Most previous studies estimate the intergenerational relationship between fathers and sons, but his analysis uses a sample that includes both sons and daughters. He does not estimate the educational reform effects of intergenerational earnings elasticity separately by gender.

Richey and Jeong (2014) use a quantile regression approach to calculate the effects of fathers' earnings on the shape of sons' earnings distribution. When they add sons' college completion, the intergenerational earnings association is weakened or disappears over quantiles. Similar to Ueda (2013) and Kim (2017), they also employ multi-year average earnings as a measure of permanent earnings of fathers. The results 
show that the transmission of fathers' earnings is relatively larger in the upper quantile of the sons' income distribution than at the bottom, and that college education can be a "tunnel of transmission" of income between generations. Intergenerational earnings elasticity is higher in the top quantile than the bottom, which means that movement into the top quantile of the earnings' distribution for sons is more strongly predicted by high father's earnings than is mean or median earnings.

Recent studies focus on the intergenerational persistence of earnings in Korea, but only a few studies consider the intergenerational mobility of education (Phang and Kim (2001); Nam (2008)). Some studies of income transmission account for the education of children, but they do not control parental education. To fill this gap, we control detailed fathers' and children's educational attainment to analyze how fathers' education is associated with children's education and earnings.

\subsection{The Education System in Korea}

\subsubsection{General Education Structure}

Korean education consists of primary education (first to ninth grade), secondary education (10th to 12th grade), and post-secondary education (above 12th grade). After graduating from ninth grade (middle school, seventh to ninth grade), students determine which type of high school they would like to attend. Generally, high school entry decisions depend on students' achievements in middle school. If they do not

decide where to attend, they are automatically assigned to a general academic high school.

High schools are categorized as 1) specific-purpose academic high schools for foreign languages or science, 2) general academic high schools, 3) vocational high schools, offering practical education or job training, or 4) art and athletic training high schools. 
Students who have high achievement in middle school can enter a specific-purpose high school after passing the school's entrance tests. Art and athletic training high schools have different curricula, focusing on art, music, or physical education. Lastly, 9th-grade students can go to a vocational high school if they would like to learn practical job specific skills. The application decision is made by the students themselves and/or by their parents, although students with low GPAs are more likely to attend vocational high schools. After graduating from a vocational high school, the students can advance to college if they take the Korean College Scholastic Ability Test (Korean SAT). Because many universities have special admission standards for vocational high school graduates, they can attend a college without competing with academic high school students. They can also attend junior colleges to attain two-year degrees. However, vocational high school graduates often enter the market directly, obtaining jobs based on specialized skills learned in high school.

\subsubsection{The Role of Vocational High School}

Vocational education at the secondary level has existed in a variety of forms since Korea was ruled by the Japanese. After the war, demand for high school education in Korea increased, but academic and vocational high schools were not formally distinguished until the middle of the 1960s, when the government initiated the second National Curriculum Plan, which specified high school and vocational high school curricula. This plan specified a vocational curriculum designed for students who planned to look for a job after graduation from high school. The demand for vocational high schools surged in the 1970s. The number of vocational high schools was slightly more than the number of academic high schools due to demand for low and middle level skills. In 1973, there were 563 vocational high schools and 452 academic high schools in Korea. However, the number of graduates of vocational high schools was slightly smaller than those from academic high schools. For over a decade, from the 1970s 
Table 1.1 Transition in vocational high school curriculum: 1998-2012

\begin{tabular}{|c|c|c|c|}
\hline Transition & General Field & & Specialized Field \\
\hline \multirow{5}{*}{ Major Transition } & Technical & $\Rightarrow$ & $\begin{array}{c}\text { Mechanics } \\
\text { Computers (IT) } \\
\text { Architecture } \\
\text { Energy } \\
\text { Mass Media }\end{array}$ \\
\hline & Commercial & $\Rightarrow$ & $\begin{array}{c}\text { Business (bank teller, finance) } \\
\text { Design (graphic, web, fashion) } \\
\text { Business information }\end{array}$ \\
\hline & Domestic economy & $\Rightarrow$ & $\begin{array}{c}\text { Beauty (cosmetic) } \\
\text { Nursing } \\
\text { Tourism \& hospitality } \\
\text { Nutrition }\end{array}$ \\
\hline & Agricultural science & $\Rightarrow$ & Agricultural life science \\
\hline & Marine science & $\Rightarrow$ & $\begin{array}{l}\text { Marine life science } \\
\text { Ship building }\end{array}$ \\
\hline
\end{tabular}

and 1980s, wages of vocational high school graduates rose with those of academic high school graduates, and their job opportunities in the market were not different from academic high school graduates.

In the late 1980s, market opportunities for vocational high school graduates were no longer improving, reflecting changes in the skills demanded by the labor market. In 1998, the government began to reform the structure of vocational education. General vocational high schools became specialized vocational high schools. Table 1 shows the transformation from comprehensive vocational fields to specialized voca- 
tional majors. This transformation was completed in 2012. Technical vocational high schools now specialize in mechanics (including automobile engineering), computers, architecture, energy, or mass media. Commercial vocational high schools specialize in business (mostly for the banking industry), business information (basic management or accounting techniques), or design (graphics, web designs, or fashion designs). Graphic design is often included in the computer major of technical vocational high schools although the design major is primarily included in the commercial vocational high schools, and a shipbuilding major is the focus of marine science vocational high schools although it would appear to be closely related to architecture. ${ }^{3}$

\subsection{Data}

\subsubsection{Korean Labor and Income Panel Study (KLIPS)}

To estimate the intergenerational mobility of economic outcomes in Korea, this study uses the Korean Labor and Income Panel Study (hereafter KLIPS) conducted by the Korean Labor Institute. ${ }^{4}$ KLIPS studies the Korean labor market and income structure of both households and individuals who lived in urban and suburban areas from 1998 to 2016. This is an annual longitudinal survey, and is based on an initial sample with 5,000 households and 13,321 individuals aged 15 and older in 16 metropolitan areas in 1998. An additional 1,415 households were included in the survey in 2009 to improve representativeness of the data and to overcome limitations of attrition and concentration of urban residence.

KLIPS consists of three different data sets: households, household members, and supplemental surveys. KLIPS provides both fathers' and mothers' labor earnings, so

\footnotetext{
${ }^{3}$ The information on majors in vocational high school is available in HIFIVE, which shows vocational high school statistics by each school: http ://www.hifive.go.kr/index.do

${ }^{4}$ The KLIPS is the first Korean panel survey focusing on labor issues. These data are available on the site of the Korea Labor Institute: https ://www.kli.re.kr/klips_eng/index.do
} 
pre-tax earnings of parents in a household can be calculated by summing up labor earnings of fathers and mothers if both parents are employed. These reported earnings include both an average monthly salary for employed workers and average monthly after-tax earnings for those who are self-employed. I restrict the sample to those survey years when children have positive earnings from a regular job. The earnings we consider are of children after they have finished their education, and generally after leaving their parental home. All earnings are converted to real terms using the Korean consumer price index $(2015=100) .{ }^{5}$ I average parental earnings when children were between 15 and 21 years of age. This is because parental earnings are expected to have direct impacts on children's education and future earnings at the time children are in primary or secondary school; using such an average can also reduce measurement error (Solon (1992)).

KLIPS provides an educational supplemental survey at the 11th survey year (2008). All household members between ages 15 and 65 answer the supplementary educational survey. This educational survey contains the educational history of individuals, which includes their final educational attainment, type of high school, major, name of schools attended, location of schools, and academic achievement in middle school and high school. As indicated above, there are several types of high schools in Korea, specific-purposed high schools for foreign languages and science, academic high schools, vocational high schools, and art and athletic training high schools. It is not possible to distinguish art and athletic training high school graduates from specific-purposed academic high school graduates, or individuals who took the GED (high school general equivalency diploma). Altogether, these three make up less than $2 \%$ of individuals in our sample, so we code them with general academic high school graduates. I combine education history data with family background information from both household and individual data. The latter includes age, gender, marital

\footnotetext{
${ }^{5}$ The consumer price index (CPI) in Korea is available on a website of the Bank of Korea: https : //ecos.bok.or.kr/
} 
status, job history, the area of residence, and separation from family when the child was between 15 and 21 years old, usually an indication of attendance at a private boarding school.

This study uses information primarily on fathers and children, although I use total parental earnings as well. I examine the intergenerational persistence effects on labor market outcomes separately for sons and daughters because sons and daughters have different labor market experiences. Richey and Jeong (2014) and Kim (2017) estimate fathers' earnings transmission for only sons. Lee (2014) includes daughters in his sample; he does not separately estimate the educational reform effects on intergenerational earnings elasticity of sons and daughters.

KLIPS contains detailed education information on all household members, and so it allows us to identify educational persistence effects between two generations with very detailed educational information. This study uses the final educational attainment and type of high school (academic or vocational) that the individual attended. I omit children still attending educational institutions in the last year of the survey because I cannot anticipate their final educational attainment.

\subsubsection{Sample Description}

Tables 2 and 3 provide summary statistics of earnings and education of parents and children. Table 2 shows the number of observations and individuals in this sample of monthly earnings of both sons and daughters and their parents. Parental earnings are calculated by summation of average monthly earnings of father and mother. Parental earnings are averaged for the period when children were between 15 and 21 years of age. I exclude parental earnings from this average for years in which the data are missing and where we have zero total earnings, which are likely to be due to non-response. As expected, parental earnings of sons and daughters have similar distributions. Averaged parental earnings are higher than children's earnings. The 
Table 1.2 Earnings distribution of parents and children

\begin{tabular}{crccc}
\hline \hline \multirow{2}{*}{ Children } & Earnings & Observations & Individuals & \multirow{2}{*}{ Mean } \\
\multirow{2}{*}{ Son } & Children log earnings & 15,743 & 2,630 & 5.35 \\
& Parental log average earnings & 15,743 & 2,630 & 6.00 \\
\hline \multirow{2}{*}{ Daughter } & Children log earnings & 11,398 & 2,217 & 5.00 \\
& Parental log average earnings & 11,398 & 2,217 & 6.22 \\
\hline \hline
\end{tabular}

earnings of children are from either a regular job or self-employment. The proportion of daughters with incomes is approximately 20 percentage points below that for sons. When we look at the overall distribution of earnings, sons' log earnings average .35 log points above those of daughters and stochastically dominate daughters' earnings.

The number of fathers of sons (daughters) should be smaller than the number of sons (daughters) because some fathers have more than one son or more than one daughter. The number of average number of children of a father is 1.6, but I consider each child's father separately although there may be more than one child. Table 3 shows the number of observations and individuals and detailed educational information of children and their fathers. KLIPS provides educational attainment, completion status, and type of high school attended. I divide the type of high school into either academic or vocational high school, including the small number of graduates from the specific-purpose high schools and art and athletic training high schools in the academic category.

I group Some high school (high school dropouts) separately from the Less than 9thgrade. I denote Some vocational high school or Some academic high school to indicate high school dropouts by type of high school. Vocational $H S$ identifies graduates of vocational high schools and Academic HS graduates of academic high schools. Some college includes junior college dropouts and completers and four year college dropouts. I divide them into Some college with VHS, which identifies individuals who go to junior college or drop out of college after graduating from vocational high school, 
Table 1.3 Sample statistics of education

\begin{tabular}{|c|c|c|c|c|c|c|c|c|}
\hline & \multicolumn{2}{|c|}{ Son } & \multicolumn{2}{|c|}{ Father } & \multicolumn{2}{|c|}{ Daughter } & \multicolumn{2}{|c|}{ Father } \\
\hline & Observations & Individuals & Observations & Individuals & Observations & Individuals & Observations & Individuals \\
\hline Less than 9th-grade & 739 & 78 & 7,437 & 1,022 & 152 & 23 & 5,075 & 892 \\
\hline Some vocational hs & 301 & 31 & 212 & 25 & 69 & 11 & 98 & 17 \\
\hline Some academic hs & 179 & 20 & 258 & 41 & 38 & 5 & 93 & 19 \\
\hline Vocational hs & 2,931 & 464 & 2,064 & 457 & 2,181 & 419 & 2,090 & 422 \\
\hline Academic hs & 2,029 & 331 & 1,822 & 381 & 907 & 177 & 1,811 & 371 \\
\hline Some college with vhs & 1,567 & 259 & 392 & 69 & 1,502 & 281 & 169 & 36 \\
\hline Some college with ahs & 2,159 & 365 & 461 & 95 & 2,220 & 428 & 246 & 55 \\
\hline College with vhs & 1,635 & 286 & 747 & 124 & 466 & 103 & 611 & 137 \\
\hline College with ahs & 3,634 & 689 & 2,092 & 371 & 3,504 & 676 & 1,038 & 228 \\
\hline Graduate school & 569 & 107 & 258 & 45 & 359 & 94 & 167 & 40 \\
\hline Total & 15,743 & 2,630 & 15,743 & 2,630 & 11,398 & 2,217 & 11,398 & 2,217 \\
\hline
\end{tabular}

and Some college with AHS, for academic high school graduates. College means college completion and Graduate school denotes those who complete either master's or doctoral programs.

Children are more likely to complete high school than their fathers because they are required to complete 9th-grade by law. Once they enroll in high school, they are likely to finish 12th-grade. In contrast, fathers were not required to complete 9thgrade (middle school) or even 6th-grade (elementary school), so the second biggest educational group for fathers is Less than 9th-grade. A small number of fathers went to either junior college or college rather than entering the labor market after earning a high school diploma. Both children and their fathers who graduate from academic high schools are more likely to advance to post-secondary education than are vocational high school graduates.

Other family background variables I control in this paper are father's type of job (permanent or fixed term worker), house ownership, home address (metro/suburban address), and an indicator if the child was living with parents, which are all measured when the child was between 15 and 21 years of age. Also included are the child's age and age squared. 


\subsection{Empirical Strategies}

\subsubsection{The Effects of Parental Earnings on Children's Earn- ings}

As a first step, I estimate the intergenerational elasticity of earnings. The basic OLS model is:

$$
Y_{i t}^{c}=\alpha_{1}+\rho Y_{i}^{p}+\varepsilon_{i t},
$$

where $Y_{i t}^{c}$ is the $\log$ monthly earnings of a child from family $i$ in year $t$, and $Y_{i}^{p}$ denotes the log monthly average earnings of parents in family $i$, when the child was between 15 and 21 years of age.

In this paper, the coefficient of interest is $\rho$, which indicates the intergenerational earnings elasticity. Additionally, this paper also estimates the intergenerational transmission of father's educational attainment because the father's educational attainment is an important factor influencing children's economic outcomes. I fit an additive model that uses the education of both fathers and children along with parental earnings:

$$
Y_{i t}^{c}=\alpha_{2}+\rho Y_{i}^{p}+E d u c_{i t}^{f} \beta+E d u c_{i t}^{c} \gamma+X_{i s}^{p} \delta+X_{i t}^{c} \zeta+\varepsilon_{i s t}^{\prime},
$$

where $Y_{i t}^{c}$ and $Y_{i}^{p}$ denote the log of earnings of children and parents, respectively, as in equation (1). Intergenerational earnings elasticity is usually defined as the degree of persistence in earnings of parents. $\rho$ in equation (2) indicates the relationship between a parental earnings and a child's earnings, controlling for a paternal educational level, children's education as well as selected parents' and children's characteristics.

$E d u c_{i t}^{f}$ measures detailed educational attainment of fathers. Paternal educational attainment consists of dummies for nine categories: less than 9th-grade, vocational high school dropouts, academic high school dropouts, vocational high school graduates, academic high school graduates, some college after vocational high school, some 
college after academic high school, college graduation after vocational high school, and college graduation after academic high school. The dummy for academic high school graduation is the omitted category. Although I can distinguish fathers who hold a graduate school diploma, I code them as college graduates in empirical models due to the small number of observations. $E d u c_{i t}^{c}$ denotes the educational attainment of children. I add two more dummies beyond those used for paternal educational attainment, graduate school after vocational high school and graduate school after academic high school. As for fathers, academic high school graduation is the omitted category. $X_{i s}^{p}$ captures fathers' characteristics, father's type of job, house ownership, home address (metropolitan area or not), and an indicator if the child was living with parents. These characteristics are measured when the child was between 15 and 21 years of age. $X_{i t}^{c}$ captures children's characteristics at time $t$, including location of residence when they were in school, age, and age squared.

In equation (2), the coefficient $\rho$ provides direct effects of parental earnings on children's earnings after controlling for father's education and children's education. Also, the model captures the direct effects of father's education on children's earnings, although we expect that children's own education is the most important factor in determining their future earnings.

Conventional regression deals with only the relationship between independent variables and the expected value of the dependent variable. Quantile regression, however, allows estimation of the effects of explanatory variables (parental average earnings and father's education) on a dependent variable (log earnings of either son or daughter) at each quantile of the conditional distribution of the dependent variables (Koenker and Bassett Jr (1978)). It is an alternative approach to standard linear regression for summarizing information about the relationship between the outcome variable and various regressors (Cameron and Trivedi (2010)). Richey and Jeong (2014) employ a quantile regression to estimate the persistence of earnings in Korea. I extend 
Richey and Jeong's analysis, including detailed educational attainment of fathers and children, family background, and children's characteristics in the quantile regression model.

One important remaining issue is the effects of vocational high school for children on their future earnings after controlling for father's earnings and education. This model structure is similar to that of equation (2), but the measure of children's educa-

tion only codes education up through high school. The variable $E \bar{d} \bar{u} c_{i t}^{c}$ includes Less than 12th-grade and Vocational high school for children's education with Academic high school as the omitted category. The model is:

$$
Y_{i t}^{c}=\alpha_{3}+\rho Y_{i}^{p}+E d u c_{i t}^{f} \beta+\overline{E d u c_{i t}^{c}} \gamma+X_{i s}^{p} \delta+X_{i t}^{c} \zeta+\varepsilon_{i s t}^{\prime \prime} .
$$

In equation (2), $E d u c_{i t}^{c}$ has dummies representing 11 categories, but I combine two variables, less than 9th-grade and some high school, to make less than 12th-grade for children because equation (3) is concerned with the effects of vocational high school graduates on their earnings. Vocational high school in $\overline{E d u c_{i t}^{c}}$ denotes all individuals who graduate from vocational high schools, whether or not they pursue higher education after graduation. The omitted category is all academic high school graduates, including those who pursue higher education after graduation. $E d u c_{i t}^{f}$ is identical to that in equation (2) above. Equation (3) can explain the effects of children's vocational high school degree on their earnings regardless of their final education. $\rho$ in equation (3) indicates the relationship between parental earnings and children's earnings controlling for fathers' and children's educational level.

\subsubsection{Total Education Effects}

In this section, I construct a fully saturated model in education to estimate the joint impacts of fathers' schooling attainment and children's educational attainment 
on children's earnings. This model can show how father's educational attainment influences the return to a child's education. The education effects can be estimated using the following equation:

$$
Y_{i t}^{c}=\alpha_{4}+E d u c_{i t}^{f} \beta+E d u c_{i t}^{c} \gamma+\left(E d u c_{i t}^{f} * E d u c_{i t}^{c}\right) \eta+\epsilon_{i t} .
$$

Equation (4) adds an interaction term to equation (2) and remove parental earnings to identify fathers' educational effects on children's future earnings, including their effects through the financial circumstances of the family.

$E d u c_{i t}^{f}$ includes dummies for 9 categories, and $E d u c_{i t}^{c}$ includes dummies for 11 categories, so $E d u c_{i t}^{f} * E d u c_{i t}^{c}$ is composed by 80 dummy interaction terms. As in other equations, the omitted educational group is the Academic high school of both fathers and children. This approach estimates effects of father's education joint with children's education. For example, if a son whose father holds a vocational high school degree graduated from college after attending an academic high school, the effects would be $\beta_{4}+\gamma_{9}+\eta_{49}$, relative to an individual who graduated from an academic high school and whose father graduated from an academic high school. This specification then shows how the return of a child's college degree after attending an academic high school depends on the father's vocational high school degree. Thus, this specification shows how children's future labor income depends jointly on their educational decisions and paternal educational attainment. Paternal schooling both affects children's educational choices, and it impacts children's earnings based on those decisions.

\subsubsection{Intergenerational Transmission of Education}

I use the linear probability model (LPM) in this section to identify the impacts of father's labor market outcomes on children's educational achievement. LPM has a 
distinct drawback, as it can predict probabilities above one or below zero. Nevertheless, LPM usually provides very similar effect estimates to other discrete response models, such as a logit or a probit model. Additionally, it enables us to easily interpret estimated coefficients.

To explore the effects of father's education and earnings on children's educational achievement, I construct the linear probability model (LPM) and estimate the following equation:

$$
\text { Achievement }{ }_{i}^{c}=\alpha_{5}+\rho Y_{i}^{p}+\widetilde{\operatorname{Educ}_{i}^{f}} \beta+\widetilde{\operatorname{Educ}_{i}^{c}} \gamma+X_{i}^{p} \delta+e_{i}
$$

where Achievement ${ }_{i j}^{c}$ denotes either college attendance or college completion of children and $\widetilde{E d u c_{i}^{c}}$ captures education through high school. College attendance includes those who attended college for some period, those who graduated from college, and those who attended graduate school; and college completion includes those who graduated from college, including those who attended graduate school. I simplify the educational attainment of both fathers and children, as I do not distinguish educational attainment above high school by high school type. Father's education variables, $\widetilde{E d u c_{i}^{f}}$, identifies the categories less than 12th-grade, vocational high school, academic high school, some college, and college. Father's academic high school is an omitted category for fathers' education. The control for children's education, $\widetilde{E d u c_{i}^{c}}$, is coded in two dummies less than 12th-grade, and vocational high school, with academic high school the omitted category. I combine Less than 9th-grade with Some high school to construct the variable Less than 12th-grade for fathers in equation (5). The coefficients of interest, $\rho$ and $\beta$, provide a prediction of the impact of father's earnings and education on children's educational achievements, to wit, college attendance and college completion.

Finally, we wish to identify how father's earnings and education influence a child's 
decision of attending an academic or vocational high school. We specify the relevant equation as:

$$
V H S_{i}^{c}=\alpha_{6}+\rho Y_{i}^{p}+\widetilde{E_{d u c_{i}^{f}}} \beta+X_{i}^{p} \delta+u_{i}
$$

where $V H S_{i}^{c}$ denotes vocational high school graduation, with academic high school the omitted category. In this specification, those who obtain post-secondary education are included, and they are identified by their high school of graduation. $\beta$ is a vector of the coefficients of interest, which estimate the effects of father's education on children's graduation from a vocational high school rather than an academic high school.

\subsection{Empirical Results}

\subsubsection{Estimation of Intergenerational Earnings Relationships}

Tables 4 and 5 report estimates for children based on equations (1) and (2). Analysis for both tables are limited to years in which sons and daughters had non-zero earn-

ings, so any effect on employment is not included. As expected, parental earnings is strongly related to children's earnings, and its coefficient measures the intergenerational correlation of earnings. Table 4, panel A shows the effects of family's earnings on son's average earnings controlling for father's education based on simple regressions. Panel B shows results of its effects using the quantile regression, based on the 10th percentile, 25th percentile, median, 75th percentile, and 90th percentile of the sons' earnings. Whereas Panel A presents alternative specifications with differing control variables, I include all variables for the quantile regression model.

Estimated values for the parental earnings effects on son's earnings vary from 0.08 to 0.40 depending on the control variables. Column (1) provides an estimate of the intergenerational earnings elasticity, which is 0.40 , indicating a 1 percent increase in 
parents' income is associated with a son's income increase of 0.4 percent. 40 percent of a family's earnings advantage is passed on to the adult labor incomes of a family's son. Kim (2017) also finds that earnings transmission effects from parents are about $40 \%$ in Korea. Corak (2013b) calculates the intergenerational earnings elasticity between father and son of some developed countries. This intergenerational earnings elasticity in Korea is as high as the elasticity of the United States, which is 0.40 on average. The elasticity, however, is higher than in Scandinavian countries, which are 0.27 for Sweden, and 0.18 for Finland (Corak (2013a, b)).

Column (2) controls for sons' final education, age, and age squared. After controlling for sons' educational attainment and age, the parental earnings effect decreases to 0.08 . This means that a son's education and characteristics are more important in determining earnings than parental income, although $8 \%$ of parents' earnings advantages are passed to sons even when these factors are controlled. As expected, if sons do not hold a high school degree, earnings are less than for those who graduated from high school. Those who graduate from a vocational high school have 4 percent lower earnings than those who graduated from an academic high school. As expected, those who enroll post-secondary education have higher earnings than those who discontinued their schooling after graduating from high school.

Column (3) and column (4) include father's educational level and family background, and exclude son's education and characteristics. Without sons' education, but controlling father's education and family background, the family's earnings transmission coefficient is 0.11 . Fathers who attended higher education but did not complete college have sons with slightly lower earning than those who have only a diploma from an academic high school. If a father holds a vocational high school degree, and did not attend higher education, this has a $6 \%$ negative effect relative to sons whose a father graduated from an academic high school. When parental earnings are not taken into account (column (4)), a father graduating from college increases sons' earn- 
Table 1.4 The effects of parental earnings on sons' earnings

\begin{tabular}{|c|c|c|c|c|c|c|c|c|c|c|}
\hline \multirow{2}{*}{ Dep. var: Son's Log Earnings } & \multicolumn{5}{|c|}{ Panel A: OLS } & \multicolumn{5}{|c|}{ Panel B: Quantiles } \\
\hline & $(1)$ & $(2)$ & $(3)$ & $(4)$ & (5) & $10 \mathrm{p}$ & $25 \mathrm{p}$ & $50 \mathrm{p}$ & $75 \mathrm{p}$ & $90 \mathrm{p}$ \\
\hline Log Avg Parental Earnings & $\begin{array}{c}0.40 \\
(0.01)\end{array}$ & $\begin{array}{c}0.08 \\
(0.01)\end{array}$ & $\begin{array}{c}0.11 \\
(0.01)\end{array}$ & & $\begin{array}{c}0.08 \\
(0.01)\end{array}$ & $\begin{array}{c}0.08 \\
(0.01)\end{array}$ & $\begin{array}{c}0.08 \\
(0.01)\end{array}$ & $\begin{array}{c}0.07 \\
(0.01)\end{array}$ & $\begin{array}{c}0.07 \\
(0.01)\end{array}$ & $\begin{array}{c}0.07 \\
(0.01)\end{array}$ \\
\hline Son's Less Than 9th & & $\begin{array}{l}-0.25 \\
(0.06)\end{array}$ & & & $\begin{array}{l}-0.25 \\
(0.06)\end{array}$ & $\begin{array}{c}-0.18 \\
(0.06)\end{array}$ & $\begin{array}{l}-0.24 \\
(0.07)\end{array}$ & $\begin{array}{l}-0.23 \\
(0.06)\end{array}$ & $\begin{array}{l}-0.23 \\
(0.07)\end{array}$ & $\begin{array}{c}-0.24 \\
(0.08)\end{array}$ \\
\hline Son's Some VHS & & $\begin{array}{l}-0.08 \\
(0.05)\end{array}$ & & & $\begin{array}{l}-0.07 \\
(0.05)\end{array}$ & $\begin{array}{l}-0.02 \\
(0.05)\end{array}$ & $\begin{array}{c}-0.06 \\
(0.06)\end{array}$ & $\begin{array}{l}-0.08 \\
(0.05)\end{array}$ & $\begin{array}{c}-0.11 \\
(0.05)\end{array}$ & $\begin{array}{c}-0.13 \\
(0.04)\end{array}$ \\
\hline Son's Some AHS & & $\begin{array}{l}-0.18 \\
(0.08)\end{array}$ & & & $\begin{array}{l}-0.19 \\
(0.08)\end{array}$ & $\begin{array}{l}-0.11 \\
(0.05)\end{array}$ & $\begin{array}{l}-0.27 \\
(0.05)\end{array}$ & $\begin{array}{c}-0.18 \\
(0.14)\end{array}$ & $\begin{array}{l}-0.18 \\
(0.08)\end{array}$ & $\begin{array}{c}-0.24 \\
(0.05)\end{array}$ \\
\hline Son's Vocational HS & & $\begin{array}{l}-0.04 \\
(0.02)\end{array}$ & & & $\begin{array}{l}-0.03 \\
(0.02)\end{array}$ & $\begin{array}{c}0.01 \\
(0.03)\end{array}$ & $\begin{array}{l}-0.05 \\
(0.02)\end{array}$ & $\begin{array}{l}-0.06 \\
(0.02)\end{array}$ & $\begin{array}{l}-0.06 \\
(0.02)\end{array}$ & $\begin{array}{c}-0.04 \\
(0.03)\end{array}$ \\
\hline Son's Some College-VHS & & $\begin{array}{c}0.06 \\
(0.03)\end{array}$ & & & $\begin{array}{c}0.07 \\
(0.03)\end{array}$ & $\begin{array}{c}0.11 \\
(0.03)\end{array}$ & $\begin{array}{c}0.06 \\
(0.02)\end{array}$ & $\begin{array}{c}0.03 \\
(0.02)\end{array}$ & $\begin{array}{c}0.05 \\
(0.03)\end{array}$ & $\begin{array}{c}0.08 \\
(0.05)\end{array}$ \\
\hline Son's Some College-AHS & & $\begin{array}{c}0.01 \\
(0.02)\end{array}$ & & & $\begin{array}{c}0.01 \\
(0.02)\end{array}$ & $\begin{array}{c}0.07 \\
(0.03)\end{array}$ & $\begin{array}{c}0.04 \\
(0.02)\end{array}$ & $\begin{array}{l}-0.003 \\
(0.02)\end{array}$ & $\begin{array}{l}-0.02 \\
(0.02)\end{array}$ & $\begin{array}{c}-0.06 \\
(0.03)\end{array}$ \\
\hline Son's College-VHS & & $\begin{array}{c}0.05 \\
(0.03)\end{array}$ & & & $\begin{array}{c}0.05 \\
(0.04)\end{array}$ & $\begin{array}{c}0.06 \\
(0.07)\end{array}$ & $\begin{array}{c}0.04 \\
(0.04)\end{array}$ & $\begin{array}{c}0.02 \\
(0.03)\end{array}$ & $\begin{array}{c}0.05 \\
(0.06)\end{array}$ & $\begin{array}{c}0.07 \\
(0.07)\end{array}$ \\
\hline Son's College-AHS & & $\begin{array}{c}0.11 \\
(0.02)\end{array}$ & & & $\begin{array}{c}0.10 \\
(0.02)\end{array}$ & $\begin{array}{c}0.12 \\
(0.03)\end{array}$ & $\begin{array}{c}0.09 \\
(0.02)\end{array}$ & $\begin{array}{c}0.08 \\
(0.02)\end{array}$ & $\begin{array}{c}0.11 \\
(0.03)\end{array}$ & $\begin{array}{c}0.10 \\
(0.03)\end{array}$ \\
\hline Son's Grad-VHS & & $\begin{array}{c}0.22 \\
(0.13)\end{array}$ & & & $\begin{array}{c}0.23 \\
(0.13)\end{array}$ & $\begin{array}{c}0.19 \\
(0.12)\end{array}$ & $\begin{array}{c}0.26 \\
(0.21)\end{array}$ & $\begin{array}{c}0.23 \\
(0.20)\end{array}$ & $\begin{array}{c}0.32 \\
(0.11)\end{array}$ & $\begin{array}{c}0.45 \\
(0.15)\end{array}$ \\
\hline Son's Grad-AHS & & $\begin{array}{c}0.27 \\
(0.04)\end{array}$ & & & $\begin{array}{c}0.25 \\
(0.04)\end{array}$ & $\begin{array}{c}0.25 \\
(0.06)\end{array}$ & $\begin{array}{c}0.24 \\
(0.04)\end{array}$ & $\begin{array}{c}0.25 \\
(0.04)\end{array}$ & $\begin{array}{c}0.26 \\
(0.04)\end{array}$ & $\begin{array}{c}0.29 \\
(0.06)\end{array}$ \\
\hline Father's Less Than 9th Grade & & & $\begin{array}{l}-0.06 \\
(0.02)\end{array}$ & $\begin{array}{l}-0.05 \\
(0.02)\end{array}$ & $\begin{array}{l}-0.05 \\
(0.01)\end{array}$ & $\begin{array}{l}-0.07 \\
(0.02)\end{array}$ & $\begin{array}{l}-0.06 \\
(0.02)\end{array}$ & $\begin{array}{l}-0.05 \\
(0.01)\end{array}$ & $\begin{array}{l}-0.05 \\
(0.02)\end{array}$ & $\begin{array}{c}-0.06 \\
(0.02)\end{array}$ \\
\hline Father's Some VHS & & & $\begin{array}{l}-0.03 \\
(0.07)\end{array}$ & $\begin{array}{c}0.01 \\
(0.08)\end{array}$ & $\begin{array}{c}-0.06 \\
(0.05)\end{array}$ & $\begin{array}{c}0.01 \\
(0.06)\end{array}$ & $\begin{array}{c}0.01 \\
(0.04)\end{array}$ & $\begin{array}{l}-0.07 \\
(0.04)\end{array}$ & $\begin{array}{c}-0.08 \\
(0.07)\end{array}$ & $\begin{array}{c}-0.08 \\
(0.06)\end{array}$ \\
\hline Father's Some AHS & & & $\begin{array}{l}-0.03 \\
(0.08)\end{array}$ & $\begin{array}{l}-0.01 \\
(0.08)\end{array}$ & $\begin{array}{c}0.01 \\
(0.04)\end{array}$ & $\begin{array}{l}-0.02 \\
(0.05)\end{array}$ & $\begin{array}{c}0.01 \\
(0.05)\end{array}$ & $\begin{array}{l}-0.01 \\
(0.05)\end{array}$ & $\begin{array}{l}-0.05 \\
(0.05)\end{array}$ & $\begin{array}{c}-0.06 \\
(0.08)\end{array}$ \\
\hline Father's Vocational HS & & & $\begin{array}{l}-0.06 \\
(0.03)\end{array}$ & $\begin{array}{l}-0.02 \\
(0.03)\end{array}$ & $\begin{array}{l}-0.02 \\
(0.02)\end{array}$ & $\begin{array}{l}-0.02 \\
(0.03)\end{array}$ & $\begin{array}{l}-0.02 \\
(0.02)\end{array}$ & $\begin{array}{l}-0.01 \\
(0.02)\end{array}$ & $\begin{array}{l}-0.01 \\
(0.03)\end{array}$ & $\begin{array}{c}-0.02 \\
(0.03)\end{array}$ \\
\hline Father's Some College-VHS & & & $\begin{array}{l}-0.09 \\
(0.07)\end{array}$ & $\begin{array}{l}-0.02 \\
(0.07)\end{array}$ & $\begin{array}{c}0.11 \\
(0.06)\end{array}$ & $\begin{array}{c}0.22 \\
(0.04)\end{array}$ & $\begin{array}{c}0.09 \\
(0.04)\end{array}$ & $\begin{array}{c}0.07 \\
(0.04)\end{array}$ & $\begin{array}{c}0.04 \\
(0.04)\end{array}$ & $\begin{array}{c}0.11 \\
(0.07)\end{array}$ \\
\hline Father's Some College-AHS & & & $\begin{array}{l}-0.09 \\
(0.07)\end{array}$ & $\begin{array}{c}-0.01 \\
(0.07)\end{array}$ & $\begin{array}{c}0.01 \\
(0.05)\end{array}$ & $\begin{array}{c}0.06 \\
(0.08)\end{array}$ & $\begin{array}{c}0.01 \\
(0.04)\end{array}$ & $\begin{array}{c}0.02 \\
(0.04)\end{array}$ & $\begin{array}{c}0.03 \\
(0.04)\end{array}$ & $\begin{array}{c}-0.04 \\
(0.05)\end{array}$ \\
\hline Father's College-VHS & & & $\begin{array}{c}0.06 \\
(0.04)\end{array}$ & $\begin{array}{c}0.10 \\
(0.04)\end{array}$ & $\begin{array}{c}0.03 \\
(0.04)\end{array}$ & $\begin{array}{l}-0.03 \\
(0.04)\end{array}$ & $\begin{array}{l}-0.05 \\
(0.05)\end{array}$ & $\begin{array}{c}0.02 \\
(0.04)\end{array}$ & $\begin{array}{c}0.05 \\
(0.06)\end{array}$ & $\begin{array}{c}0.06 \\
(0.09)\end{array}$ \\
\hline Father's College-AHS & & & $\begin{array}{c}0.04 \\
(0.04)\end{array}$ & $\begin{array}{c}0.10 \\
(0.04)\end{array}$ & $\begin{array}{c}0.06 \\
(0.03)\end{array}$ & $\begin{array}{c}0.01 \\
(0.04)\end{array}$ & $\begin{array}{c}0.05 \\
(0.04)\end{array}$ & $\begin{array}{c}0.08 \\
(0.03)\end{array}$ & $\begin{array}{c}0.10 \\
(0.04)\end{array}$ & $\begin{array}{c}0.12 \\
(0.04)\end{array}$ \\
\hline Constant & $\begin{array}{c}5.19 \\
(0.06)\end{array}$ & $\begin{array}{c}2.11 \\
(0.13)\end{array}$ & $\begin{array}{c}4.59 \\
(0.05)\end{array}$ & $\begin{array}{c}5.15 \\
(0.02)\end{array}$ & $\begin{array}{c}2.12 \\
(0.11)\end{array}$ & $\begin{array}{c}1.27 \\
(0.17)\end{array}$ & $\begin{array}{c}1.91 \\
(0.16)\end{array}$ & $\begin{array}{c}2.35 \\
(0.15)\end{array}$ & $\begin{array}{c}2.92 \\
(0.17)\end{array}$ & $\begin{array}{c}3.24 \\
(0.19)\end{array}$ \\
\hline Family Background & & $\mathrm{x}$ & $\mathrm{x}$ & $\mathrm{x}$ & $\mathrm{x}$ & $\mathrm{x}$ & $\mathrm{x}$ & $\mathrm{x}$ & $\mathrm{x}$ & $\mathrm{x}$ \\
\hline Observations & 15,743 & 15,743 & 15,743 & 15,743 & 15,743 & 15,743 & 15,743 & 15,743 & 15,743 & 15,743 \\
\hline Individuals & 2,630 & 2,630 & 2,630 & 2,630 & 2,630 & 2,630 & 2,630 & 2,630 & 2,630 & 2,630 \\
\hline $\mathrm{R}^{2}$ & 0.349 & 0.372 & 0.355 & 0.317 & 0.376 & 0.355 & 0.371 & 0.374 & 0.368 & 0.365 \\
\hline
\end{tabular}

Note: Standard errors are adjusted for clustering to account for multiple observations for individuals. Parental earnings are averaged when their sons were between 15 and 21. Family background includes father's job type, house ownership, metro/suburban address, and whether a son lived with parents when the son was between 15 and 21. I include son's age and age squared.

$\star$ Father's college includes college graduates as well as those who attended graduate school. 
Table 1.5 The effects of parental earnings on daughters' earnings

\begin{tabular}{|c|c|c|c|c|c|c|c|c|c|c|}
\hline \multirow{2}{*}{ Dep. var: Daughter's Log Earnings } & \multicolumn{5}{|c|}{ Panel A: OLS } & \multicolumn{5}{|c|}{ Panel B: Quantiles } \\
\hline & (1) & $(2)$ & $(3)$ & $(4)$ & (5) & $10 \mathrm{p}$ & $25 \mathrm{p}$ & $50 \mathrm{p}$ & $75 \mathrm{p}$ & $90 \mathrm{p}$ \\
\hline Log Avg Parental Earnings & $\begin{array}{c}0.41 \\
(0.01)\end{array}$ & $\begin{array}{c}0.10 \\
(0.01)\end{array}$ & $\begin{array}{c}0.15 \\
(0.01)\end{array}$ & & $\begin{array}{c}0.10 \\
(0.01)\end{array}$ & $\begin{array}{c}0.09 \\
(0.01)\end{array}$ & $\begin{array}{c}0.10 \\
(0.01)\end{array}$ & $\begin{array}{c}0.11 \\
(0.01)\end{array}$ & $\begin{array}{c}0.11 \\
(0.01)\end{array}$ & $\begin{array}{c}0.09 \\
(0.01)\end{array}$ \\
\hline Daughter's Less Than 9th & & $\begin{array}{l}-0.10 \\
(0.07)\end{array}$ & & & $\begin{array}{l}-0.10 \\
(0.07)\end{array}$ & $\begin{array}{c}0.08 \\
(0.07)\end{array}$ & $\begin{array}{l}-0.01 \\
(0.09)\end{array}$ & $\begin{array}{l}-0.03 \\
(0.07)\end{array}$ & $\begin{array}{l}-0.14 \\
(0.06)\end{array}$ & $\begin{array}{l}-0.22 \\
(0.04)\end{array}$ \\
\hline Daughter's Some VHS & & $\begin{array}{c}0.15 \\
(0.08)\end{array}$ & & & $\begin{array}{c}0.16 \\
(0.08)\end{array}$ & $\begin{array}{c}0.22 \\
(0.13)\end{array}$ & $\begin{array}{c}0.10 \\
(0.05)\end{array}$ & $\begin{array}{c}0.18 \\
(0.07)\end{array}$ & $\begin{array}{c}0.09 \\
(0.09)\end{array}$ & $\begin{array}{c}0.01 \\
(0.06)\end{array}$ \\
\hline Daughter's Some AHS & & $\begin{array}{c}-0.05 \\
(0.03)\end{array}$ & & & $\begin{array}{l}-0.08 \\
(0.03)\end{array}$ & $\begin{array}{c}0.49 \\
(0.07)\end{array}$ & $\begin{array}{c}0.08 \\
(0.08)\end{array}$ & $\begin{array}{c}-0.30 \\
(0.06)\end{array}$ & $\begin{array}{l}-0.45 \\
(0.04)\end{array}$ & $\begin{array}{c}-0.62 \\
(0.06)\end{array}$ \\
\hline Daughter's Vocational HS & & $\begin{array}{c}-0.05 \\
(0.02)\end{array}$ & & & $\begin{array}{l}-0.03 \\
(0.02)\end{array}$ & $\begin{array}{c}0.06 \\
(0.03)\end{array}$ & $\begin{array}{c}0.02 \\
(0.02)\end{array}$ & $\begin{array}{l}-0.07 \\
(0.02)\end{array}$ & $\begin{array}{l}-0.07 \\
(0.03)\end{array}$ & $\begin{array}{c}-0.08 \\
(0.03)\end{array}$ \\
\hline Daughter's SomeCollege-VHS & & $\begin{array}{c}0.05 \\
(0.02)\end{array}$ & & & $\begin{array}{c}0.06 \\
(0.02)\end{array}$ & $\begin{array}{c}0.12 \\
(0.03)\end{array}$ & $\begin{array}{c}0.08 \\
(0.03)\end{array}$ & $\begin{array}{c}0.02 \\
(0.03)\end{array}$ & $\begin{array}{l}-0.01 \\
(0.03)\end{array}$ & $\begin{array}{c}-0.02 \\
(0.03)\end{array}$ \\
\hline Daughter's Some College-AHS & & $\begin{array}{c}0.04 \\
(0.02)\end{array}$ & & & $\begin{array}{c}0.04 \\
(0.02)\end{array}$ & $\begin{array}{c}0.07 \\
(0.03)\end{array}$ & $\begin{array}{c}0.05 \\
(0.02)\end{array}$ & $\begin{array}{c}0.02 \\
(0.03)\end{array}$ & $\begin{array}{c}0.01 \\
(0.02)\end{array}$ & $\begin{array}{c}-0.02 \\
(0.03)\end{array}$ \\
\hline Daughter's College-VHS & & $\begin{array}{c}0.14 \\
(0.04)\end{array}$ & & & $\begin{array}{c}0.15 \\
(0.04)\end{array}$ & $\begin{array}{c}0.18 \\
(0.05)\end{array}$ & $\begin{array}{c}0.11 \\
(0.04)\end{array}$ & $\begin{array}{c}0.07 \\
(0.06)\end{array}$ & $\begin{array}{c}0.11 \\
(0.04)\end{array}$ & $\begin{array}{c}0.13 \\
(0.05)\end{array}$ \\
\hline Daughter's College-AHS & & $\begin{array}{c}0.19 \\
(0.02)\end{array}$ & & & $\begin{array}{c}0.18 \\
(0.02)\end{array}$ & $\begin{array}{c}0.23 \\
(0.03)\end{array}$ & $\begin{array}{c}0.18 \\
(0.02)\end{array}$ & $\begin{array}{c}0.16 \\
(0.02)\end{array}$ & $\begin{array}{c}0.16 \\
(0.02)\end{array}$ & $\begin{array}{c}0.14 \\
(0.03)\end{array}$ \\
\hline Daughter's Grad-VHS & & $\begin{array}{c}0.19 \\
(0.21)\end{array}$ & & & $\begin{array}{c}0.18 \\
(0.20)\end{array}$ & $\begin{array}{c}0.04 \\
(0.15)\end{array}$ & $\begin{array}{c}0.19 \\
(0.12)\end{array}$ & $\begin{array}{c}0.19 \\
(0.16)\end{array}$ & $\begin{array}{c}0.20 \\
(0.16)\end{array}$ & $\begin{array}{c}0.34 \\
(0.12)\end{array}$ \\
\hline Daughter's Grad-AHS & & $\begin{array}{c}0.30 \\
(0.05)\end{array}$ & & & $\begin{array}{c}0.30 \\
(0.05)\end{array}$ & $\begin{array}{c}0.34 \\
(0.06)\end{array}$ & $\begin{array}{c}0.32 \\
(0.05)\end{array}$ & $\begin{array}{c}0.29 \\
(0.05)\end{array}$ & $\begin{array}{c}0.24 \\
(0.04)\end{array}$ & $\begin{array}{c}0.17 \\
(0.05)\end{array}$ \\
\hline Father's Less Than 9th Grade & & & $\begin{array}{c}-0.04 \\
(0.02)\end{array}$ & $\begin{array}{l}-0.04 \\
(0.02)\end{array}$ & $\begin{array}{l}-0.06 \\
(0.02)\end{array}$ & $\begin{array}{l}-0.07 \\
(0.02)\end{array}$ & $\begin{array}{l}-0.08 \\
(0.02)\end{array}$ & $\begin{array}{l}-0.07 \\
(0.02)\end{array}$ & $\begin{array}{l}-0.07 \\
(0.02)\end{array}$ & $\begin{array}{l}-0.05 \\
(0.02)\end{array}$ \\
\hline Father's Some VHS & & & $\begin{array}{c}0.03 \\
(0.12)\end{array}$ & $\begin{array}{c}0.07 \\
(0.13)\end{array}$ & $\begin{array}{c}0.01 \\
(0.12)\end{array}$ & $\begin{array}{c}0.11 \\
(0.11)\end{array}$ & $\begin{array}{c}0.09 \\
(0.05)\end{array}$ & $\begin{array}{c}-0.01 \\
(0.07)\end{array}$ & $\begin{array}{c}0.04 \\
(0.16)\end{array}$ & $\begin{array}{c}0.08 \\
(0.10)\end{array}$ \\
\hline Father's Some AHS & & & $\begin{array}{c}0.01 \\
(0.08)\end{array}$ & $\begin{array}{c}0.01 \\
(0.08)\end{array}$ & $\begin{array}{c}0.01 \\
(0.07)\end{array}$ & $\begin{array}{c}0.04 \\
(0.07)\end{array}$ & $\begin{array}{l}-0.04 \\
(0.06)\end{array}$ & $\begin{array}{c}0.01 \\
(0.07)\end{array}$ & $\begin{array}{c}0.01 \\
(0.06)\end{array}$ & $\begin{array}{c}-0.04 \\
(0.19)\end{array}$ \\
\hline Father's Vocational HS & & & $\begin{array}{c}0.02 \\
(0.03)\end{array}$ & $\begin{array}{c}0.06 \\
(0.03)\end{array}$ & $\begin{array}{c}0.02 \\
(0.02)\end{array}$ & $\begin{array}{c}0.01 \\
(0.03)\end{array}$ & $\begin{array}{l}-0.01 \\
(0.02)\end{array}$ & $\begin{array}{c}0.03 \\
(0.03)\end{array}$ & $\begin{array}{c}0.02 \\
(0.02)\end{array}$ & $\begin{array}{c}0.03 \\
(0.03)\end{array}$ \\
\hline Father's Some College-VHS & & & $\begin{array}{c}-0.10 \\
(0.07)\end{array}$ & $\begin{array}{c}-0.06 \\
(0.07)\end{array}$ & $\begin{array}{c}-0.02 \\
(0.06)\end{array}$ & $\begin{array}{l}-0.06 \\
(0.11)\end{array}$ & $\begin{array}{l}-0.03 \\
(0.07)\end{array}$ & $\begin{array}{c}0.01 \\
(0.19)\end{array}$ & $\begin{array}{l}-0.03 \\
(0.03)\end{array}$ & $\begin{array}{c}-0.10 \\
(0.05)\end{array}$ \\
\hline Father's Some College-AHS & & & $\begin{array}{c}0.01 \\
(0.07)\end{array}$ & $\begin{array}{c}0.07 \\
(0.07)\end{array}$ & $\begin{array}{c}0.02 \\
(0.05)\end{array}$ & $\begin{array}{c}-0.02 \\
(0.04)\end{array}$ & $\begin{array}{c}-0.06 \\
(0.06)\end{array}$ & $\begin{array}{c}0.05 \\
(0.08)\end{array}$ & $\begin{array}{c}0.06 \\
(0.04)\end{array}$ & $\begin{array}{c}0.02 \\
(0.05)\end{array}$ \\
\hline Father's College-VHS & & & $\begin{array}{c}0.06 \\
(0.07)\end{array}$ & $\begin{array}{c}0.14 \\
(0.07)\end{array}$ & $\begin{array}{c}0.02 \\
(0.06)\end{array}$ & $\begin{array}{c}0.01 \\
(0.04)\end{array}$ & $\begin{array}{l}-0.02 \\
(0.06)\end{array}$ & $\begin{array}{c}-0.04 \\
(0.06)\end{array}$ & $\begin{array}{c}0.02 \\
(0.14)\end{array}$ & $\begin{array}{c}0.12 \\
(0.10)\end{array}$ \\
\hline Father's College-AHS & & & $\begin{array}{c}0.02 \\
(0.05)\end{array}$ & $\begin{array}{c}0.06 \\
(0.05)\end{array}$ & $\begin{array}{c}0.03 \\
(0.04)\end{array}$ & $\begin{array}{c}-0.06 \\
(0.06)\end{array}$ & $\begin{array}{c}-0.05 \\
(0.04)\end{array}$ & $\begin{array}{c}0.01 \\
(0.04)\end{array}$ & $\begin{array}{c}0.04 \\
(0.03)\end{array}$ & $\begin{array}{c}0.06 \\
(0.04)\end{array}$ \\
\hline Constant & & $\begin{array}{c}2.00 \\
(0.16)\end{array}$ & $\begin{array}{c}3.96 \\
(0.06)\end{array}$ & $\begin{array}{c}4.87 \\
(0.02)\end{array}$ & $\begin{array}{c}2.03 \\
(0.16)\end{array}$ & $\begin{array}{c}1.12 \\
(0.26)\end{array}$ & $\begin{array}{c}1.62 \\
(0.19)\end{array}$ & $\begin{array}{c}2.21 \\
(0.19)\end{array}$ & $\begin{array}{c}3.04 \\
(0.16)\end{array}$ & $\begin{array}{c}3.38 \\
(0.15)\end{array}$ \\
\hline Family Background & & $\mathrm{x}$ & $\mathrm{x}$ & $\mathrm{x}$ & $\mathrm{x}$ & $\mathrm{x}$ & $\mathrm{x}$ & $\mathrm{x}$ & $\mathrm{x}$ & $\mathrm{x}$ \\
\hline Observations & 11,398 & 11,398 & 11,398 & 11,398 & 11,398 & 11,398 & 11,398 & 11,398 & 11,398 & 11,398 \\
\hline Individuals & 2,217 & 2,217 & 2,217 & 2,217 & 2,217 & 2,217 & 2,217 & 2,217 & 2,217 & 2,217 \\
\hline $\mathrm{R}^{2}$ & 0.228 & 0.251 & 0.231 & 0.188 & 0.253 & 0.184 & 0.243 & 0.245 & 0.230 & 0.223 \\
\hline
\end{tabular}

Note: Standard errors are adjusted for clustering to account for multiple observations for individuals. Parental earnings are averaged when their daughters were between 15 and 21. Family background includes father's job type, house ownership, metro/suburban address, and whether a daughter lived with parents when the daughter was between 15 and 21 . I include daughter's age and age squared.

$\star$ Father's college includes college graduates as well as those who attended graduate school. 
ings by $10 \%$ relative to fathers who graduated from high school. Column (5) reports the results when all controls are included. The education effects of both fathers and sons are not very different from other column results.

Panel B in Table 4 provides the results of the parental earnings effects on sons' earnings using quantile regressions, which predict the quantiles of sons' earnings. The model is identical to that in column (5). Panel A shows the conditional effects on average earnings of sons, whereas Panel B accounts for the effects on the distribution of earnings. Parental earnings are passed on to their sons' earnings about 8 percent at each quantile. The important observation in Panel B is that the effects of family's earnings at each quantile are very similar. A vocational high school degree of both fathers and sons slightly reduces sons' future earnings, compared to an academic high school degree, but it is not an overwhelming effect. Fathers who have college degrees help their sons to achieve earnings at the upper end of the earnings distribution relative to fathers who only graduated from high school, but only the effects of father's college after graduating from an academic high school are statistically significant. Although fathers' graduation from college has a stronger positive effect at the upper quantiles of the earnings distribution, sons' college education has very similar effects at all quantiles. This suggests that sons' college education moves the earnings distribution but does not affect the shape of the distribution, whereas father's education extends the upper tail of the earnings distribution

Table 5 presents the effects of parental earnings on daughter's earnings, and the format is the same as Table 4. The intergenerational earnings elasticity of daughters in column (1) is 0.41 , which is very similar to the elasticity for sons. Also, the effects of parental earnings on daughters are somewhat greater than sons' regardless of controls, with coefficients between 0.10 and 0.15 in alternative specifications controlling for fathers' and daughters' education. The vocational high school degree of daughters does not reduce earnings very much on average, but there are slightly stronger nega- 
Table 1.6 Effects of children's vocational high school degree on their earnings

\begin{tabular}{|c|c|c|c|c|}
\hline \multirow{2}{*}{$\begin{array}{c}\text { Sample } \\
\text { Dep. var: Children's Log Earnings }\end{array}$} & \multicolumn{2}{|c|}{ Son } & \multicolumn{2}{|c|}{ Daughter } \\
\hline & (1) & $(2)$ & $(3)$ & $(4)$ \\
\hline \multirow[b]{3}{*}{ Children's Vocational HS Graduates } & $\begin{array}{c}0.11 \\
(0.01)\end{array}$ & $\begin{array}{c}0.10 \\
(0.01)\end{array}$ & $\begin{array}{c}0.14 \\
(0.01)\end{array}$ & $\begin{array}{c}0.13 \\
(0.01)\end{array}$ \\
\hline & $\begin{array}{c}-0.21 \\
(0.05)\end{array}$ & $\begin{array}{l}-0.21 \\
(0.05)\end{array}$ & $\begin{array}{l}-0.25 \\
(0.13)\end{array}$ & $\begin{array}{c}-0.24 \\
(0.13)\end{array}$ \\
\hline & $\begin{array}{c}-0.03 \\
(0.02)\end{array}$ & $\begin{array}{c}-0.01 \\
(0.02)\end{array}$ & $\begin{array}{l}-0.02 \\
(0.02)\end{array}$ & $\begin{array}{l}-0.01 \\
(0.02)\end{array}$ \\
\hline Father's Less Than 9th Grade & & $\begin{array}{c}-0.07 \\
(0.02)\end{array}$ & & $\begin{array}{l}-0.04 \\
(0.02)\end{array}$ \\
\hline Father's Some VHS & & $\begin{array}{c}-0.04 \\
(0.07)\end{array}$ & & $\begin{array}{c}0.08 \\
(0.12)\end{array}$ \\
\hline Father's Some AHS & & $\begin{array}{c}0.02 \\
(0.05)\end{array}$ & & $\begin{array}{c}0.03 \\
(0.07)\end{array}$ \\
\hline Father's Vocational HS & & $\begin{array}{c}-0.02 \\
(0.02)\end{array}$ & & $\begin{array}{c}0.02 \\
(0.02)\end{array}$ \\
\hline Father's Some College-VHS & & $\begin{array}{c}0.06 \\
(0.06)\end{array}$ & & $\begin{array}{l}-0.01 \\
(0.06)\end{array}$ \\
\hline Father's Some College-AHS & & $\begin{array}{l}-0.02 \\
(0.05)\end{array}$ & & $\begin{array}{c}0.06 \\
(0.07)\end{array}$ \\
\hline Father's College-VHS & & $\begin{array}{c}0.03 \\
(0.04)\end{array}$ & & $\begin{array}{c}0.03 \\
(0.07)\end{array}$ \\
\hline Father's College-AHS & & $\begin{array}{c}0.08 \\
(0.04)\end{array}$ & & $\begin{array}{c}0.04 \\
(0.04)\end{array}$ \\
\hline Constant & $\begin{array}{c}1.45 \\
(0.13)\end{array}$ & $\begin{array}{c}1.46 \\
(0.13)\end{array}$ & $\begin{array}{c}1.26 \\
(0.17)\end{array}$ & $\begin{array}{c}1.29 \\
(0.17)\end{array}$ \\
\hline Family Background & $\mathrm{x}$ & $\mathrm{x}$ & $\mathrm{x}$ & $\mathrm{x}$ \\
\hline Observations & 15,743 & 15,743 & 11,398 & 11,398 \\
\hline Individuals & 2,630 & 2,630 & 2,217 & 2,217 \\
\hline $\mathrm{R}^{2}$ & 0.356 & 0.361 & 0.263 & 0.287 \\
\hline
\end{tabular}

Note: Standard errors are adjusted for clustering to account for multiple observations of individuals. Parental earnings are averaged when child was between ages 15 and 21 .

Family background includes father's job type, house ownership, metro/suburban address, and whether a child lived with parents when a child was between 15 and 21 . I include children's age and age squared.

* Children's less than 12th includes Children's less than 9th and children's Some high school. Children's vocational high school denotes all individuals who graduate from vocational high schools, including those who pursue higher education

** Father's college includes college graduates as well as those who attended graduate school.

tive effects at the 50th percentile and top 90th percentile as compared to daughters who graduated from an academic high school. On the other hand, a vocational high school degree of a daughter has positive effects on her earnings at the bottom quantile, and the effects on the 10th percentile are statistically significant. Fathers who 
graduated from vocational high school help their daughters to have higher earnings relative to fathers who graduated from an academic high school, but it is statistically insignificant. In contrast, sons whose fathers hold only a vocational high school degree are likely to have lower earnings than sons whose fathers hold only an academic high school degree, although this difference is not statistically significant. Another difference between sons and daughters is that a father who went to college does not help daughters achieve earnings in the top tenth percentile, as is observed for sons.

Table 6 shows estimates based on equation (3), which identifies the effects of vocational high school on the future earnings of sons and daughters, controlling for fathers' educational attainment. Although vocational high schools enable students to enter the labor force earlier if they get a job after graduation, one of the potential costs of vocational high school may be that it reduces the chance of continuing education. In order to capture this effect, I code education only up through high school graduation, so all the effect of vocational (versus academic) high school through further educational attainment is captured in the measure. Hence, this is a way to look at the total effect of graduating from one type of high school rather than another. This means the measure Children's vocational high school graduates includes those with higher levels of education. It should be noted that despite this alternative coding of children's education variables (Less than 12th-grade and Vocational high school graduates), I use the fathers' education coded in the same way as equation (2). Academic high school graduates is the omitted category for children. Sons and daughters who graduate from vocational high school do face lower earnings, compared to academic high school graduates, although the effects for neither sons nor daughters are statistically significant.

Based on the analyses in Tables 4, 5, and 6, the conclusion is that there are no overwhelming effects of father's vocational high school on children's earnings. Jyung (1997) points out that vocational high schools in the father's generation provided 
technical and skilled workers to the labor market. Those workers were considered as one of main driving forces of South Korea's phenomenal economic development over the period 1960 - 1980. However, in the children's generation, a vocational high school degree without further education reduces the chance of obtaining earnings at the higher quantiles of the income distribution relative to children who have an academic high school degree. The purpose of vocational education, which is to provide training at the secondary level of skills to facilitate direct entry into the labor market, may be less valuable in the children's generation, as indicated by the negative impacts of the vocational education in high school on children's earnings in Table 4 and Table 5. However, if I consider all vocational high school graduates (including those who enter post-secondary education), the earnings outcome for the vocational high school degree is not statistically different from the academic high school. It does not appear that vocational high school graduates are seriously handicapped by lower ultimate educational attainment. Their earnings are reduced, however, relative to academic high school graduates if they do not obtain additional schooling.

\subsubsection{Total Effects of Education}

Figures 1 to 4 plot the effects of education on children's earnings based on equation (4). Figures 1 and 3 show the effects of children's lower levels of education within all levels of father's education, and Figures 2 and 4 present the effects of children's higher levels of education within all levels of father's education. I include vocational high school and academic high school for all panels to allow easy comparison of earnings.

An outcome of a son who graduated from a vocational high school shows a similar labor income level of a son who graduated from an academic high school regardless of father's educational attainment in Figures 1 and 2. However, a son who obtained a college degree after graduating from an academic high school has higher earnings for most educational levels of fathers than a son who has obtained a college degree 

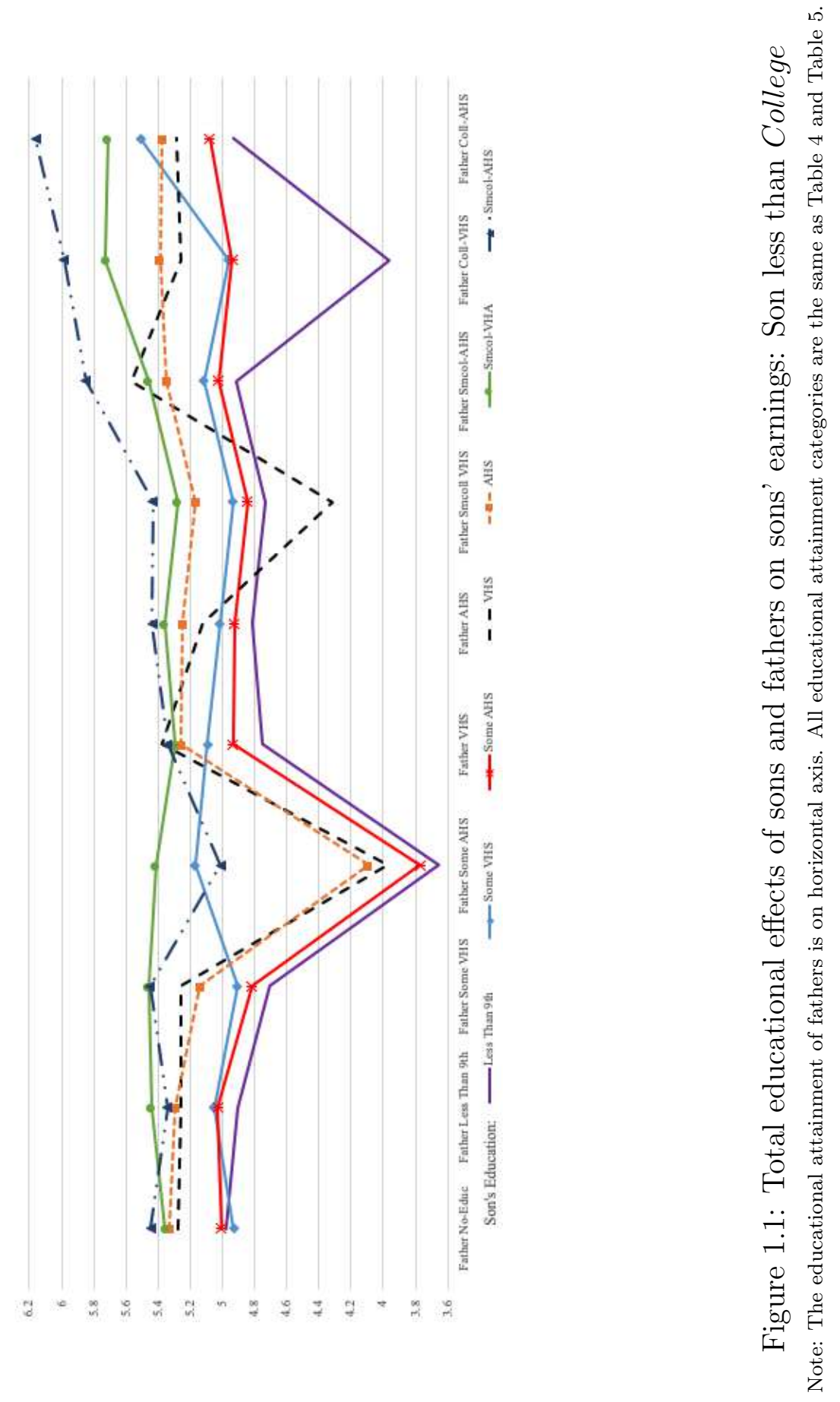


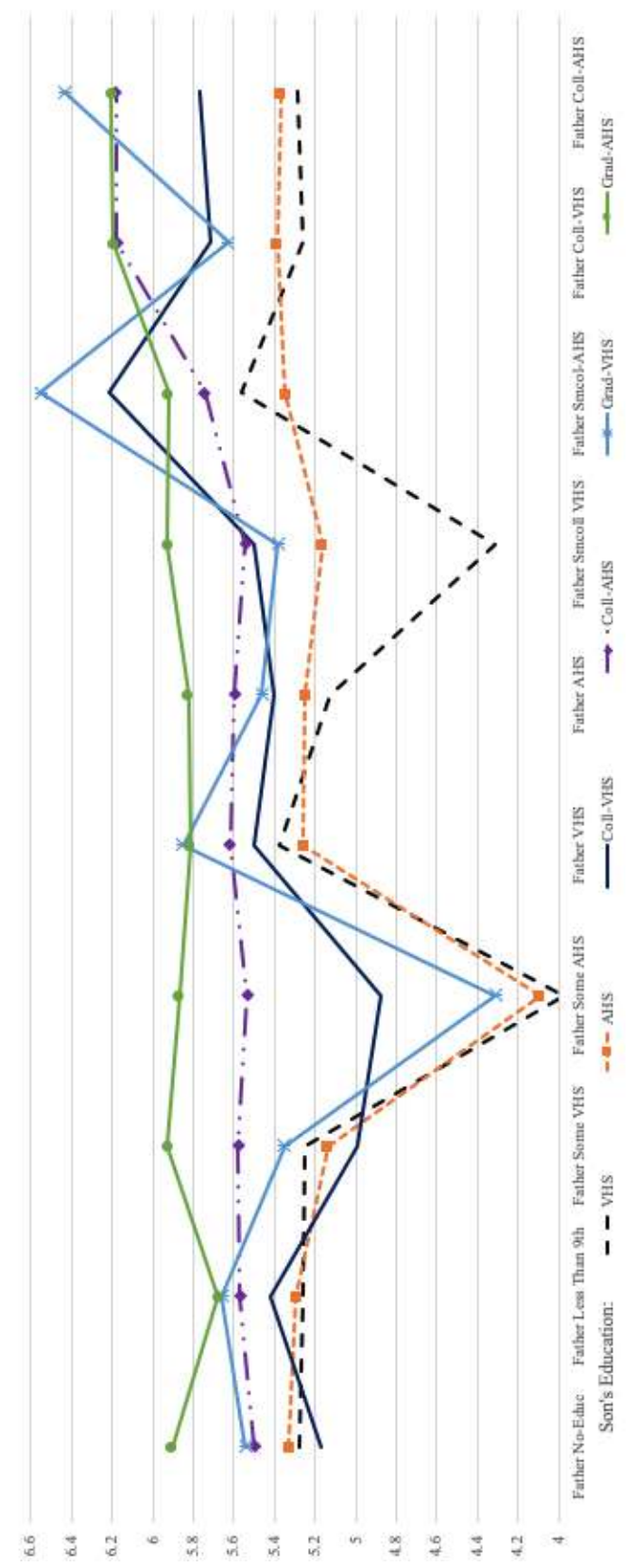

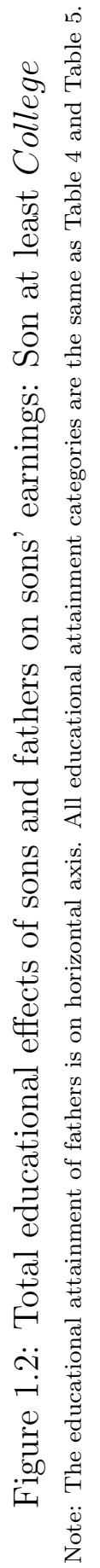




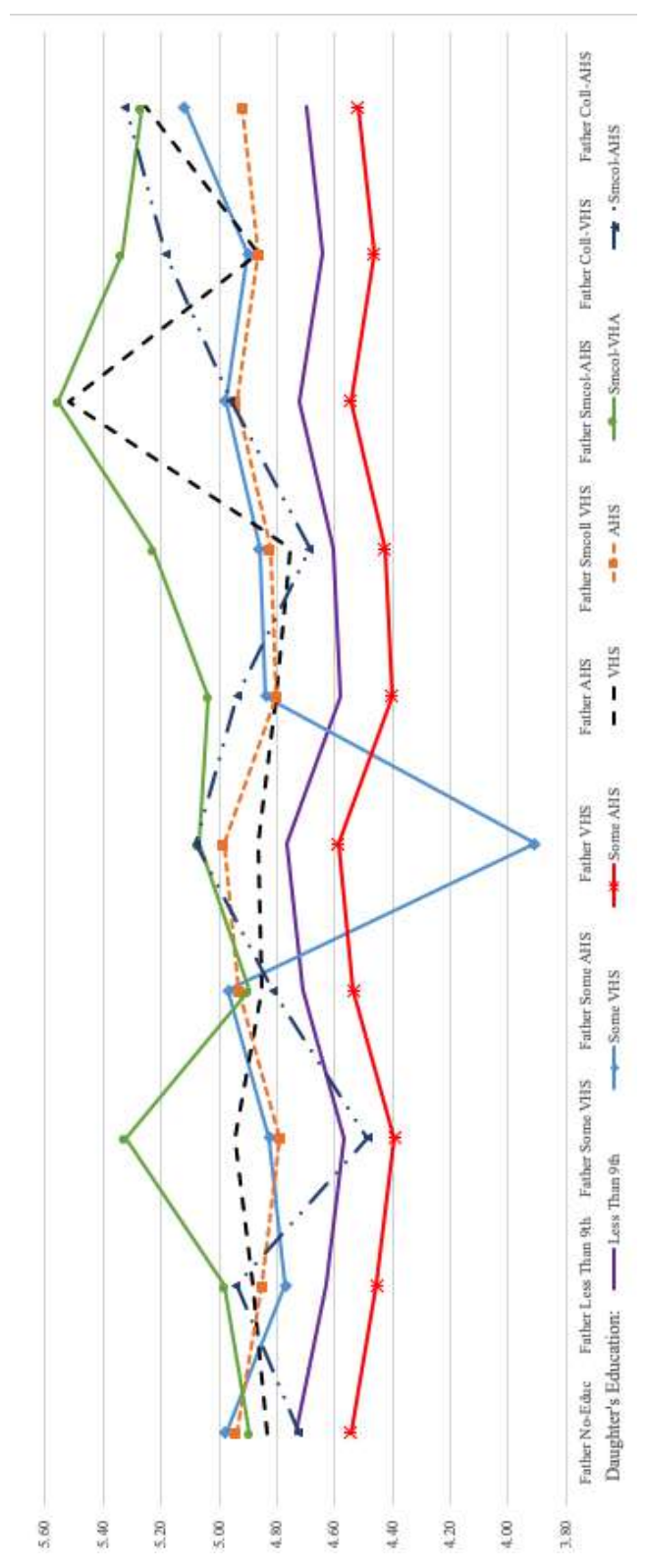

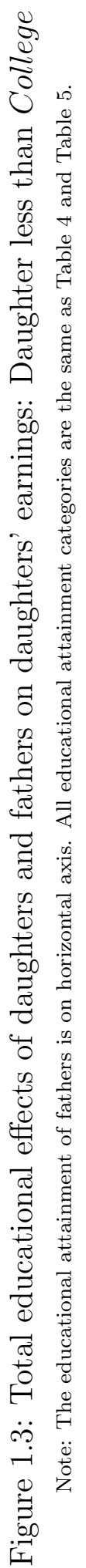




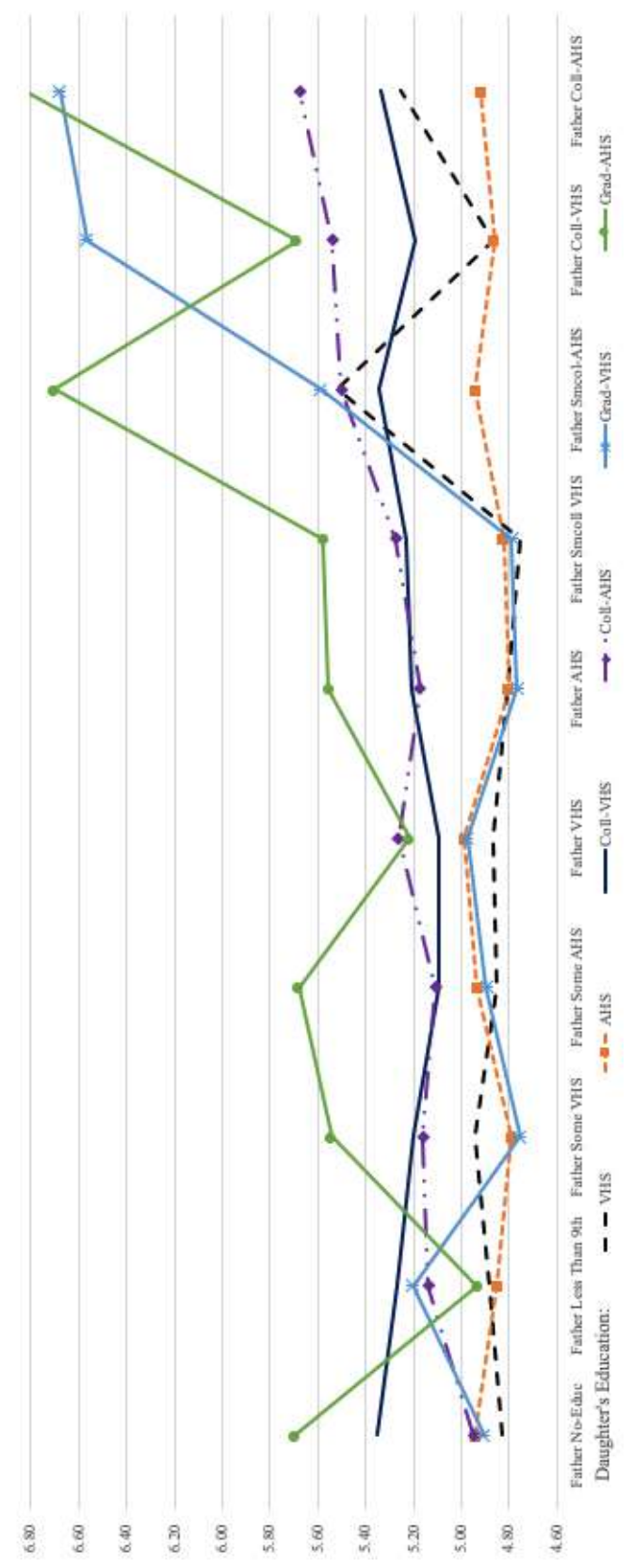

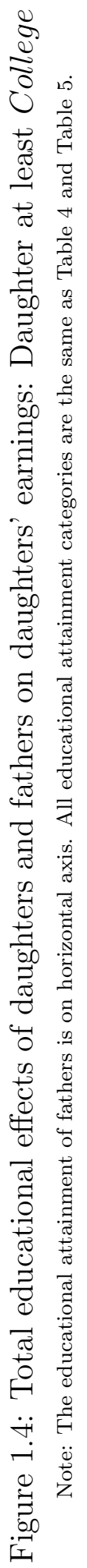


after graduating from a vocational high school. This is very likely because vocational high school graduates have to accustom themselves to an academic curriculum in college. We can find a similar pattern, which is that the outcome for vocational high school graduates is similar to those who graduated from an academic high school in all levels of father's education in Figures 3 and 4. From Figures 1 to 4, we confirm that the outcomes for children who graduated from a vocational high school are comparable to academic high school graduates who do not obtain any further education.

Children with greater educational attainment have greater earnings, no matter what their father's final education is. The educational effects of fathers on their children's earnings are stronger when children's own educational attainment is higher, as we can see that the lines tend to fan out to the right. Equivalently, the benefit of a child's education is greater for those with more educated fathers. I can find this phenomenon for both sons and daughters. These four figures support the view that the education for a parent and a child contribute in potentially complex ways to a child's earnings. At the same time, the patterns are similar enough that the additive model that is the basis for the models in the other sections of our paper is not seriously misleading.

\subsubsection{Estimation of Intergenerational Transmission of Edu- cation and the Role of Vocational and Academic High School}

The analysis in this section examines how paternal education, other family background characteristics, and father's high school influence educational attainment of children. The focus is on how these factors determine college attendance and college completion of children, which are critical points in the educational distribution of those entering the labor force in the last two decades, given that essentially everyone completes high school and some proportion obtain graduate degrees. Our analysis fo- 
Table 1.7 The effects of father's schooling on sons' educational achievement

\begin{tabular}{|c|c|c|c|c|c|c|c|c|}
\hline \multirow[t]{2}{*}{ Dependent Variable } & \multicolumn{4}{|c|}{ College Attendance } & \multicolumn{4}{|c|}{ College Completion } \\
\hline & (1) & $(2)$ & $(3)$ & $(4)$ & $(5)$ & $(6)$ & $(7)$ & $(8)$ \\
\hline Log Avg. Parental Earnings & & & $\begin{array}{c}0.05 \\
(0.01)\end{array}$ & $\begin{array}{c}0.02 \\
(0.01)\end{array}$ & & & $\begin{array}{c}0.04 \\
(0.01)\end{array}$ & $\begin{array}{c}0.02 \\
(0.01)\end{array}$ \\
\hline Son's Less Than 12th-Grade & $\begin{array}{l}-0.58 \\
(0.01)\end{array}$ & $\begin{array}{l}-0.58 \\
(0.01)\end{array}$ & $\begin{array}{l}-0.61 \\
(0.01)\end{array}$ & $\begin{array}{l}-0.59 \\
(0.02)\end{array}$ & $\begin{array}{l}-0.36 \\
(0.01)\end{array}$ & $\begin{array}{l}-0.36 \\
(0.01)\end{array}$ & $\begin{array}{l}-0.37 \\
(0.02)\end{array}$ & $\begin{array}{l}-0.36 \\
(0.02)\end{array}$ \\
\hline Son's Vocational HS Grads* & $\begin{array}{l}-0.22 \\
(0.02)\end{array}$ & $\begin{array}{l}-0.20 \\
(0.02)\end{array}$ & $\begin{array}{c}-0.21 \\
(0.02)\end{array}$ & $\begin{array}{c}-0.18 \\
(0.02)\end{array}$ & $\begin{array}{l}-0.24 \\
(0.02)\end{array}$ & $\begin{array}{l}-0.23 \\
(0.02)\end{array}$ & $\begin{array}{l}-0.25 \\
(0.02)\end{array}$ & $\begin{array}{r}-0.23 \\
(0.02)\end{array}$ \\
\hline Father's Less Than 12th-Grade & $\begin{array}{l}-0.02 \\
(0.02)\end{array}$ & $\begin{array}{l}-0.01 \\
(0.02)\end{array}$ & $\begin{array}{c}0.06 \\
(0.03)\end{array}$ & $\begin{array}{c}0.05 \\
(0.03)\end{array}$ & $\begin{array}{l}-0.01 \\
(0.02)\end{array}$ & $\begin{array}{l}0.002 \\
(0.02)\end{array}$ & $\begin{array}{c}0.04 \\
(0.02)\end{array}$ & $\begin{array}{c}0.04 \\
(0.02)\end{array}$ \\
\hline Father's Vocational HS & $\begin{array}{c}0.04 \\
(0.03)\end{array}$ & $\begin{array}{c}0.02 \\
(0.03)\end{array}$ & $\begin{array}{c}0.07 \\
(0.03)\end{array}$ & $\begin{array}{c}0.06 \\
(0.03)\end{array}$ & $\begin{array}{c}0.04 \\
(0.02)\end{array}$ & $\begin{array}{c}0.03 \\
(0.03)\end{array}$ & $\begin{array}{l}0.05 \\
(0.03)\end{array}$ & $\begin{array}{c}0.04 \\
(0.03)\end{array}$ \\
\hline Father's Some College & $\begin{array}{l}-0.02 \\
(0.04)\end{array}$ & $\begin{array}{l}-0.05 \\
(0.04)\end{array}$ & $\begin{array}{l}-0.04 \\
(0.04)\end{array}$ & $\begin{array}{l}-0.05 \\
(0.04)\end{array}$ & $\begin{array}{c}0.06 \\
(0.04)\end{array}$ & $\begin{array}{c}0.05 \\
(0.04)\end{array}$ & $\begin{array}{c}0.06 \\
(0.04)\end{array}$ & $\begin{array}{l}0.05 \\
(0.04)\end{array}$ \\
\hline Father's College & $\begin{array}{c}0.03 \\
(0.03)\end{array}$ & $\begin{array}{l}0.05 \\
(0.03)\end{array}$ & $\begin{array}{c}0.08 \\
(0.03)\end{array}$ & $\begin{array}{c}0.08 \\
(0.03)\end{array}$ & $\begin{array}{c}0.13 \\
(0.03)\end{array}$ & $\begin{array}{c}0.12 \\
(0.03)\end{array}$ & $\begin{array}{c}0.09 \\
(0.03)\end{array}$ & $\begin{array}{c}0.08 \\
(0.03)\end{array}$ \\
\hline Constant & $\begin{array}{c}0.67 \\
(0.02)\end{array}$ & $\begin{array}{c}0.57 \\
(0.03)\end{array}$ & $\begin{array}{c}0.33 \\
(0.09)\end{array}$ & $\begin{array}{c}0.34 \\
(0.09)\end{array}$ & $\begin{array}{c}0.42 \\
(0.02)\end{array}$ & $\begin{array}{c}0.35 \\
(0.02)\end{array}$ & $\begin{array}{c}0.14 \\
(0.08)\end{array}$ & $\begin{array}{c}0.12 \\
(0.08)\end{array}$ \\
\hline Family Background & & $\mathrm{x}$ & & $\mathrm{x}$ & & $\mathrm{x}$ & & $\mathrm{x}$ \\
\hline Observation No. & 2,630 & 2,630 & 2,630 & 2,630 & 2,630 & 2,630 & 2,630 & 2,630 \\
\hline $\mathrm{R}^{2}$ & 0.142 & 0.167 & 0.164 & 0.198 & 0.123 & 0.147 & 0.133 & 0.169 \\
\hline
\end{tabular}

Note: I control for family background, which includes home address (metropolitan area versus small urban), whether the son lived with parents between ages 15 and 21, and parents' house ownership. Family background is measured when son are aged between 15 and 21. Also, parental earnings are averaged when their sons were between 15 and 21. Robust standard errors are estimated.

$\star$ Both vocational and academic high school graduates include those who advance to higher education.

cuses on the influence of vocational high school versus academic high school. College attendance and college completion are the dependent variables that I use as measures of educational success (Tables 7 and 8). I estimate only the father's educational effects without considering parental earnings in the first two columns of each panel.

Tables 7 and 8 show how a father's education is associated with the educational success of sons and Table 8 for daughters, respectively. A father who obtained only a vocational high school degree helps a son to attend a college relative to a father who graduated from an academic high school, but the effect is statistically insignificant. Perhaps surprisingly, after controlling for parental earnings, sons whose fathers graduated from a vocational high school and have no further education, however, have relatively greater chances of entering college than sons whose fathers hold only academic high school degrees. However, this difference is not statistically significant for earning a college diploma. A father's college degree has positive impacts on both col- 
Table 1.8 The effects of father's schooling on daughters' educational achievement

\begin{tabular}{|c|c|c|c|c|c|c|c|c|}
\hline \multirow[t]{2}{*}{ Dependent Variable } & \multicolumn{4}{|c|}{ College Attendance } & \multicolumn{4}{|c|}{ College Completion } \\
\hline & $(1)$ & $(2)$ & $(3)$ & $(4)$ & $(5)$ & $(6)$ & $(7)$ & $(8)$ \\
\hline Log Avg. Parental Earnings & & & $\begin{array}{c}0.07 \\
(0.01)\end{array}$ & $\begin{array}{c}0.05 \\
(0.02)\end{array}$ & & & $\begin{array}{c}0.05 \\
(0.01)\end{array}$ & $\begin{array}{c}0.03 \\
(0.01)\end{array}$ \\
\hline Daughter's Less Than 12th-Grade & $\begin{array}{c}-0.66 \\
(0.02)\end{array}$ & $\begin{array}{l}-0.65 \\
(0.02)\end{array}$ & $\begin{array}{l}-0.67 \\
(0.02)\end{array}$ & $\begin{array}{l}-0.64 \\
(0.02)\end{array}$ & $\begin{array}{l}-0.42 \\
(0.02)\end{array}$ & $\begin{array}{l}-0.40 \\
(0.02)\end{array}$ & $\begin{array}{l}-0.41 \\
(0.02)\end{array}$ & $\begin{array}{l}-0.39 \\
(0.02)\end{array}$ \\
\hline Daughter's Vocational HS Grads ${ }^{\star}$ & $\begin{array}{l}-0.26 \\
(0.02)\end{array}$ & $\begin{array}{l}-0.24 \\
(0.02)\end{array}$ & $\begin{array}{l}-0.22 \\
(0.02)\end{array}$ & $\begin{array}{l}-0.20 \\
(0.02)\end{array}$ & $\begin{array}{l}-0.28 \\
(0.02)\end{array}$ & $\begin{array}{l}-0.26 \\
(0.02)\end{array}$ & $\begin{array}{l}-0.26 \\
(0.02)\end{array}$ & $\begin{array}{l}-0.24 \\
(0.02)\end{array}$ \\
\hline Father's Less Than 12th-Grade & $\begin{array}{c}-0.04 \\
(0.02)\end{array}$ & $\begin{array}{l}-0.03 \\
(0.02)\end{array}$ & $\begin{array}{c}-0.01 \\
(0.03)\end{array}$ & $\begin{array}{c}-0.02 \\
(0.03)\end{array}$ & $\begin{array}{l}-0.07 \\
(0.02)\end{array}$ & $\begin{array}{l}-0.06 \\
(0.02)\end{array}$ & $\begin{array}{l}-0.05 \\
(0.03)\end{array}$ & $\begin{array}{l}-0.05 \\
(0.03)\end{array}$ \\
\hline Father's Vocational HS & $\begin{array}{c}0.03 \\
(0.03)\end{array}$ & $\begin{array}{c}0.02 \\
(0.03)\end{array}$ & $\begin{array}{c}0.04 \\
(0.03)\end{array}$ & $\begin{array}{c}0.03 \\
(0.03)\end{array}$ & $\begin{array}{c}0.01 \\
(0.03)\end{array}$ & $\begin{array}{c}-0.01 \\
(0.03)\end{array}$ & $\begin{array}{c}0.02 \\
(0.03)\end{array}$ & $\begin{array}{l}-0.01 \\
(0.03)\end{array}$ \\
\hline Father's Some College & $\begin{array}{l}-0.01 \\
(0.04)\end{array}$ & $\begin{array}{l}-0.02 \\
(0.04)\end{array}$ & $\begin{array}{l}-0.03 \\
(0.04)\end{array}$ & $\begin{array}{l}-0.03 \\
(0.04)\end{array}$ & $\begin{array}{c}0.05 \\
(0.04)\end{array}$ & $\begin{array}{c}0.04 \\
(0.04)\end{array}$ & $\begin{array}{c}0.04 \\
(0.04)\end{array}$ & $\begin{array}{c}0.04 \\
(0.04)\end{array}$ \\
\hline Father's College & $\begin{array}{c}0.08 \\
(0.03)\end{array}$ & $\begin{array}{c}0.07 \\
(0.03)\end{array}$ & $\begin{array}{c}0.03 \\
(0.03)\end{array}$ & $\begin{array}{c}0.04 \\
(0.03)\end{array}$ & $\begin{array}{c}0.10 \\
(0.03)\end{array}$ & $\begin{array}{c}0.09 \\
(0.03)\end{array}$ & $\begin{array}{c}0.07 \\
(0.03)\end{array}$ & $\begin{array}{c}0.06 \\
(0.03)\end{array}$ \\
\hline Constant & $\begin{array}{c}0.72 \\
(0.02)\end{array}$ & $\begin{array}{c}0.58 \\
(0.03)\end{array}$ & $\begin{array}{c}0.27 \\
(0.10)\end{array}$ & $\begin{array}{l}0.24 \\
0.10\end{array}$ & $\begin{array}{c}0.48 \\
(0.02)\end{array}$ & $\begin{array}{c}0.34 \\
(0.03)\end{array}$ & $\begin{array}{c}0.15 \\
(0.10)\end{array}$ & $\begin{array}{c}0.11 \\
(0.09)\end{array}$ \\
\hline Family Background & & $\mathrm{x}$ & & $\mathrm{x}$ & & $\mathrm{x}$ & & $\mathrm{x}$ \\
\hline Observation No. & 2,217 & 2,217 & 2,217 & 2,217 & 2,217 & 2,217 & 2,217 & 2,217 \\
\hline $\mathrm{R}^{2}$ & 0.144 & 0.173 & 0.153 & 0.182 & 0.143 & 0.177 & 0.143 & 0.182 \\
\hline
\end{tabular}

Note: I control for family background, which includes home address (metropolitan area versus small urban), whether the daughter lived with parents between ages 15 and 21, and parents' house ownership. Family background is measured when daughters are aged between 15 and 21. Also, parental earnings are averaged when their daughters were between 15 and 21 . Robust standard errors are estimated.

$\star$ Both vocational and academic high school graduates include those who advance to higher education.

lege attendance and college completion of children. Sons whose fathers hold college diplomas have an 8 percentage point greater likelihood of attending or completing college than those whose fathers obtained only academic high school degrees when I control parental earnings in column (4) and column (8). Similarly, a father with a college diploma has a greater likelihood that his daughter attends and completes college, but these effects are slightly smaller than for sons.

When predicting college attendance, the coefficient of parental earnings declines from .05 to .02 when sons' family background is controlled (columns (3) and (4) in Table 7). Also, the coefficient on parental earnings shows a similar pattern in predicting college completion in Table 7. A 1 percent increase in a father's earnings increases the chance that a son attends or graduates from a college by about 0.02 percent. According to Table 8, parental earnings have a greater impact on daughters' educational success than on sons', when parental education is controlled. Similarly, 
Table 1.9 The effects of family characteristics on children's vocational high school entrance

\begin{tabular}{|c|c|c|c|c|}
\hline Dependent Variable & \multicolumn{4}{|c|}{ Vocational HS Attendance* } \\
\hline \multirow[t]{2}{*}{ Sample } & \multicolumn{2}{|c|}{ Son } & \multicolumn{2}{|c|}{ Daughter } \\
\hline & (1) & $(2)$ & $(3)$ & $(4)$ \\
\hline Log Avg. Parental Earnings & $\begin{array}{l}-0.05 \\
(0.01)\end{array}$ & $\begin{array}{l}-0.05 \\
(0.01)\end{array}$ & $\begin{array}{l}-0.08 \\
(0.01)\end{array}$ & $\begin{array}{l}-0.08 \\
(0.01)\end{array}$ \\
\hline Father's Less Than 12th & $\begin{array}{c}0.16 \\
(0.02)\end{array}$ & $\begin{array}{c}0.14 \\
(0.03)\end{array}$ & $\begin{array}{c}0.20 \\
(0.02)\end{array}$ & $\begin{array}{c}0.21 \\
(0.03)\end{array}$ \\
\hline Father's Vocational HS & & $\begin{array}{l}-0.05 \\
(0.03)\end{array}$ & & $\begin{array}{c}0.02 \\
(0.03)\end{array}$ \\
\hline Father's Some College & $\begin{array}{l}0.003 \\
(0.04)\end{array}$ & $\begin{array}{l}-0.02 \\
(0.04)\end{array}$ & $\begin{array}{l}-0.04 \\
(0.04)\end{array}$ & $\begin{array}{l}-0.03 \\
(0.04)\end{array}$ \\
\hline Father's College & $\begin{array}{l}-0.12 \\
(0.03)\end{array}$ & $\begin{array}{l}-0.14 \\
(0.03)\end{array}$ & $\begin{array}{l}-0.14 \\
(0.02)\end{array}$ & $\begin{array}{c}-0.13 \\
(0.03)\end{array}$ \\
\hline Constant & $\begin{array}{c}0.78 \\
(0.09)\end{array}$ & $\begin{array}{c}0.80 \\
(0.09)\end{array}$ & $\begin{array}{c}0.93 \\
(0.09)\end{array}$ & $\begin{array}{c}0.92 \\
(0.10)\end{array}$ \\
\hline Family Background & $\mathrm{x}$ & $\mathrm{x}$ & $\mathrm{x}$ & $\mathrm{x}$ \\
\hline Observations & 2,129 & 2,129 & 1,897 & 1,897 \\
\hline $\mathrm{R}^{2}$ & 0.092 & 0.100 & 0.137 & 0.137 \\
\hline
\end{tabular}

Note: I include family background, which includes home address, whether the child lived with parents between ages 15 and 21, and house ownership. Parental earnings are averaged when. children are between 15 and 21. Family background variables are measured when their children are between 15 and 21. Robustness option is applied to all equations.

* Vocational high school entrance includes high school dropouts, high school graduates, and those who obtained higher education after vocational high school attendance.

a 1 percent increment of a father's earnings increases a daughter's probability of entering a college 0.05 percent and completing college 0.03 percent. The effects of parental earnings on children's educational achievement are tiny after controlling for paternal education. Both sons and daughters who graduate from vocational high school are 20 percentage points less likely to attend a college than academic high school graduates.

Table 9 reports the effects of family background on children's attendance of a 
vocational high school. The dependent variable includes all children who graduated from high school, independent of whether they obtained further education, with those who attended a vocational high school coded as one. This excludes from the sample the small number of respondents who did not attend a high school. Table 9 shows that both sons and daughters are more likely to enroll in a vocational high school if a father has a lower income and is less educated. The coefficient $\rho$, which shows how parental earnings affect the likelihood that sons and daughters attend a vocational high school, is -0.05 for sons and -0.06 for daughters, coefficients that are statistically significant. A father's vocational high school degree increases the likelihood of a daughter attending a vocational high school and it is statistically significant, but the effect is statistically insignificant for sons. However, a father's college diploma reduces the chance that a child attends vocational high school by 8 percentage points.

\subsection{Robustness Checks}

This section presents robustness checks of intergenerational earnings relationships. Chetty et al. (2014a) use the income rank of both a child and their parents to investigate intergenerational income mobility because they find that the relationship between children's and parents' income is nonlinear, with a flatter relationship in the bottom $10 \%$ and top $10 \%$ of the parents' income distribution. Table 10 tests the intergenerational earnings elasticity when either the bottom $10 \%$ or top $10 \%$ of the parental earnings distribution is selected. Both groups have a lower intergenerational earnings elasticity, around 0.22 or 0.23 for sons. A daughter whose parents have earnings in the bottom 10th percentile of the earnings distribution has slightly higher elasticity, 0.29 , while a daughter with parents in the top 10th percentile has an elasticity of 0.21 . In contrast, the middle $80 \%$ of the parental earnings distribution of sons (daughters) has a higher elasticity, $0.52(0.54)$. In contrast, in Tables 4 and 5 , 
the intergenerational earnings elasticity is 0.40 for sons and 0.41 for daughters when the full parental earnings distribution is considered.

Columns (4) and (5) show the intergenerational earnings association after controlling for either educational attainment of fathers or children when parental earnings are in the middle $80 \%$ of the parental earnings distribution. Column (6) shows the association with both fathers' and children's education. Although the effects of parental earnings are 12 percentage points greater than the original sample, after controlling for educational levels, the effects of parental earnings on children' labor income is only 2 percentage point higher than estimates in the original sample. Estimates of the educational attainment of fathers and children (sons and daughters) also show almost identical patterns in predicting children's earnings as compared with the original sample.

Tables 11 and 12 estimate the intergenerational earnings relationships using the multiyear-average method to test the sensitivity of the relationship. There are three different dependent variables in both Tables 11 and 12, child's log current earnings for Panel A, the log of 2-year averaged earnings for Panel B, and the log of 5-year averaged earnings for Panel C. We average two or five years of earnings to use a dependent variable as a better measure of a child's earnings. Each panel also uses three samples, the original sample (the same sample in Tables 4 and 5), a sample in which each child has earnings in at least 5 years, and a sample with parental earnings between $10 \%$ and $90 \%$ of the parental earnings distribution. Averaging 5 years of earnings allows us to observe more stable earnings. However, there could be the selection bias because a more educated child is more likely to have a shorter period of earnings. For parental earnings in the top and bottom 10th percentile, Table 10 shows weaker effects of parental earnings on children's earnings, that is, a lower intergenerational earnings elasticity, than the full sample (column (1) in Table 4). The sample of parental earnings between $10 \%$ and $90 \%$ allows us to focus on the 
Table 1.10 Intergenerational earnings association by parental earnings distribution

\begin{tabular}{|c|c|c|c|c|c|c|}
\hline \multirow{2}{*}{$\begin{array}{c}\text { Panel A: Sons } \\
\text { Parental Earnings Distribution }\end{array}$} & \multirow{3}{*}{$\frac{\text { Bottom } 10 \%}{(1)}$} & \multirow{3}{*}{$\frac{\text { Top } 10 \%}{(2)}$} & \multirow{2}{*}{\multicolumn{4}{|c|}{ Middle $80 \%$}} \\
\hline & & & & & & \\
\hline & & & (3) & $(4)$ & $(5)$ & (6) \\
\hline Log Avg Parental Earnings & $\begin{array}{c}0.22 \\
(0.05) \\
\end{array}$ & $\begin{array}{c}0.23 \\
(0.07) \\
\end{array}$ & $\begin{array}{c}0.52 \\
(0.01)\end{array}$ & $\begin{array}{c}0.10 \\
(0.01)\end{array}$ & $\begin{array}{c}0.12 \\
(0.01)\end{array}$ & $\begin{array}{c}0.10 \\
(0.07) \\
\end{array}$ \\
\hline Observations & 1,917 & 1,408 & 12,418 & 12,418 & 12,418 & 12,418 \\
\hline Individuals & 764 & 580 & 2,400 & 2,400 & 2,400 & 2,400 \\
\hline $\mathrm{R}^{2}$ & 0.046 & 0.014 & 0.279 & 0.390 & 0.378 & 0.393 \\
\hline \multicolumn{7}{|l|}{ Panel B: Daughters } \\
\hline \multirow[t]{2}{*}{ Parental Earnings Distribution } & Bottom 10\% & Top $10 \%$ & \multicolumn{4}{|c|}{ Middle $80 \%$} \\
\hline & $(1)$ & $(2)$ & (3) & $(4)$ & $(5)$ & (6) \\
\hline Log Avg Parental Earnings & $\begin{array}{c}0.22 \\
(0.05)\end{array}$ & $\begin{array}{c}0.23 \\
(0.07)\end{array}$ & $\begin{array}{c}0.54 \\
(0.01)\end{array}$ & $\begin{array}{c}0.12 \\
(0.01)\end{array}$ & $\begin{array}{c}0.13 \\
(0.02)\end{array}$ & $\begin{array}{c}0.12 \\
(0.02)\end{array}$ \\
\hline Observations & 1,098 & 1,230 & 9,070 & 9,070 & 9,070 & 9,070 \\
\hline Individuals & 481 & 513 & 2,039 & 2,039 & 2,039 & 2,039 \\
\hline $\mathrm{R}^{2}$ & 0.041 & 0.013 & 0.125 & 0.231 & 0.213 & 0.233 \\
\hline \multicolumn{7}{|l|}{ Other Controls } \\
\hline Son's Education & & & & $\mathrm{x}$ & & $\mathrm{x}$ \\
\hline Father's Education & & & & & $\mathrm{x}$ & $\mathrm{x}$ \\
\hline Family Background & & & & $\mathrm{x}$ & $\mathrm{x}$ & $\mathrm{x}$ \\
\hline
\end{tabular}

Note: This table shows the intergenerational earnings elasticity where parental earnings is in the bottom $10 \%$, the top $10 \%$, and the middle $80 \%$.

range of parental earnings with a more linear intergenerational earnings relationship.

Table 11 shows results for sons. In Panel A, columns (1) to (4) are identical to those of Table 4. The intergenerational earnings elasticity declines to 0.26 in column (5) from 0.40 when we restrict the sample to individuals who have at least 5 years of earnings. This result is consistent with the assumption that a more educated son is more likely to be omitted from this sample. The effect of parental earnings with both averaged earnings samples show similar patterns to the results with the original sample after controlling for the educational attainment of fathers and sons. Columns (9) to (12) in Panel A shows the same results to columns (3) to (6) of Panel A in Table 10.

I also estimate the intergenerational earnings relationship using a 2-year or 5-year- 
Table 1.11 Robustness checks for sons

\begin{tabular}{|c|c|c|c|c|c|c|c|c|c|c|c|c|}
\hline \multirow[t]{2}{*}{ Sample } & \multicolumn{4}{|c|}{ Original } & \multicolumn{4}{|c|}{$\geq 5$ Years of Earnings } & \multicolumn{4}{|c|}{ Parents Earnings 10-90* } \\
\hline & (1) & $(2)$ & $(3)$ & (4) & $(5)$ & (6) & (7) & (8) & (9) & $(10)$ & (11) & $(12)$ \\
\hline Log Avg Parental Earnings & $\begin{array}{c}0.40 \\
(0.01) \\
\end{array}$ & $\begin{array}{c}0.08 \\
(0.01) \\
\end{array}$ & $\begin{array}{c}0.11 \\
(0.01) \\
\end{array}$ & $\begin{array}{c}0.08 \\
(0.01) \\
\end{array}$ & $\begin{array}{c}0.26 \\
(0.01)\end{array}$ & $\begin{array}{c}0.09 \\
(0.01) \\
\end{array}$ & $\begin{array}{c}0.10 \\
(0.01) \\
\end{array}$ & $\begin{array}{c}0.09 \\
(0.01) \\
\end{array}$ & $\begin{array}{c}0.52 \\
(0.01)\end{array}$ & $\begin{array}{c}0.10 \\
(0.01) \\
\end{array}$ & $\begin{array}{c}0.12 \\
(0.01)\end{array}$ & $\begin{array}{c}0.10 \\
(0.01)\end{array}$ \\
\hline Observations & 15,743 & 15,743 & 15,743 & 15,743 & 13,485 & 13,485 & 13,485 & 13,485 & 12,418 & 12,418 & 12,418 & 12,418 \\
\hline Individuals & 2,630 & 2,630 & 2,630 & 2,630 & 1,561 & 1,561 & 1,561 & 1,561 & 2,400 & 2,400 & 2,400 & 2,400 \\
\hline $\mathrm{R}^{2}$ & 0.349 & 0.372 & 0.355 & 0.376 & 0.324 & 0.350 & 0.331 & 0.355 & 0.379 & 0.390 & 0.369 & 0.393 \\
\hline
\end{tabular}

Panel B. Dependent Variable: 2-year-averaged Log Earnings of Son

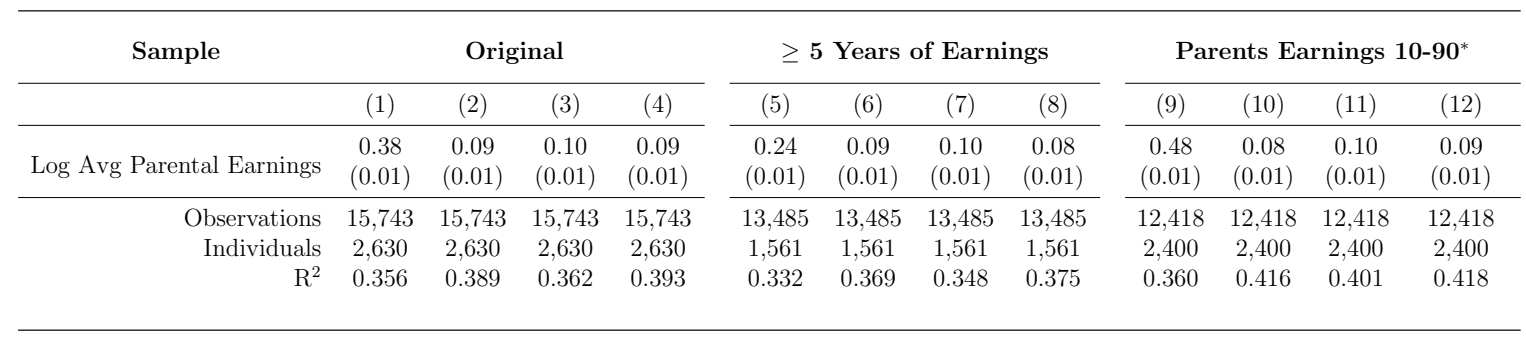

Panel C. Dependent Variable: 5-year-averaged Log Earnings of Son

\begin{tabular}{|c|c|c|c|c|c|c|c|c|c|c|c|c|}
\hline \multirow[t]{2}{*}{ Sample } & \multicolumn{4}{|c|}{ Original } & \multicolumn{4}{|c|}{$\geq 5$ Years of Earnings } & \multicolumn{4}{|c|}{ Parents Earnings $10-90^{*}$} \\
\hline & (1) & (2) & (3) & (4) & (5) & (6) & (7) & (8) & (9) & (10) & (11) & (12) \\
\hline Log Avg Parental Earnings & $\begin{array}{c}0.35 \\
(0.01)\end{array}$ & $\begin{array}{c}0.08 \\
(0.01)\end{array}$ & $\begin{array}{c}0.09 \\
(0.01)\end{array}$ & $\begin{array}{c}0.08 \\
(0.01)\end{array}$ & $\begin{array}{c}0.21 \\
(0.01)\end{array}$ & $\begin{array}{c}0.08 \\
(0.01)\end{array}$ & $\begin{array}{c}0.09 \\
(0.01)\end{array}$ & $\begin{array}{c}0.07 \\
(0.01)\end{array}$ & $\begin{array}{c}0.43 \\
(0.01)\end{array}$ & $\begin{array}{c}0.06 \\
(0.01)\end{array}$ & $\begin{array}{c}0.08 \\
(0.01)\end{array}$ & $\begin{array}{c}0.06 \\
(0.01)\end{array}$ \\
\hline $\begin{array}{r}\text { Observations } \\
\text { Individuals } \\
\mathrm{R}^{2}\end{array}$ & $\begin{array}{c}15,743 \\
2,630 \\
0.375\end{array}$ & $\begin{array}{c}15,743 \\
2,630 \\
0.396\end{array}$ & $\begin{array}{l}15,743 \\
2,630 \\
0.377\end{array}$ & $\begin{array}{c}15,743 \\
2,630 \\
0.401\end{array}$ & $\begin{array}{c}13,485 \\
1,561 \\
0.335\end{array}$ & $\begin{array}{c}13,485 \\
1,561 \\
0.377\end{array}$ & $\begin{array}{c}13,485 \\
1,561 \\
0.353\end{array}$ & $\begin{array}{c}13,485 \\
1,561 \\
0.383\end{array}$ & $\begin{array}{l}12,418 \\
2,400 \\
0.379\end{array}$ & $\begin{array}{c}12,418 \\
2,400 \\
0.429\end{array}$ & $\begin{array}{c}12,418 \\
2,400 \\
0.411\end{array}$ & $\begin{array}{c}12,418 \\
2,400 \\
0.431\end{array}$ \\
\hline $\begin{array}{l}\text { Other Controls } \\
\text { Son's Education } \\
\text { Father's Education } \\
\text { Family Background }\end{array}$ & & $\mathrm{x}$ & $\begin{array}{l}x \\
x\end{array}$ & $\begin{array}{l}\mathrm{x} \\
\mathrm{x} \\
\mathrm{x}\end{array}$ & & $\mathrm{x}$ & $\begin{array}{l}x \\
x\end{array}$ & $\begin{array}{l}\mathrm{x} \\
\mathrm{x} \\
\mathrm{x}\end{array}$ & & $\mathrm{x}$ & $\begin{array}{l}\mathrm{x} \\
\mathrm{x}\end{array}$ & $\begin{array}{l}\mathrm{x} \\
\mathrm{x} \\
\mathrm{x}\end{array}$ \\
\hline
\end{tabular}

average method in Panels B and C. The elasticity declines when we use multiyearaverage earnings as a dependent variable in columns (1), (5), and (9). However, we can identify an identical pattern in Panel A, in Panel B, and Panel C that the elasticity declines when we use a sample where each case has five years of earnings, so the difference appears to be due to the sample difference not to averaging. Table 12 presents the results of daughters' intergenerational earnings relationships. A daughter is slightly more affected by parental earnings than a son, but all phenomena we can find in Table 11 appear in Table 12. 
Table 1.12 Robustness checks for daughters

Panel A. Dependent Variable: Current Year Log Earnings of Daughter

\begin{tabular}{|c|c|c|c|c|c|c|c|c|c|c|c|c|}
\hline \multirow[t]{2}{*}{ Sample } & \multicolumn{4}{|c|}{ Original } & \multicolumn{4}{|c|}{$\geq 5$ Years of Earnings } & \multicolumn{4}{|c|}{ Parents Earnings 10-90* } \\
\hline & $(1)$ & $(2)$ & $(3)$ & $(4)$ & $(5)$ & $(6)$ & $(7)$ & $(8)$ & (9) & $(10)$ & (11) & $(12)$ \\
\hline Log Avg Parental Earnings & $\begin{array}{c}0.41 \\
(0.01)\end{array}$ & $\begin{array}{c}0.10 \\
(0.01)\end{array}$ & $\begin{array}{c}0.15 \\
(0.01)\end{array}$ & $\begin{array}{c}0.11 \\
(0.01)\end{array}$ & $\begin{array}{c}0.30 \\
(0.01)\end{array}$ & $\begin{array}{c}0.12 \\
(0.01)\end{array}$ & $\begin{array}{c}0.13 \\
(0.01)\end{array}$ & $\begin{array}{c}0.12 \\
(0.01)\end{array}$ & $\begin{array}{c}0.54 \\
(0.01)\end{array}$ & $\begin{array}{c}0.12 \\
(0.01)\end{array}$ & $\begin{array}{c}0.13 \\
(0.01)\end{array}$ & $\begin{array}{c}0.12 \\
(0.01)\end{array}$ \\
\hline Observations & 11,398 & 11,398 & 11,398 & 11,398 & 9,013 & 9,013 & 9,013 & 9,013 & 9,070 & 9,070 & 9,070 & 9,070 \\
\hline Individuals & 2,217 & 2,217 & 2,217 & 2,217 & 1,113 & 1,113 & 1,113 & 1,113 & 2,039 & 2,039 & 2,039 & 2,039 \\
\hline $\mathrm{R}^{2}$ & 0.228 & 0.251 & 0.231 & 0.253 & 0.225 & 0.248 & 0.227 & 0.250 & 0.195 & 0.231 & 0.214 & 0.233 \\
\hline
\end{tabular}

Panel B. Dependent Variable: 2-year-averaged Log Earnings of Daughter

\begin{tabular}{|c|c|c|c|c|c|c|c|c|c|c|c|c|}
\hline \multirow[t]{2}{*}{ Sample } & \multicolumn{4}{|c|}{ Original } & \multicolumn{4}{|c|}{$\geq 5$ Years of Earnings } & \multicolumn{4}{|c|}{ Parents Earnings 10-90* } \\
\hline & $(1)$ & $(2)$ & $(3)$ & $(4)$ & $(5)$ & $(6)$ & (7) & (8) & $(9)$ & $(10)$ & (11) & $(12)$ \\
\hline Log Avg Parental Earnings & $\begin{array}{c}0.38 \\
(0.01)\end{array}$ & $\begin{array}{c}0.12 \\
(0.01)\end{array}$ & $\begin{array}{c}0.13 \\
(0.01)\end{array}$ & $\begin{array}{c}0.12 \\
(0.01)\end{array}$ & $\begin{array}{c}0.28 \\
(0.01)\end{array}$ & $\begin{array}{c}0.11 \\
(0.01)\end{array}$ & $\begin{array}{c}0.13 \\
(0.01)\end{array}$ & $\begin{array}{c}0.11 \\
(0.01)\end{array}$ & $\begin{array}{c}0.51 \\
(0.01)\end{array}$ & $\begin{array}{c}0.11 \\
(0.01)\end{array}$ & $\begin{array}{c}0.12 \\
(0.01)\end{array}$ & $\begin{array}{c}0.11 \\
(0.01)\end{array}$ \\
\hline Observations & 11,398 & 11,398 & 11,398 & 11,398 & 9,013 & 9,013 & 9,013 & 9,013 & 9,070 & 9,070 & 9,070 & 9,070 \\
\hline Individuals & 2,217 & 2,217 & 2,217 & 2,217 & 1,113 & 1,113 & 1,113 & 1,113 & 2,039 & 2,039 & 2,039 & 2,039 \\
\hline $\mathrm{R}^{2}$ & 0.201 & 0.261 & 0.242 & 0.263 & 0.206 & 0.262 & 0.239 & 0.264 & 0.191 & 0.242 & 0.224 & 0.244 \\
\hline
\end{tabular}

Panel C. Dependent Variable: 5-year-averaged Log Earnings of Daughter

\begin{tabular}{|c|c|c|c|c|c|c|c|c|c|c|c|c|}
\hline \multirow[t]{2}{*}{ Sample } & \multicolumn{4}{|c|}{ Original } & \multicolumn{4}{|c|}{$\geq 5$ Years of Earnings } & \multicolumn{4}{|c|}{ Parents Earnings 10-90* } \\
\hline & (1) & $(2)$ & (3) & (4) & (5) & $(6)$ & (7) & (8) & (9) & $(10)$ & $(11)$ & $(12)$ \\
\hline Log Avg Parental Earnings & $\begin{array}{c}0.35 \\
(0.01)\end{array}$ & $\begin{array}{c}0.11 \\
(0.01)\end{array}$ & $\begin{array}{c}0.12 \\
(0.01)\end{array}$ & $\begin{array}{c}0.11 \\
(0.01)\end{array}$ & $\begin{array}{c}0.25 \\
(0.01)\end{array}$ & $\begin{array}{c}0.11 \\
(0.01)\end{array}$ & $\begin{array}{c}0.12 \\
(0.01)\end{array}$ & $\begin{array}{c}0.11 \\
(0.01)\end{array}$ & $\begin{array}{c}0.46 \\
(0.01)\end{array}$ & $\begin{array}{c}0.08 \\
(0.01)\end{array}$ & $\begin{array}{c}0.09 \\
(0.01)\end{array}$ & $\begin{array}{c}0.08 \\
(0.01)\end{array}$ \\
\hline Observations & 11,398 & 11,398 & 11,398 & 11,398 & 9,013 & 9,013 & 9,013 & 9,013 & 9,070 & 9,070 & 9,070 & 9,070 \\
\hline Individuals & 2,217 & 2,217 & 2,217 & 2,217 & 1,113 & 1,113 & 1,113 & 1,113 & 2,039 & 2,039 & 2,039 & 2,039 \\
\hline $\mathrm{R}^{2}$ & 0.184 & 0.263 & 0.241 & 0.265 & 0.203 & 0.264 & 0.239 & 0.267 & 0.166 & 0.205 & 0.189 & 0.207 \\
\hline \multicolumn{13}{|l|}{ Other Controls } \\
\hline Daughter's Education & & $\mathrm{x}$ & & $\mathrm{x}$ & & $\mathrm{x}$ & & $\mathrm{x}$ & & $\mathrm{x}$ & & $\mathrm{x}$ \\
\hline Father's Education & & & $\mathrm{x}$ & $\mathrm{x}$ & & & $\mathrm{x}$ & $\mathrm{x}$ & & & $\mathrm{x}$ & $\mathrm{x}$ \\
\hline Family Background & & & $\mathrm{x}$ & $\mathrm{x}$ & & & $\mathrm{x}$ & $\mathrm{x}$ & & & $\mathrm{x}$ & $\mathrm{x}$ \\
\hline
\end{tabular}

Note: Standard errors are adjusted for clustering to account for multiple observations of individuals. Parental earnings are averaged when daughters were between 15 and 21. Family background includes father's job type, house ownership, metro/suburban address, and whether a daughter lived with parents between ages 15 and 21. I add daughter's age and age squared.

$\star$ It means that the middle $80 \%$ of the parental earnings distribution.

Table 13 estimates the intergenerational earnings relationship using year fixed effects. The models fitted corresponds to columns (1) to (3) and (5) of Tables 4 and 5 , and show the intergenerational earnings relationships after controlling for father's and children's educational attainment and family background. The intergenerational earnings relationships estimated in Tables 4 and 5 may be biased because the earnings of parents and children increase as time passes. The year fixed effects remove the spurious time relationship between parents' and children's earnings.

In columns (1) to (8) of Table 13, the intergenerational earnings relationships are 
Table 1.13 Year fixed effect of the intergenerational earnings relationship

\begin{tabular}{|c|c|c|c|c|c|c|c|c|}
\hline \multirow{2}{*}{ Dep. var: Children's Log Earnings } & \multicolumn{4}{|c|}{ Son } & \multicolumn{4}{|c|}{ Daughter } \\
\hline & (1) & $(2)$ & $(3)$ & (4) & $(5)$ & $(6)$ & $(7)$ & $(8)$ \\
\hline Log Avg Parental Earnings & $\begin{array}{c}0.39 \\
(0.01)\end{array}$ & $\begin{array}{c}0.09 \\
(0.01)\end{array}$ & $\begin{array}{c}0.10 \\
(0.01)\end{array}$ & $\begin{array}{c}0.09 \\
(0.01)\end{array}$ & $\begin{array}{c}0.39 \\
(0.01)\end{array}$ & $\begin{array}{c}0.12 \\
(0.01)\end{array}$ & $\begin{array}{c}0.13 \\
(0.01)\end{array}$ & $\begin{array}{c}0.12 \\
(0.01)\end{array}$ \\
\hline Children's Less Than 9th & & $\begin{array}{l}-0.25 \\
(0.02)\end{array}$ & & $\begin{array}{l}-0.25 \\
(0.02)\end{array}$ & & $\begin{array}{l}-0.12 \\
(0.06)\end{array}$ & & $\begin{array}{l}-0.11 \\
(0.06)\end{array}$ \\
\hline Children's Some VHS & & $\begin{array}{l}-0.06 \\
(0.03)\end{array}$ & & $\begin{array}{l}-0.05 \\
(0.03)\end{array}$ & & $\begin{array}{c}0.09 \\
(0.11)\end{array}$ & & $\begin{array}{c}0.09 \\
(0.11)\end{array}$ \\
\hline Children's Some AHS & & $\begin{array}{l}-0.17 \\
(0.05)\end{array}$ & & $\begin{array}{l}-0.19 \\
(0.05)\end{array}$ & & $\begin{array}{l}-0.06 \\
(0.03)\end{array}$ & & $\begin{array}{l}-0.10 \\
(0.03)\end{array}$ \\
\hline Children's Vocational HS & & $\begin{array}{l}-0.02 \\
(0.01)\end{array}$ & & $\begin{array}{c}-0.01 \\
(0.01)\end{array}$ & & $\begin{array}{l}-0.05 \\
(0.01)\end{array}$ & & $\begin{array}{c}-0.06 \\
(0.01)\end{array}$ \\
\hline Children's Some College-VHS & & $\begin{array}{c}0.06 \\
(0.01)\end{array}$ & & $\begin{array}{c}0.07 \\
(0.01)\end{array}$ & & $\begin{array}{c}0.11 \\
(0.02)\end{array}$ & & $\begin{array}{c}0.11 \\
(0.02)\end{array}$ \\
\hline Children's Some College-AHS & & $\begin{array}{c}0.03 \\
(0.01)\end{array}$ & & $\begin{array}{c}0.03 \\
(0.01)\end{array}$ & & $\begin{array}{c}0.08 \\
(0.01)\end{array}$ & & $\begin{array}{c}0.08 \\
(0.01)\end{array}$ \\
\hline Children's College-VHS & & $\begin{array}{c}0.05 \\
(0.02)\end{array}$ & & $\begin{array}{c}0.05 \\
(0.02)\end{array}$ & & $\begin{array}{c}0.20 \\
(0.03)\end{array}$ & & $\begin{array}{c}0.20 \\
(0.03)\end{array}$ \\
\hline Children's College-AHS & & $\begin{array}{c}0.13 \\
(0.01)\end{array}$ & & $\begin{array}{c}0.13 \\
(0.01)\end{array}$ & & $\begin{array}{c}0.21 \\
(0.01)\end{array}$ & & $\begin{array}{c}0.21 \\
(0.01)\end{array}$ \\
\hline Children's Grad-VHS & & $\begin{array}{c}0.24 \\
(0.06)\end{array}$ & & $\begin{array}{c}0.25 \\
(0.06)\end{array}$ & & $\begin{array}{c}0.17 \\
(0.08)\end{array}$ & & $\begin{array}{c}0.16 \\
(0.08)\end{array}$ \\
\hline Children's Grad-AHS & & $\begin{array}{c}0.30 \\
(0.02)\end{array}$ & & $\begin{array}{c}0.29 \\
(0.02)\end{array}$ & & $\begin{array}{c}0.20 \\
(0.03)\end{array}$ & & $\begin{array}{c}0.21 \\
(0.03)\end{array}$ \\
\hline Father's Less Than 9th Grade & & & $\begin{array}{l}-0.06 \\
(0.01)\end{array}$ & $\begin{array}{l}-0.06 \\
(0.01)\end{array}$ & & & $\begin{array}{l}-0.03 \\
(0.01)\end{array}$ & $\begin{array}{l}-0.02 \\
(0.01)\end{array}$ \\
\hline Father's Some VHS & & & $\begin{array}{c}-0.03 \\
(0.04)\end{array}$ & $\begin{array}{l}-0.06 \\
(0.04)\end{array}$ & & & $\begin{array}{c}0.10 \\
(0.05)\end{array}$ & $\begin{array}{c}0.07 \\
(0.05)\end{array}$ \\
\hline Father's Some AHS & & & $\begin{array}{c}0.01 \\
(0.04)\end{array}$ & $\begin{array}{l}-0.03 \\
(0.03)\end{array}$ & & & $\begin{array}{c}0.05 \\
(0.06)\end{array}$ & $\begin{array}{c}0.05 \\
(0.05)\end{array}$ \\
\hline Father's Vocational HS & & & $\begin{array}{l}-0.02 \\
(0.01)\end{array}$ & $\begin{array}{l}-0.03 \\
(0.03)\end{array}$ & & & $\begin{array}{c}0.03 \\
(0.01)\end{array}$ & $\begin{array}{c}0.01 \\
(0.01)\end{array}$ \\
\hline Father's Some College-VHS & & & $\begin{array}{c}0.03 \\
(0.05)\end{array}$ & $\begin{array}{l}-0.01 \\
(0.04)\end{array}$ & & & $\begin{array}{l}-0.01 \\
(0.04)\end{array}$ & $\begin{array}{l}-0.04 \\
(0.04)\end{array}$ \\
\hline Father's Some College-AHS & & & $\begin{array}{l}-0.04 \\
(0.04)\end{array}$ & $\begin{array}{l}-0.04 \\
(0.03)\end{array}$ & & & $\begin{array}{c}0.06 \\
(0.04)\end{array}$ & $\begin{array}{c}0.04 \\
(0.04)\end{array}$ \\
\hline Father's College-VHS & & & $\begin{array}{c}0.05 \\
(0.03)\end{array}$ & $\begin{array}{c}0.01 \\
(0.03)\end{array}$ & & & $\begin{array}{c}0.05 \\
(0.03)\end{array}$ & $\begin{array}{c}0.02 \\
(0.03)\end{array}$ \\
\hline Father's College-AHS & & & $\begin{array}{c}0.08 \\
(0.02)\end{array}$ & $\begin{array}{c}0.05 \\
(0.02)\end{array}$ & & & $\begin{array}{c}0.05 \\
(0.02)\end{array}$ & $\begin{array}{c}0.04 \\
(0.02)\end{array}$ \\
\hline Constant & $\begin{array}{c}5.19 \\
(0.03)\end{array}$ & $\begin{array}{c}1.77 \\
(0.08)\end{array}$ & $\begin{array}{c}5.20 \\
(0.03)\end{array}$ & $\begin{array}{c}1.78 \\
(0.08)\end{array}$ & $\begin{array}{c}4.43 \\
(0.04)\end{array}$ & $\begin{array}{c}1.76 \\
(0.10)\end{array}$ & $\begin{array}{c}4.43 \\
(0.10)\end{array}$ & $\begin{array}{c}1.77 \\
(0.10)\end{array}$ \\
\hline Family Background & & $\mathrm{x}$ & $\mathrm{x}$ & $\mathrm{x}$ & & $\mathrm{x}$ & $\mathrm{x}$ & $\mathrm{x}$ \\
\hline Year Fixed Effect & $\mathrm{x}$ & $\mathrm{x}$ & $\mathrm{x}$ & $\mathrm{x}$ & $\mathrm{x}$ & $\mathrm{x}$ & $\mathrm{x}$ & $\mathrm{x}$ \\
\hline Observations & 15,743 & 15,743 & 15,743 & 15,743 & 11,398 & 11,398 & 11,398 & 11,398 \\
\hline $\mathrm{R}^{2}$ & 0.359 & 0.379 & 0.362 & 0.381 & 0.237 & 0.257 & 0.236 & 0.258 \\
\hline
\end{tabular}

Note: Parental earnings are averaged when their children were between 15 and 21. Family background includes father's job type, house ownership, metro/suburban address, and whether a child lived with parents when the child was between 15 and 21 . I add child's age and age squared. 
less by approximately one percentage point for sons and two percentage points for daughters than in Tables 4 and 5. Results of educational attainment for both a father and children are also consistent with estimates in Tables 4 and 5. As estimates are consistent with the results of the early model, we can confirm that the intergenerational earnings relationships in both Tables 4 and 5 are not seriously biased by the exclusion of calendar time.

\subsection{Conclusion}

Intergenerational mobility emerges as another aspect of economic and social inequality because family wealth and the educational levels of a father can enhance the educational opportunities of children. The purpose of this study is to estimate the intergenerational transmission effects of earnings and education in Korea with detailed educational attainment and earning information on both fathers and children. The intergenerational earnings association in Korea changes widely depending on controls. The overall intergenerational earnings elasticity (with no controls) is similar to the intergenerational earnings elasticity in the U.S., but the association is somewhat lower compared to some developed countries such as the United Kingdom.

I provide evidence that daughters in lower-income families are more likely to go to vocational high school. This reduces their chance of attaining earnings at the upper end of the distribution, but it helps to reduce the chance of very low earnings. Meanwhile, there is no overwhelming effect of a father's vocational high school degree on whether sons attend vocational high school. Also, if a son graduated from vocational high school and does not obtain further education, it does not decrease his earnings on average relative to an academic high school graduate, but it has a negative effects at the upper quantiles of the earnings distribution, meaning that his chance of having very high earnings is reduced. There are small negative impacts of children's voca- 
tional high school degrees on their earnings, compared to an academic high school. But, overall, vocational education and training does not seriously damage child's earnings relative to those who graduated from an academic high school.

In the children's generation, students who did not do well in primary and middle school usually attend a vocational high school. If they were to attend an academic high school, they might be less likely to achieve at school. Since they learn practical skills in vocational high school, the labor market outcomes of vocational high school graduates are comparable to outcomes of academic high school graduates who do not obtain any higher education. Therefore, the purpose of vocational education and training, which is to provide skilled workers in the labor market, may be still relevant in the most recent period. However, a vocational high school degree reduces the chance of attending or completing college relative to those who graduate from an academic high school, presumably because vocational high school does not provide a regular academic curriculum.

If a father holds only a vocational high school degree, this decreases the chance that his sons go to vocational high school and encourages them to attend and complete college, relative to a son whose father graduated from an academic high school without any higher education. On the other hand, we do not see a significant effect on daughter's educational achievement if a daughter's father graduated only from a vocational high school. Additionally, father's higher education, for instance college, and higher parental earnings help children to move to the upper end of the earnings distribution and to achieve higher education.

This study focuses on the intergenerational elasticity of earnings after controlling for fathers' schooling, and the intergenerational transmission effects of education, especially father's vocational high school graduation. The one important shortcoming of this analysis is that it fails to control for parents' characteristics that are correlated with education such as genetic factors, unmeasured aspects of family environment 
(e.g., grandparents' education) and the like. Hence, although it captures associations between parents' and children's earnings and education, these may not be causal in the sense that enducing a parent to obtain an additional year of education, or increasing a father's earnings, would have the "estimated" impact. The literature on the intergenerational transmission of schooling using nonparametric bounds analysis (de Haan (2011)), attempts to further shed light on the causal effects of father's educational attainment on children's schooling.

Notwithstanding the extraordinary growth in Korea's economy and dramatic increase in educational attainment, measures of intergenerational inheritance are similar to those of other developed countries. This means that even when parents' educational attainment and family incomes were much lower than those of their children, the inheritance of relative social position was not seriously disrupted. Although the details of inheritance are clearly tied to specific Korean institutions, the broad similarity across countries in the way that families pass on advantages from one generation to the next are confirmed. 


\section{Chapter 2}

\section{Nonparametric Bounds on Intergenerational Transmission of Human Capital in Korea}

\section{$2.1 \quad$ Introduction}

Parents' schooling level is one of the most important determinants of children's educational outcomes. An extensive empirical literature has examined the association between parental education and children's schooling. Haveman and Wolfe (1995) and Black and Devereux (2011) review the relevant studies and confirm that parents' schooling is positively related to children's educational outcomes in different surveys of the U.S. Blanden et al. (2007) and Gronqvist et al. (2017) find that parent's cognitive and noncognitive abilities are positively related to a child's labor market outcomes. However, the positive relationships that are observed are not necessarily causal because unobserved characteristics such as genetic endowments, acquired personal characteristics, and acquired abilities may underlie observed relationships (Holmlund et al., 2011).

There have been a variety of approaches used to estimate the causal effects of 
parental education. One approach uses an adoptee sample in order to remove the genetic factors shared by parents and their birth children in estimating intergenerational schooling effects (Bjorklund et al., 2006; Sacerdote, 2007). A second identification strategy uses a sample of identical twins (Behrman and Rosenzweig, 2002; Bingley et al., 2009), allowing a model of the process of attainment for individuals who have the same genetic makeup. Another method is the use of instrumental variables, taking advantage of a change in the environment such as that due to compulsory schooling reform, a change in university admission policy, or college tuition (Black et al., 2005; Oreopoulos et al., 2006; Maurin and McNally, 2008; Carneiro et al., 2013). However, the findings of these studies do not reach a consensus on the effects of parental education. Some studies suggest large positive effects of a father's schooling, but other studies find that a mother's schooling has significant impacts on a child's educational attainment whereas father's education has minimal effects.

Holmlund et al. (2011) give an overview of the relevant empirical literature on intergenerational causal schooling effects and present estimates of causal impacts with these three identification specifications using Swedish registry data to verify the reason for different results. They point out that estimates differ because of differences between datasets and differences in empirical methods. The estimates using families of adoptees and twins represent the effects of parental schooling in a subpopulation rather than representing the whole population. The instrumental variables approach relies on satisfying the requirements of an instrument to estimate the causal effects. If an instrument violates the requirements, the estimates may not be consistent. They find that the differences in estimates across the three methods using Swedish data are not as big as between other studies, although the estimates are consistent with patterns of results in other studies. Holmlund et al. (2011) also conclude that the causal effects of parental education represent a small part of the determinants of a child's schooling in Sweden, although parental schooling plays a substantial role in a 
child's success in school in the reviewed studies. In other words, parental schooling is associated with children's outcomes because of parents' experience and parenting skills, not primarily through causal channels.

This article applies an alternative empirical method, the nonparametric bounds approach, to identify the intergenerational causal relation using Korean data, following from the work of Manski $(1989,1990,1997)$, and Manski and Pepper (2000, 2009). The nonparametric bounds method allows us to investigate the causal relationship between parents' and children's education that comprehends all causal transmission channels of parental schooling. A detailed empirical explication of the method is provided in the next section. There are two important advantages of using this method. The method provides the bounds on the average treatment effects by imposing nonparametric assumptions, in particular monotone treatment response, monotone treatment selection, and monotone instrumental variables. It does not require the assumption of homogeneous effects of parental schooling. Another advantage is that the nonparametric assumptions are relatively weaker than assumption underlying other methods and are more amenable to testing.

There are many recent studies applying the nonparametric bounds approach to obtain bounds on average treatment effects, most of them focused on the economic return to skills (Lechner, 1999; Pepper, 2000; Gonzalez, 2005; de Haan, 2011; Giustinelli, 2011; Gundersen et al., 2012; Kang, 2014; Hof, 2014; Okumura and Usui, 2014; Kikuchi, 2017). Closely paralleling the work here, de Haan (2011) applies the nonparametric bounds approach to identify the true average treatment effect of parents' educational levels on the child's years of schooling using U.S. data. She obtains bounds implying that an increase in both fathers' and mothers' educational level have positive impacts on children's educational outcomes. Also, she finds that the lower bounds are significantly greater than zero, and the least upper bounds are substantially lower than the OLS results. Kikuchi (2017) uses the nonparametric bounds 
approach to analyze the causal effects of the intergenerational schooling effects in Japan. His findings with Japanese data are consistent with those of de Haan.

The educational structure in Korea has changed substantially with economic growth over the last several decades. The proportion attending college has increased drastically since the beginning of the 1990s, and so there is a substantial difference between parents' and children's average educational attainment. According to Ministry of Education \& Technology (2008), only $27 \%$ of high school graduates attended a college in 1980, but the attendance rate of college has been around 85\% since 2000 . Looking at recent entrants into the labor market, the low college attendance rate in their parents' generation suggests that factors other than parental education may be more important in leading their children to attend a college. More generally, insofar as parents guide their children according to their own experiences in a particular level of schooling, if parents who attend college are able to prepare their children for college, we might expect that effects would be weaker in an environment with large differences in educational achievement between parents and children. As a result, the intergenerational transmission of education may show different patterns than in western countries where children's educational achievements are more similar to those of their parents.

Most studies of intergenerational status transmission in Korea have focused on the effects of parents' income or wealth on economic outcomes of children (Kim, 2009; Ueda 2013; Ma and Kwon, 2013; Richey and Jeong, 2014; Lee, 2014; Kang, 2014; Kim, 2017) or parents' educational investment in children (Lee, 2008; Kang, 2011) rather than the educational transmission process itself (Nam, 2008; Kim, 2015). Nam (2008) finds a strong positive association between parents' and children's education in Korea, a relationship that is much stronger than in the central and western European countries (Iannelli, 2002). These empirical studies, however, have focus on the zeroorder relationship between parents' and children's education but have not considered 
the causal effects of parental education.

Using the nonparametric bounds approach, we find that the estimated tightest bounds on the average treatment effects are informative. We estimate lower bounds that are significantly different from zero and upper bounds that are less than the OLS estimates. These are consistent with findings for the U.S. and for Japan (de Haan, 2011; Kikuchi, 2017).

The remainder of this study is organized as follows: Section 2 presents the detailed empirical specification. Section 3 describes the Korean Labor and Income Panel Study (KLIPS) dataset, which is used in this study. We discuss the results in section 4. Section 5 summarizes and concludes.

\subsection{Empirical Specification}

To identify the causal intergenerational effects of education, this study uses a nonparametric bounds approach developed by Manski $(1989,1990,1997)$ and Manski and Pepper (2000). We assume there is a function $y_{j}(\cdot): T \rightarrow Y$ that maps the parental education level $t$ into education of child $j . j$ is contained in population $J$. Also, we assume that children's education, $y$ and the treatment set $T$ is an ordered set. Following de Haan (2011) and Kikuchi (2017), we take either years of schooling or college completion of a child as the dependent variable, so I denote $y_{j} \equiv y_{j}\left(z_{j}\right)$ as a child's outcome with a parent's realized completed schooling, $z_{j}$ and $y_{j}(t)$ as the counterfactual that cannot be observed if a parent has a schooling level, $z_{j} \neq t$. Also,

$y_{\min }\left(y_{\max }\right)$ represents the lowest (greatest) value of a child's educational outcome. In the analysis examining years of education, the minimum is 8 years and the maximum is 16 years, and in the analysis examining college graduation, coded on the $0-1$ scale. I will drop the subscript $j$ from here to simplify notation.

The main interest in this analysis is the average treatment effect (ATE) with an 
increase in parent schooling from $t_{1}$ to $t_{2}\left(t_{1} \leq t_{2}\right)$, that is, ${ }^{1}$

$$
\Delta\left(t_{2}, t_{1}\right) \equiv E\left[y\left(t_{2}\right)\right]-E\left[y\left(t_{1}\right)\right]
$$

This provides the ATE of increasing a parent's schooling level from $t_{1}$ to $t_{2}$, averaged across all individuals in the sample. One approach to identifying this latent outcome is to assume exogenous treatment selection (ETS), meaning that $y$ is mean independent of $z$, observed parental schooling level. In our example, assuming observable measures $x$ were controlled, the relevant conditional independence assumption would be written $E[y(t) \mid x]=E\left[y(t) \mid z=t_{1}, x\right]=E\left[y(t) \mid z=t_{2}, x\right]$, implying that the mean child's educational outcome would be the same if parental educational levels were equalized, controlling for measured characteristic $x$.

This may not be appropriate to identify the intergenerational causal educational relationship, although this assumption can be valid in a particular model of a structure. Manski (1989, 1990, 1997) and Manski and Pepper (2000) suggests estimating the average treatment effect without imposing the ETS assumption. By imposing weaker and testable assumptions, this approach allows us to look at the more reliable average treatment effects.

\subsubsection{No Assumption Bounds}

Manski $(1989,1990)$ proposes an analysis method of treatment response that can identify bounds on treatment effects without imposing any assumptions if the support of a dependent variable is bounded. In our analysis, the dependent variable is either a child's years of schooling or college completion. The dependent variable is bounded between $\left[y_{\min }, y_{\max }\right]$, where obviously $y_{\min }<y_{\max }$. To build the basic bounds on $E[y(t)]$, we can expand $E[y(t)]$ using the law of iterated expectations and the fact

\footnotetext{
${ }^{1}$ Equations (1) and (2) are adapted from equations (1) and (2) in de Haan (2011). In addition to, equation (2) corresponds to equation (1) in Manski (1989).
} 
that $E[y(t) \mid z=t]=E[y \mid z=t]$ :

$$
E[y(t)]=E[y \mid z=t] \cdot P(z=t)+E[y(t) \mid z \neq t] \cdot P(z \neq t) .
$$

With the data set this study uses, we can observe $E[y \mid z=t], P(z=t)$, and $P(z \neq t)$. An issue is that we cannot observe $E[y(t) \mid z \neq t]$. Because $y$ must be in a range of $\left[y_{\min }, y_{\max }\right], E[y \mid z \neq t]$ also should be bounded by $\left[y_{\min }, y_{\max }\right]: y_{\min } \leq E[y \mid z \neq t] \leq$ $y_{\max }$.

We can derive the bounds of $E[y(t)]$ by replacing $E[y \mid z \neq t]$ in equation (2) with $y_{\min }$ to obtain a lower bound and by replacing $E[y \mid z \neq t]$ with $y_{\max }$ to obtain a upper bound. Using these values, Manski (1989, 1990) derives "no assumption" bounds:

$$
\begin{gathered}
E[y \mid z=t] \cdot P(z=t)+y_{\text {min }} \cdot P(z \neq t) \\
\leq E[y(t)] \leq \\
E[y \mid z=t] \cdot P(z=t)+y_{\max } \cdot P(z \neq t) .
\end{gathered}
$$

The no-assumption bounds on $E[y(t)]$ allow us to calculate the bounds on the average treatment effect (ATE), $\Delta\left(t_{2}, t_{1}\right)$, by subtracting a upper(lower) bound of $E\left[y\left(t_{1}\right)\right]$ from a lower(upper) bound of $E\left[y\left(t_{2}\right)\right]$. The no-assumption bounds on ATE are: ${ }^{2}$

$$
\begin{gathered}
E\left[y \mid z=t_{2}\right] \cdot P\left(z=t_{2}\right)+y_{\text {min }} \cdot P\left(z \neq t_{2}\right)-\left\{E\left[y \mid z=t_{1}\right] \cdot P\left(z=t_{1}\right)+y_{\text {max }} \cdot P\left(z \neq t_{1}\right)\right\} \\
\leq \Delta\left(t_{2}, t_{1}\right) \leq \\
E\left[y \mid z=t_{2}\right] \cdot P\left(z=t_{2}\right)+y_{\text {max }} \cdot P\left(z \neq t_{2}\right)-\left\{E\left[y \mid z=t_{1}\right] \cdot P\left(z=t_{1}\right)+y_{\text {min }} \cdot P\left(z \neq t_{1}\right)\right\} .
\end{gathered}
$$

Although no-assumption bounds are meaningful to identify bounds on $E[y(t)]$, these are generally not informative. Imposing some weak assumptions on the no-assumption

\footnotetext{
${ }^{2}$ This equation (4) is taken from an equation on page 4 in Kikuchi (2017, and an error has been corrected.
} 
bounds can tighten the bounds and provide informative results: I will consider (1) monotone treatment response (MTR), (2) monotone treatment selection (MTS), and (3) monotone instrumental variables (MIV).

\subsubsection{Monotone Treatment Response}

Manski (1997) and Manski and Pepper (2000) introduce MTR and MTS assumptions. In this paper, we apply that the MTR assumption, implying that outcomes are weakly increasing in a parent's education. The MTR assumption is:

$$
t_{1} \leq t_{2} \Rightarrow y\left(t_{1}\right) \leq y\left(t_{2}\right)
$$

Equation (5) assumes that child's educational outcomes (either years of schooling or college completion) are an increasing function of a parent's. This assumption is consistent with models based on human capital theory, which posits a positive relationship between parents' and children's schooling (Becker and Tomes, 1979, 1986; Solon, 1999). Parental education could be transmitted to children through several channels, as more educated parents are more likely to invest in educational environments and create an educational atmosphere for a child than those who have less education. Empirically, we observe a strong association between parents' and children's education. However, it does not allow us to conclude that parental schooling has causal impacts on the child's outcomes due to the selection problem. It is for this reason that the MTR assumption does not rule out a zero effect.

To tighten the no assumption bounds using the MTR assumption, children in the sample can be divided to three groups: (1) children who have a parent with realized schooling level below $t(z<t)$, (2) children who have a parent with schooling level $t$ $(z=t)$, and $(3)$ children who have a parent with realized schooling level greater than 
$t(z>t)$. This relationship is: ${ }^{3}$

$$
\begin{aligned}
& t<z \Rightarrow y_{\text {min }} \leq y(t) \leq y \\
& t=z \Rightarrow y(t)=y \\
& t>z \Rightarrow y \leq y(t) \leq y_{\text {max }} .
\end{aligned}
$$

The outcomes $y(t)$ for $z>t$ and $z<t$ are counterfactuals, and so are not observed. $y(t)$ for $z=t$ is the value of the educational outcome observed for parents with education level $z$. To obtain more informative bounds, we need to consider what children's education would have been for values of parents' education that are not observed. MTR implies that for $z<t$ the observed mean educational outcome of a child with a parent who has actual schooling level $z$ is less than the mean outcome a child would have had if a parent had the educational level $t$. The child's observed maximum educational outcome, $y_{\max }$, can be replaced with $E[y \mid z>t]$ to tighten the upper bound. We already know that the mean educational outcome of a child is the same when a parent has an educational level of $z=t$. For $t<z$, when a parent's actual schooling level $z$ is greater than schooling level $t$, it is certain that a child's observed mean educational outcome would be less than a child with a parent who has educational attainment $z=t$. The observed mean educational outcome of a child when a parent has schooling level $z$ can tighten the lower bound. A combination of the no assumption bounds and the MTR assumption provides (equation (5) in de Haan (2011)):

$$
\begin{gathered}
E[y \mid z<t] \cdot P(z<t)+E[y \mid z=t] \cdot P(z=t)+y_{\min } \cdot P(z>t) \\
\leq E[y(t)] \leq \\
y_{\max } \cdot P(z<t)+E[y \mid z=t] \cdot P(z=t)+E[y \mid z>t] \cdot P(z>t) .
\end{gathered}
$$

\footnotetext{
${ }^{3}$ The approach presented here was first developed in Manski (1997).
} 


\subsubsection{Monotone Treatment Selection}

The next assumption imposed in our analysis is the monotone treatment selection (MTS) assumption (Manski and Pepper (2000)). The MTS assumption is:

$$
\begin{aligned}
& \text { for each } t \in T \text { and } \forall\left(u_{1}, u_{2}\right) \in T \times T \\
& \qquad u_{1} \leq u_{2} \Rightarrow E\left[y(t) \mid z=u_{1}\right] \leq E\left[y(t) \mid z=u_{2}\right] .
\end{aligned}
$$

The MTS assumption asserts that a child who has a parent with higher levels of education has a weakly greater mean function of education. This means that a child with a more educated parent would obtain more (or at least as much) education even if the parent did not have more schooling. There is (or may be) something other than parental education that makes a child of a more educated parent obtain more schooling. This assumption is consistent with economic models that parents who have higher ability are likely to have higher education and obtain greater average earnings, factors that contribute to children's educational achievement.

We divide the sample into three groups again to apply the MTS assumption: (1) children with a parent with an educational level lower than schooling $t(z<t)$, (2) children with a parent who has educational level equal to $t(z=t)$, and (3) children with a parent who has greater schooling than educational level $t(z>t)$. Outcomes for the three groups can be written as: ${ }^{4}$

$$
\begin{aligned}
& u<t \Rightarrow y_{\min } \leq E[y(t) \mid z=u] \leq E[y(t) \mid z=t] \\
& u=t \Rightarrow \quad E[y(t) \mid z=u]=E[y(t) \mid z=t] \\
& u>t \Rightarrow E[y(t) \mid z=t] \leq E[y(t) \mid z=u] \leq y_{\max } .
\end{aligned}
$$

Considering the first case $(u>t)$, we know that the mean educational outcome for a child with a parent who has educational level less than $t$ would be less than or

\footnotetext{
${ }^{4}$ Equations (9) and (10) in this paper are adapted from equations (12) and (13) in Manski and Pepper (2000).
} 
equal to that for one who has a parent with schooling $t$, even if the former parent had obtained schooling level $t$. We also know that the mean outcome of a child whose parent's education is greater than $t$ is greater than or equal to the outcome for a child who has a parent with education $t$, even if the former parent had obtained schooling level $t$. The MTS bounds obtained by combining the no assumption bounds and the MTS assumption are:

$$
\begin{gathered}
y_{\text {min }} \cdot P(z<t)+E[y \mid z=t] \cdot P(z=t)+E[y \mid z=t] \cdot P(z>t) \\
\leq E[y(t)] \leq \\
E[y \mid z=t] \cdot P(z<t)+E[y \mid z=t] \cdot P(z=t)+y_{\text {max }} \cdot p(z>t) .
\end{gathered}
$$

Manski and Pepper (2000) suggest combining the MTR and MTS assumptions to obtain more informative bounds. As assuming that the MTS and MTR assumptions hold, we obtain the MTR-MTS bounds (equation (7) in de Haan (2011)):

$$
\begin{gathered}
E[y \mid z<t] \cdot P(z<t)+E[y \mid z=t] \cdot P(z=t)+E[y \mid z=t] \cdot P(z>t) \\
\leq E[y(t)] \leq \\
E[y \mid z=t] \cdot P(z<t)+E[y \mid z=t] \cdot P(z=t)+E[y \mid z>t] \cdot p(z>t) .
\end{gathered}
$$

The combined assumption substantially tightens the bounds compared to the no assumption bounds or the single assumption bounds.

Manski and Pepper (2000) suggest that we can test the validity of the joint MTRMTS assumptions. The joint MTR-MTS assumptions imply: ${ }^{5}$

$$
\begin{aligned}
u_{1} \leq u_{2} \Rightarrow E\left[y \mid z=u_{1}\right] & =E\left[y\left(u_{1}\right) \mid z=u_{1}\right] \\
& \leq E\left[y\left(u_{1}\right) \mid z=u_{2}\right] \leq E\left[y\left(u_{2}\right) \mid z=u_{2}\right]=E\left[y \mid z=u_{2}\right]
\end{aligned}
$$

The first inequality comes from the MTS assumption and the second inequality follows from the MTR assumption. In other words, a child's mean educational outcome has

\footnotetext{
${ }^{5}$ This equation (12) is adapted from equation (19) in Manski and Pepper (2000).
} 
to be weakly increasing in parent actual educational attainment. If $E[y \mid z=u]$ in not weakly increasing in parent realized education, the joint hypothesis MTR-MTS is rejected.

The main interest in this analysis is the average treatment effects (ATE). Under the MTR-MTS assumption, it is possible to obtain bounds on each of $E\left[y\left(t_{1}\right) \mid z=u\right]$ and $E\left[y\left(t_{2}\right) \mid z=u\right]$. The upper (lower) bound on the ATE $\left(\Delta\left(t_{2}, t_{1}\right)\right)$ can be calculated by subtracting the lower (upper) bound on $E\left[y\left(t_{1}\right) \mid z=u\right]$ from the upper (lower) bound on $E\left[y\left(t_{2}\right) \mid z=u\right]$. The MTR-MTS bounds on ATE is: ${ }^{6}$

$$
\begin{gathered}
E\left[y \mid z<t_{2}\right] \cdot P\left(z<t_{2}\right)+E\left[y \mid z=t_{2}\right] \cdot P\left(z \geq t_{2}\right) \\
-\left\{E\left[y \mid z=t_{1}\right] \cdot P\left(z \leq t_{1}\right)+E\left[y \mid z>t_{1}\right] \cdot P\left(z>t_{1}\right)\right\} \\
\leq \Delta\left(t_{2}, t_{1}\right) \leq \\
E\left[y \mid z=t_{2}\right] \cdot P\left(z \leq t_{2}\right)+E\left[y \mid z>t_{2}\right] \cdot P\left(z>t_{2}\right) \\
-\left\{E\left[y \mid z<t_{1}\right] \cdot P\left(z<t_{1}\right)+E\left[y \mid z=t_{1}\right] \cdot P\left(z \geq t_{1}\right)\right\} .
\end{gathered}
$$

It is possible that these calculations yield a non-positive lower bound on $\Delta\left(t_{2}, t_{1}\right)$ if the upper bound on $E\left[y\left(t_{1}\right) \mid z=u\right]$ is greater than the lower bound on $E\left[y\left(t_{2}\right) \mid z=u\right]$. As Manski (1997) notes, however, the lower bound on $\Delta\left(t_{2}, t_{1}\right)$ has to be a nonnegative value because of the MTR assumption (equation (5)). We use zero as the lower bound on the average treatment effects when equation (13) implies a negative value.

\subsubsection{Monotone Instrumental Variables}

Many studies of intergenerational educational effects have adapted standard Instrumental Variables (IV) methods to identify causal effects (Black et al., 2005; Oreopoulos et al., 2006; Holmlund et al., 2011). The standard IV assumption of the

\footnotetext{
${ }^{6}$ To obtain the $\Delta\left(t_{2}, t_{1}\right)$, we follow the method of Manski and Pepper (2000, page 1005).
} 
mean-independence can be written as (Manski and Pepper (2000)):

$$
\begin{aligned}
& \text { For each } t \in T, u \in V \text { and } \forall\left(u_{1}, u_{2}\right) \in V \times V, \\
& \qquad E\left[y(t) \mid v=u_{1}, z=t\right]=E\left[y(t) \mid v=u_{2}, z=t\right] .
\end{aligned}
$$

However, it is often difficult to find a useful instrument that satisfies the meanindependence assumption. Even when an instrument satisfies the requirements, IV methods identify the local average treatment effect (LATE), the effect for compliers, distinct from the average treatment effect (ATE). In many cases, this is of relatively little interest, as it may include few or no cases. Huber et al. (2017) construct IV bounds to estimate the average treatment effect (ATE) while using an instrumental variable, although their derivation is limited to the case of a binary instrumental variable and a binary treatment. As an alternative, Manski and Pepper (2000, 2009) propose the monotone instrumental variable (MIV) assumption, which is weaker and more credible, replacing the equality in equation (14) with an inequality. The assumption indicates that the mean response function is weakly monotone in specific sub-samples. Assuming that $V$ is an order set, we may write this assumption as:

$$
u_{1} \leq u_{2} \quad \Rightarrow \quad E\left[y(t) \mid v=u_{1}\right] \leq E\left[y(t) \mid v=u_{2}\right] .
$$

We can use paternal schooling level as a treatment and maternal schooling level as an MIV to illustrate how the MIV assumption works. To satisfy standard IV assumptions, mother's schooling level would have to have no direct effect children's educational outcome except through paternal schooling. It is hard to believe that maternal schooling is an appropriate IV, as it would appear to affect a child's education through a variety of channels. However, the maternal schooling would be acceptable as an MIV if there is a positive effect of mother's education on children's education. Maternal education as an MIV is useful to determine bounds. 
To obtain identifying power from the MIV assumption, $E[y(t) \mid v]$ also can be expanded in an identical way to equation $(2):^{7}$

$$
\begin{aligned}
& E[y(t) \mid v=u]=E[y \mid v=u, z=t] \cdot P(z=t \mid v=u)+ \\
& E[y(t) \mid v=u, z \neq t] \cdot P(z \neq t \mid v=u) .
\end{aligned}
$$

$E[y(t) \mid v=u, z \neq t]$ must be in a range of $\left[y_{\min }, y_{\max }\right]$. The bounds can be written as follows,

$$
\begin{gathered}
E[y \mid v=u, z=t] \cdot P(z=t \mid v=u)+y_{\text {min }} \cdot P(z \neq t \mid v=u) \\
\leq E[y(t) \mid v=u] \leq \\
E[y \mid v=u, z=t] \cdot P(z=t \mid v=u)+y_{\text {max }} \cdot P(z \neq t \mid v=u) .
\end{gathered}
$$

The MIV assumption implies a monotone relationship, that is,

$$
u_{1} \leq u \leq u_{2} \Rightarrow E\left[y(t) \mid v=u_{1}\right] \leq E[y(t) \mid v=u] \leq E\left[y(t) \mid v=u_{2}\right]
$$

Under equations (17) and (18), $E[y(t) \mid v=u]$ is not smaller than the lower bound on $E\left[y(t) \mid v=u_{1}\right]$ and not greater than upper bound on $E\left[y(t) \mid v=u_{2}\right]$ for all $u_{1} \leq u$ and $u \leq \mathrm{u}_{2}$ (Manski and Pepper, 2000; de Haan, 2011). Then, we have bounds under the MIV assumption, written as follows,

$$
\begin{gathered}
\sup _{u_{1} \leq u}\left[E\left(y \mid v=u_{1}, z=t\right) \cdot P\left(z=t \mid v=u_{1}\right)+y_{\text {min }} \cdot P\left(z \neq t \mid v=u_{1}\right)\right] \\
\leq E[y(t) \mid v=u] \leq \\
\inf _{u \leq u_{2}}\left[E\left(y \mid v=u_{2}, z=t\right) \cdot P\left(z=t \mid v=u_{2}\right)+y_{\max } \cdot P\left(z \neq t \mid v=u_{2}\right)\right] .
\end{gathered}
$$

The MIV bounds on $E[y(t)]$ are sharp without adding other restrictions on $E[y(t) \mid v=$ $u]$. Using the law of iterated expectation, $E[y(t)]$ can be written as

\footnotetext{
${ }^{7}$ Equations (16) to (21) are adapted from Manski and Pepper (2000, equation (4) to (9)).
} 


$$
E[y(t)]=\sum_{u \in V} P(v=u) \cdot E[y(t) \mid v=u]
$$

Then, combining equation (20) with the lower and upper MIV bounds provides the following equation.

$$
\begin{gathered}
\sum_{u \in V} P(v=u)\left\{\sup _{u_{1} \leq u}\left[E\left(y(t) \mid v=u_{1}, z=t\right) \cdot P\left(z=t \mid v=u_{1}\right)+y_{\min } \cdot P\left(z \neq t \mid v=u_{1}\right)\right]\right\} \\
\leq E[y(t)] \leq \\
\sum_{u \in V} P(v=u)\left\{\inf _{u \leq u_{2}}\left[E\left(y(t) \mid v=u_{2}, z=t\right) \cdot P\left(z=t \mid v=u_{2}\right)+y_{\max } \cdot P\left(z \neq t \mid v=u_{2}\right)\right]\right\} .
\end{gathered}
$$

Manski and Pepper (2000) introduce not only the MIV bounds but also the combined bounds of the MTR, MTS and MIV assumptions (MTR-MTS-MIV bounds), which provide the tightest bounds. We already know that the combined MTR and MTS assumption yields relatively more informative and tighter bounds than noassumption bounds and single-assumption bounds. Following Kang (2011, equation (10)), we can write the MTR-MTS-MIV bounds as,

$$
\begin{gathered}
\sum_{u \in V} P(v=u)\left\{\operatorname { s u p } _ { u _ { 1 } \leq u } \left[E\left[y(t) \mid v=u_{1}, z<t\right] \cdot P\left(z<t \mid v=u_{1}\right)+\right.\right. \\
\left.\left.E\left[y(t) \mid v=u_{1}, z=t\right] \cdot P\left(z \geq t \mid v=u_{1}\right)\right]\right\} \\
\leq E[y(t)] \leq \\
\sum_{u \in V} P(v=u)\left\{\inf _{u \leq u_{2}}\left[E\left[y(t) \mid v=u_{2}, z=t\right] \cdot P\left(z \leq t \mid v=u_{2}\right)\right]+\right. \\
\left.\left.E\left[y(t) \mid v=u_{2}, z>t\right] \cdot P\left(z>t \mid v=u_{2}\right)\right]\right\} .
\end{gathered}
$$

As mentioned above, this analysis is interested in the bounds on the average treatment effects, the effects of an increase in a parent's schooling level from $t_{1}$ to $t_{2}$ on a child's educational outcomes. We obtain the bounds on the average treatment effect by subtracting an upper(lower) bound of $E\left[y\left(t_{1}\right)\right]$ from a lower(upper) bound of $E\left[y\left(t_{2}\right)\right]$. Also, the lower bound on the average treatment effects should be non-negative due to 
the MTR assumption. The MTR-MTS-MIV bounds on the average treatment effects are,

$$
\begin{aligned}
& \sum_{u \in V} P(v=u)\left\{\operatorname { s u p } _ { u _ { 1 } \leq u } \left[E\left(y\left(t_{2}\right) \mid v=u_{1}, z<t_{2}\right) \cdot P\left(z<t_{2} \mid v=u_{1}\right)\right.\right. \\
& \left.+E\left(y\left(t_{2}\right) \mid v=u_{1}, z=t_{2}\right) \cdot P\left(z \geq t_{2} \mid v=u_{1}\right)\right]-\left\{\operatorname { i n f } _ { u \leq u _ { 2 } } \left[E\left(y\left(t_{1}\right) \mid v=u_{2}, z=t_{1}\right) \cdot P\left(z \leq t_{1} \mid v=u_{2}\right)\right.\right. \\
& \left.\left.\left.+E\left(y\left(t_{1}\right) \mid v=u_{2}, z>t_{1}\right) \cdot P\left(z>t_{1} \mid v=u_{2}\right)\right]\right\}\right\} \\
& \leq \Delta\left(t_{2}, t_{1}\right) \leq \\
& \sum_{u \in V} P(v=u)\left\{\operatorname { i n f } _ { u \leq u _ { 2 } } \left[E\left(y\left(t_{2}\right) \mid v=u_{2}, z=t_{2}\right) \cdot P\left(z \leq t_{2} \mid v=u_{2}\right)\right.\right. \\
& \left.+E\left(y\left(t_{2}\right) \mid v=u_{2}, z>t_{2}\right) \cdot P\left(z>t_{2} \mid v=u_{2}\right)\right]-\left\{\operatorname { s u p } _ { u _ { 1 } \leq u } \left[E\left(y\left(t_{1}\right) \mid v=u_{1}, z<t_{1}\right) \cdot P\left(z<t_{1} \mid v=u_{1}\right)\right.\right. \\
& \left.\left.\left.+E\left(y\left(t_{1}\right) \mid v=u_{1}, z=t_{1}\right) \cdot P\left(z \geq t_{1} \mid v=u_{1}\right)\right]\right\}\right\} .
\end{aligned}
$$

This study uses two variables as MIVs in the analysis. The first is the educational level of the other parent. For example, when father's schooling is the treatment, we use mother's educational attainment as an MIV. Also, a father's education plays the role as the MIV when a mother's schooling is used to obtain informative bounds. Both parents' schooling levels are categorized in five groups: (1) no education, (2) education less than 12th grade, (3) high school graduate, (4) some college (junior college dropouts and graduates, and college dropouts), and (5) college graduates and above. The MIV assumption is that the mean educational outcome of a child is weakly increasing in the other parent's educational level. ${ }^{8}$

Father's occupation is the second MIV in this analysis. This is a dummy variable that is coded as 0 for lower-skilled jobs and as 1 for upper-skilled jobs based on Korea's standard job classification. The upper-skilled jobs include managers, professionals, lower levels of white-collar workers, and sales jobs; the lower-skilled jobs consist of personal service, agriculture (including fisheries), technicians, and laborers. ${ }^{9}$ We as-

\footnotetext{
${ }^{8}$ For further discussion, please see a Kikuchi (2017).

${ }^{9}$ High school graduates are the overwhelming majority educational category for sales workers. Nonetheless, college graduates account for approximately 32 percent of sales workers, according to the Korean Statistical Information Service 2011 report. The proportion of college graduates in sales
} 
sume that if a father works in an upper-skilled job rather than lower-skilled job, it weakly increases the mean schooling of a child. Before we use a father's occupation as an MIV, we also test whether it shows the mean-monotone relation with children's education that is a necessary result of this assumption.

We consider the possibility that the OLS method overestimates the effects relative to the true causal relationship. We must address the possibility that differences between the OLS estimate and the bounds we obtain are due to sampling error. We apply a bias-corrected method on the least upper bounds using a bootstrap method proposed by Kreider and Pepper (2007) to estimate standard errors. ${ }^{10}$ We also conduct a one-sided test of whether the OLS overestimates causal effects employing a bootstrap method. In particular, to look into the possibility that observed differences are due to sampling error, the estimated least upper bound is subtracted from OLS estimates as follows and estimated for 1,000 bootstrap replications of random selection from the base sample.

$$
O L S_{i}-\text { Least } U B_{i}>0, \quad \forall i=1,2,3, \cdots, 1000 .
$$

$O L S_{i}$ and $L$ east $U B_{i}$ are the OLS estimates and the least upper bounds under the MTR-MTS-MIV combined assumption, respectively, and $i$ indicates the bootstrap replication. This allows us to conclude that the difference between the upper bound and the OLS is not attributed to the sampling error if the difference is positive for 95\% (90\%) of the replications. Furthermore, following Manski and Pepper (2000) and de Haan (2011), we also compute and report 95\% confidence intervals on each estimated lower and upper bounds using the bootstrap method.

jobs is greater than in other lower-skilled jobs.

${ }^{10}$ Manski and Pepper (2000) and Kreider and Pepper (2007) indicate that finite-sample bias can be generated by taking sups and infs on the MIV estimation. If the finite-sample bias is severe in the analyses, bounds under the MTR-MTS combined assumptions may have greater power because the bounds based on the combined assumptions of MTR and MTS are free from the bias. 


\subsection{Data: Korea Labor and Income Panel Study (KLIPS)}

This study uses the Korea Labor and Income Panel Study (hereafter KLIPS) conducted by the Korea Labor Institute to identify the effects of parents' educational attainment on children's years of schooling. ${ }^{11}$ KLIPS provides information on the Korean labor market and income structure of households and individuals who lived in urban and suburban areas from 1998 to 2016. This is a longitudinal survey and samples 5,000 households with 13,321 individuals aged 15 and older in 16 metropolitan areas in 1998. An additional 1,415 households were included in the survey in 2009 to improve the representativeness of the data and to overcome limitations of attrition and concentration of urban residence.

KLIPS provides extensive information related to labor market outcomes and individual and family characteristics such as education, earnings, type of job, family background, and demographic characteristics. To identify the intergenerational transmission of human capital using a nonparametric bounds analysis, a dataset must contain at least two generations' completed educational level and enough observations. For the bounds analysis, I include respondents who responded to questions regarding both father's and mother's completed educational attainment. Individuals who answered questions regarding both parental final educational levels are included, including those that lost a father or mother after entering a college. However, I drop the respondents if either father or mother were absent before they attended college because single-parent families may have substantially different educational environments than two-parent families. I also omit individuals who are still in school, and I only include those who were born before 1966. This restriction provides a final sample, containing 5,722 individuals who are aged 15 to 50 at the survey date.

\footnotetext{
${ }^{11}$ The KLIPS is the first Korean longitudinal survey focusing on labor issues. These data are available on a site of the Korea Labor Institute: https ://www.kli.re.kr/klips_eng/index.do
} 
Table 2.1 Summary Statistics

\begin{tabular}{lcc}
\hline \hline & & \\
& Mean & Std. dev. \\
\hline Child's years of schooling & 13.926 & 1.923 \\
Child's college completion & 0.361 & 0.480 \\
Child's age & 31.254 & 7.829 \\
Child's gender (son =0) & 0.448 & 0.500 \\
Father's education: & & \\
1. No education & 0.062 & 0.106 \\
2. Less than 12th grade & 0.292 & 0.463 \\
3. High school & 0.411 & 0.496 \\
4. Some college & 0.072 & 0.259 \\
5. College & 0.163 & 0.369 \\
Mother's education: & & \\
1. No education & 0.084 & 0.205 \\
2. Less than 12th grade & 0.425 & 0.499 \\
3. High school & 0.385 & 0.487 \\
4. Some college & 0.042 & 0.200 \\
5. College & 0.064 & 0.245 \\
Father's occupation & & \\
Upper-skilled jobs (=1) & 0.473 & 0.499 \\
$\quad$ & & \\
$\quad$ N & 5,722 & \\
\hline \hline
\end{tabular}

To find the causal impact of increasing parental education on child's years of schooling, I consider child's years of final schooling, coded as: 8 years (no more than primary education), 10 years (high school dropout), 12 years (high school graduate), 14 years (some college, or two or three year degree), and 16 years (bachelor's degree and above). As mentioned in the previous section, this study considers five educational levels for parents and two categories for father's occupation. In some of the analyses, we use the other parent's education or father's occupation as a monotone instrumental variable (MIV). Table 1 provides descriptive statistics. 
Table 2.2 Child's Schooling Outcomes by Parent's Education and Father's Occupation

\begin{tabular}{|c|c|c|c|c|c|}
\hline \multicolumn{2}{|l|}{ Panel A: } & \multicolumn{3}{|c|}{ Father's Education } & \multirow[b]{2}{*}{ College } \\
\hline Child's Educational Achievement & No Education & Less Than 12th-Grade & High School & Some College & \\
\hline Year of Schooling & 12.333 & 13.637 & 13.736 & 14.362 & 14.913 \\
\hline College Completion & 0.106 & 0.287 & 0.320 & 0.403 & 0.614 \\
\hline \multicolumn{2}{|l|}{ Panel B: } & \multicolumn{2}{|c|}{ Mother's Education } & & \\
\hline Year of Schooling & 13.075 & 13.716 & 14.067 & 14.377 & 14.896 \\
\hline College Completion & 0.237 & 0.322 & 0.366 & 0.461 & 0.634 \\
\hline \multirow[b]{2}{*}{ Panel C: } & \multirow{2}{*}{\multicolumn{3}{|c|}{$\begin{array}{l}\text { Father's Occupation } \\
\text { Lower-level Jobs }\end{array}$}} & \multirow{2}{*}{\multicolumn{2}{|c|}{ Upper-level Jobs }} \\
\hline & & & & & \\
\hline Year of Schooling & \multicolumn{2}{|r|}{13.581} & & \multicolumn{2}{|c|}{14.309} \\
\hline College Completion & \multicolumn{2}{|r|}{0.294} & & \multicolumn{2}{|l|}{0.436} \\
\hline
\end{tabular}

\subsection{Results}

This section shows the results of applying the nonparametric bounds approach to examining the effects of parental education on a child's educational outcomes. As stated in the Methods section, in order to determine whether the MTR-MTS combined assumption is rejected by the data, I test whether the means of the child's education are non-decreasing in parents' schooling and in father's occupation, a requirement for the MTR and MTS assumptions to be met. Table 2 shows that the MTR-MTS combined assumption is not rejected since the mean of child's schooling outcomes is weakly increasing both in the level of father's and mother's education, and outcomes are weakly increasing function in father's occupation.

\subsubsection{Treatment Effects on Child's Years of Schooling}

Table 3 reports bounds on the average treatment effects of increasing father's or mother's educational attainment to the next educational level on a child's years of schooling, i.e., $E\left[y\left(t_{2}\right)\right]-E\left[y\left(t_{1}\right)\right]$. Table 3 also shows confidence intervals at a $95 \%$ significance level obtained by 1,000 replications using the bootstrap method. In Table 
3, all bounds are shown although the bounds under a single assumption (MTR, MTS, or MIVs) are wide and not very informative compared to the tightest bounds from the MTR-MTS-MIV combined assumption. According to Table 1, most parents graduate high school: $41 \%$ of fathers and $39 \%$ of mothers had a high school degree only. Parents who have some schooling but did not graduate from a high school account for the next biggest group. In this paper, we focus on the average treatment effect of increasing a parent's education from less than high school to college graduation, or from high school to college graduation.

Columns (1) and (10) show the results of simple OLS, for father's and mother's education, respectively, which provide an unbiased estimate of the effect of parental education if we assume exogenous treatment selection. It indicates that if a father (mother) holds a college degree, it is associated with an increase in child's schooling of 1.38 (1.28) years relative to a father (mother) who did not graduate high school. When a father's (mother's) education increases from high school to college, a child has 1.18 (0.93) more years of schooling. Overall, based on the OLS results, father's schooling has a stronger positive relationship to a child's education than mother's education.

Columns (2) to (4) and (11) to (13) show what the estimated bounds would be under the case of no assumptions and bounds imposing single assumptions. Although all bounds are very wide and uninformative, imposing either MTR or MTS tightens lower and upper bounds compared to the no assumption bounds. A combination of the two assumptions, MTR and MTS (columns (7) and (16)) provides substantially tighter bounds than the no assumption cases. An increase of father's (mother's) schooling from high school to college shows bounds on the average treatment effects from 0 to 1.62 years ( 0 to 1.34 years) of a child's schooling. Since the bounds, however, include the OLS estimates, the bounds analysis based on the MTR-MTS combined assumptions does not challenge the OLS results. 


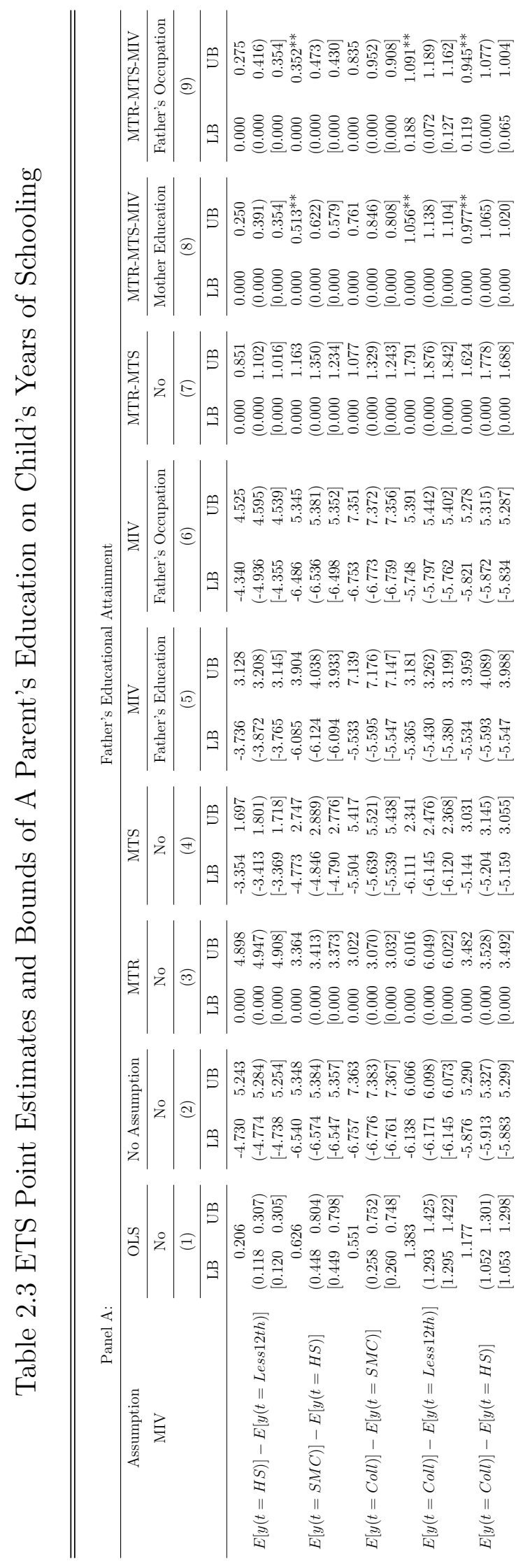




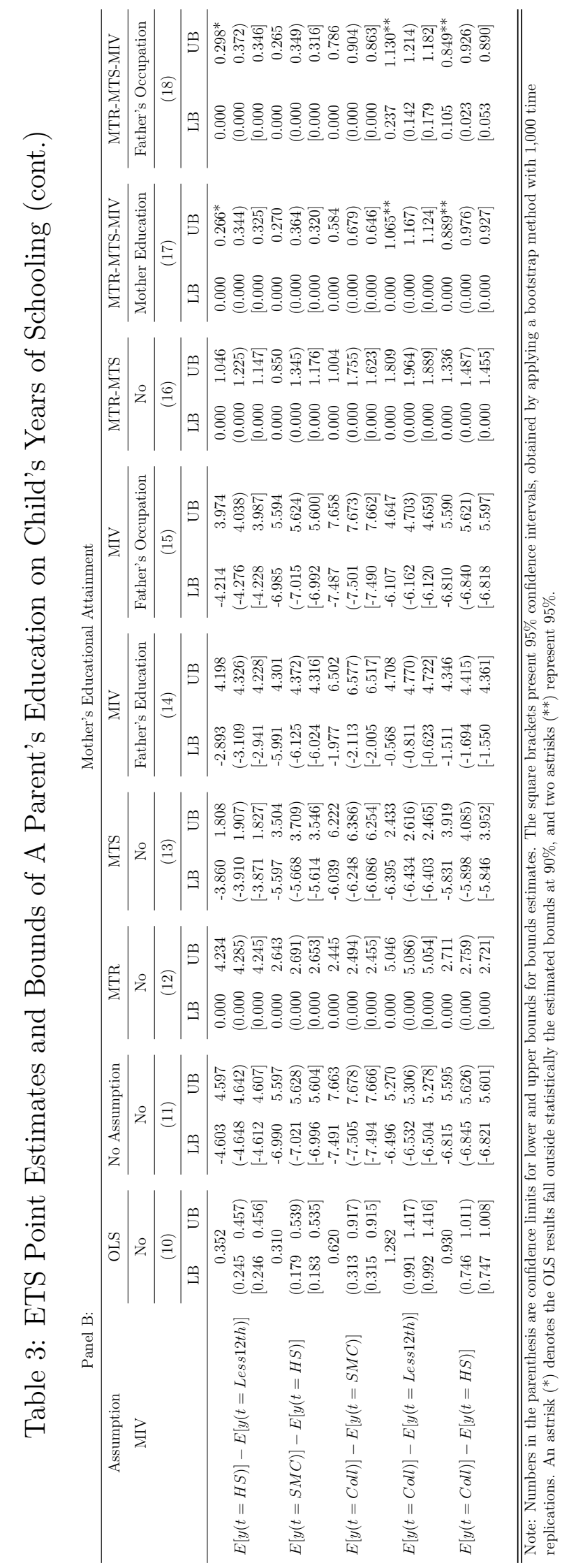


Bounds under an MIV assumption itself yields slightly tighter bounds compared to the no assumption bounds, but they are still wide enough and largely uninformative (columns (5), (6), (14), and (15)). Table 3 also gives the bounds under the joint MTRMTS-MIV assumption (columns (8), (9), (17), and (18)). These three combined assumptions yield the tightest bounds on average treatment effects, and they lead to informative bounds. When I use the mother's (father's) education as an MIV, we obtain the bounds between $0.25(0.27)$ and 1.06 (1.07); OLS point estimates fall outside of the bounds in most cases. The exception is that our bounds analysis implies that an increase of father's schooling from some college to college leads to as much as 0.76 more years of schooling for the child, but we cannot reject the OLS point estimate, 0.55. Although the bounds do not contain the OLS estimates, they contain zero effects.

With the father's occupation as an alternative MIV, the bounds estimates are similar to the bounds using the other parent's education as an MIV. We look at the effects of parents' education comparing the lower levels of education to college graduation, i.e., $E[y(t=C o l l)]-E\left[y\left(t=\operatorname{Less} 12^{t h}\right)\right]$ and $E[y(t=C o l l)]-E[y(t=H S)]$. For these effects, the lower bounds do not contain zero, and the upper bounds are significantly lower than the OLS point estimates. A father (mother) who graduated from a college as compared to not graduating from high school would increase a child's years of schooling at least 0.19 years ( 0.24 years) or as much as 1.1 years (1.13 years). A child whose a father (a mother) obtained a college degree rather than graduating only from high school is estimated to experience increases in schooling ranging from $0.12(0.11)$ years to $0.95(0.85)$ years. These bounds imply that OLS results are overestimated.

We undertake a test of the significance of the difference between the OLS estimates and the least upper bounds, as indicated in equation (25) above. We employ a bootstrap method with 1,000 replications, estimating the difference between the 
OLS and the least upper bound under the combined MTR-MTS-MIV assumptions. Asterisks in Tables 3 and 4 indicate that we can reject the null hypothesis, which is that the OLS estimates is not greater than the estimated upper bound: Two asterisks indicate that the difference is statistically significant at a $95 \%$ level, and one asterisk indicates the $90 \%$ level. We can confirm that the OLS estimates are greater than the least upper bounds of the average treatment effects of an increment of either a father's or a mother's education from high school to college, at the $95 \%$ level of significance. However, we cannot reject the OLS estimates for an increase in education of a father from some college to college graduation, which is not surprising given the small sample size for some college limits the precision of estimates.

\subsubsection{Treatment Effects on Child's College Completion}

Only small proportion of parents obtained a college degree, but many children do so. It is interesting to estimate the effects of an increase in parental education on the probability of a child's college graduation. College completion is of particular interest since it has become more important in the modern labor market environment. Table 4 provides the bounds of increasing parental educational level on the probability of a child's graduating from college along with its confidence intervals based on a bootstrap with 1,000 replications.

The OLS results indicate that an increase in father's schooling from Less than 12th grade to College increases the chance that a child graduates from college by 33 percentage points, and an increase from High school to College increases this chance by 30 percentage points. Table 4 displays the bounds for every set of assumptions, although bounds for single assumptions (MTR, MTS, or MIVs) are wide and not very informative. The joint MTR-MTS assumption tightens the bounds significantly compared to the no assumption bounds, but the bounds include the OLS point estimates in all cases. 


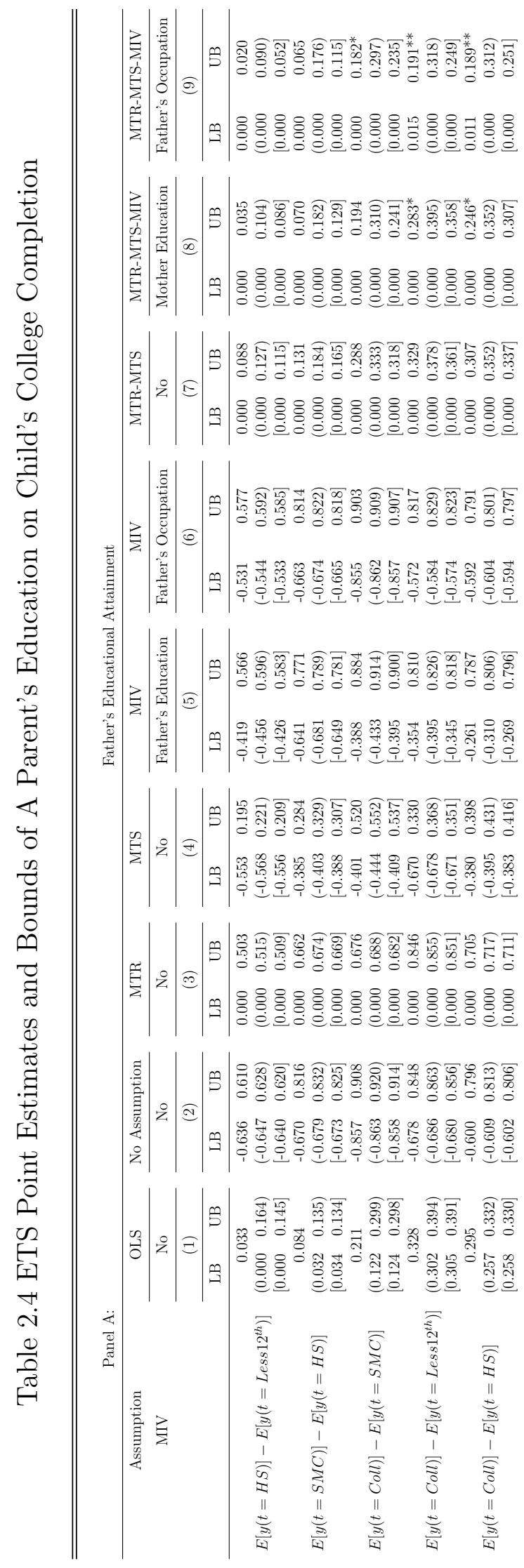




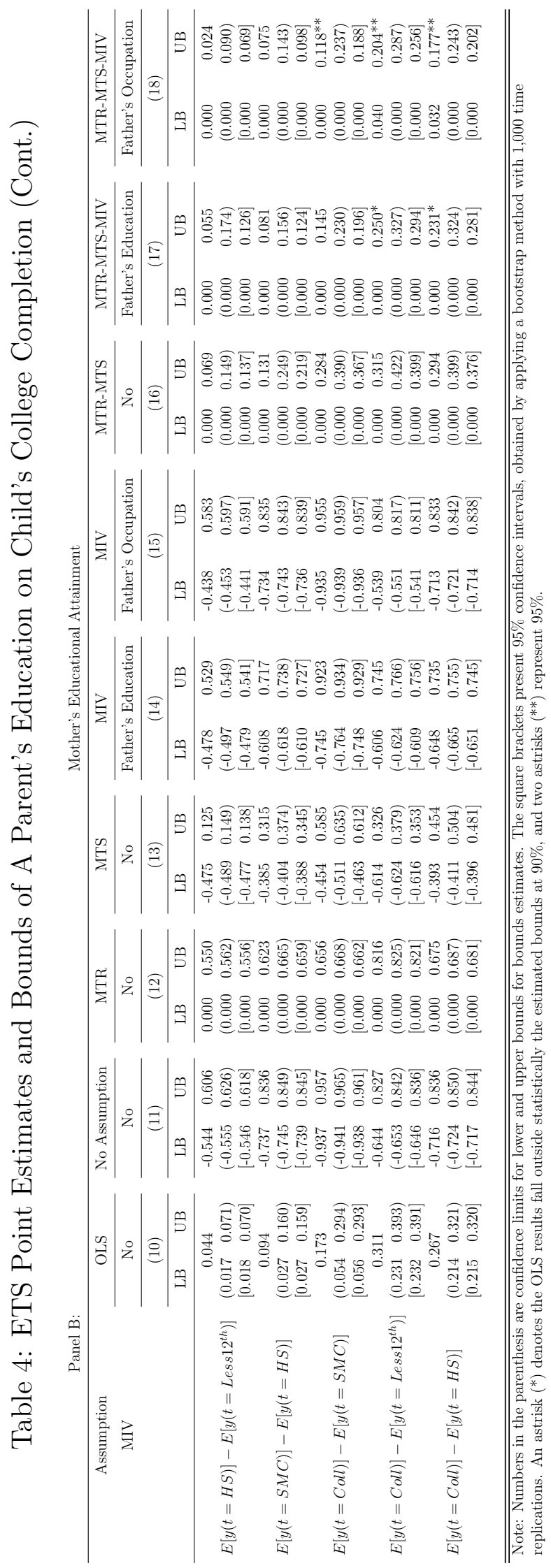


When I use the other parent's education as an MIV, the upper bounds under the MTR-MTS-MIV joint assumptions are lower than the OLS estimate in most cases. The effect of an increase in father's schooling from High school to College increases a child's chance of completing a college degree by up to 25 percentage points. However, the bounds on the treatment effects still include zero. Instead of using the other parent's education, we can also consider father's occupation as an alternative MIV. Columns (9) reports that the bounds under the MTR-MTS-MIV assumption do not contain the OLS results in any treatment effects. Similar to results presented in Table 3, the lower bounds do not include zero effects when we consider the parental schooling effects from less than high school or from high school to college. When a father's schooling increases from high school to college, the upper bound indicates that the maximum effect on the chance that a child graduates from college is 19 percentage point, whereas the OLS point estimate is 30 percentage points. This suggests that the linear probability model overestimates the effect.

We observe a similar pattern when we consider the mother's schooling as a treatment. The MTR-MTS-MIV joint assumption yields the tightest and most informative bounds, and the bounds exclude the point estimates (columns (17) and (18)) for the bottom two comparisons in the table. With the father's schooling as an MIV, the bounds include zero, while the lower bounds of the changes from less than high school or from high school to college do not contain the zero effects when we use father's occupation as an MIV. The upper bounds using the MIV father's occupation are also significantly lower than the upper bounds when father's schooling is used as an MIV. If a mother graduated from a college rather than obtaining only a high school diploma, it would increase the probability that a child obtains a college degree from 3 to 18 percentage points. The one-tailed test is conducted in this analysis as well. The null hypothesis is rejected at the $95 \%$ (90\%) significant level because the OLS estimates are greater than the least upper bounds on the average treatment effects for an 
increase in both a father's and a mother's schooling when we use father's occupation (the other parent's education) as an MIV.

\subsection{Discussion and Conclusion}

Parental education is positively associated with a child's educational outcomes. Although previous studies apply manifold empirical methods to identify the causal effects of parental education, it is not clear there is a general consensus on the causal effects of father's and mother's education on a child's schooling. Holmlund et al. (2011) review the recent literature on the intergenerational transmission of education, and they indicate that empirical evidence differs significantly across studies. Because of different data and different empirical approaches, it is challenging to achieve the consensus of the intergenerational schooling effects across previous studies.

This study investigates the causal intergenerational effects of education by adapting an alternative empirical method, the nonparametric bounds approach proposed by Manski and Pepper $(2000,2009)$. The method provides bounds on the causal effects of parents' educational level on a child's educational outcomes, years of schooling, and college completion, under nonparametric assumptions: MTR, MTS, and MIV. The assumptions are relatively weaker than the standard mean-independence assumption of IV method and partly testable. This article also combines multiple assumptions to obtain informative bounds on treatment, e.g., combining MTR with MTS or combining MTR, MTS, and MIV. We look at the causal effect of an increase in a parent's education without assuming homogeneous treatment of parental education.

While the bounds under single assumptions are wide and uninformative, we can obtain the tightest bounds by combining all three assumptions, MTR, MTS, and MIV. In particular, when we look at the average treatment effect of increasing a parent's schooling from either less than 12th grade or from high school to college, 
the highest lower bounds are positive and significantly different from zero when we use father's occupation as an MIV. Also, the least upper bounds on the average treatment effect are substantially lower than the estimates obtained from OLS. This allows us to conclude that the OLS results are overestimated relative to the true causal relationship between a parent's and a child's education. This is consistent with previous studies using the nonparametric bounds analysis to examine causal effects of parental education in the U.S. and Japan.

Our findings, we consider possible policies that may be able to support equality of educational opportunity and mitigate inequality induced by education across generations. Since this study investigates the causal relationship between parents' and children's education, policies we propose here aim at increasing the next generation's education by helping the current generation of students increase their educational achievement.

One possible policy is to provide educational vouchers to children whose parents cannot afford to buy educational materials with the goal of improving their education attainment. Increased education of children will be passed to the next generation when children who received the vouchers become parents allowing them to create better educational environments for their offspring. Another implementable policy is providing financial support to lower-income families who pay for tutoring or other supplemental instructional needs. Again, such support ultimately benefits the education of future generations.

This study pays attention to the link of education between parents and children in Korea. The link includes all transmission channels, measurable and unobservable factors, to children's educational outcomes. The nonparametric bounds approach attempts to identify effects that are causal, removing the effects of omitted variables that predate parents' and children's education. Including these channels, this study investigates how large impacts parental schooling has. For future research, we nec- 
essarily find out potentially important channels to obtain a better understanding of the transmission of parental schooling. 


\section{Chapter 3}

\section{Effects of Parents' Health Problem on Children's Education Attainment}

\subsection{Introduction}

Parents' economic outcomes play a crucial role in determining children's labor market success. An abundant literature identifies the effects of parents' characteristics and behaviors on children's labor market outcomes. Most studies have focused on either the intergenerational earnings association (Becker and Tomes, 1979; Solon, 1992; Mazumder and Levine, 2002; Mazumder, 2005; Corak, 2006, 2013a,b; Chetty et al., 2014a) or the intergenerational schooling association (Haveman and Wolfe, 1995; Björklund et al., 2006; Oreopoulos et al., 2006; Sacerdote, 2007; Blanden et al., 2007; Holmlund et al., 2011; Black and Devereux, 2011; De Haan, 2011; Grönqvist et al., 2017). Children with more educated and wealthier parents are more likely to obtain more schooling than those with less educated and poorer parents. Although these two are important channels of intergenerational transfer, there are also many other factors affecting children's educational achievement. In addition to parents' 
schooling and income, parents' health during children's early childhood and adolescence may be an important determinant of children's education (Currie and Madrian, 1999).

A parent's illness can alter family resources that affect children's schooling. Specifically, parents' health problems during children's childhood may reduce parenting quality because another parent or family members may spend time caring for a sick parent. If another parent originally allocates the time to care for children, reduced parenting quality may affect a child's educational environment. Creating an educational environment and extra educational opportunities in childhood are important in faciliating a child's educational achievement in the very competitive circumstances in the Korean education system. If parents' health problems occur when children are in school or even at younger ages, a family needs to adjust its financial budget to cover medical expenses. Such parental illness may limit children's educational activities by limiting purchase of extra educational materials, after school curriculum supplements, and private tutoring. In other words, parents' illness is likely to reduce the chance of educational investment and to change the parenting quality.

Grossman (1972) constructs a theoretical model of the demand for one's health based on the premise that health can be thought of as a capital stock, as a kind of human capital. Smith (1999) also notes the long-run effects of health conditions, noting that poor health in early childhood years is associated with health status in middleage. Wagstaff (1986) simplifies Grossman's model of the investment in good health. Currie and Madrian (1999) summarize relevant theoretical and empirical studies. They give an overview of empirical studies regarding the relationship between health and labor market outcomes, considerting labor force participation, retirement, and employment status. Most studies have noted that unexpected health problems are negatively associated with labor market outcomes, including laborforce participation (Parsons, 1982; Stern, 1989; Ettner et al., 1997) and employment status (Burtless, 
1987; Mullahy and Sindelar, 1996). Also, poor health leads to early retirement (Bazzoli, 1985; Sickles and Taubman, 1986). These relevant studies have identified the linkage of health and labor market behaviors, and they are intragenerational.

Most studies of the parents' health effects have focused on identifying the effects of one parent's death or divorce (Corak, 2001; Gertler et al., 2004; Chen et al., 2009; Adda et al., 2011; Kalil et al., 2016; Gould et al., 2020). Findings of relevant research have a similar pattern, showing that parental loss decreases children's educational achievement by inceasing in family financial risks and decreasing interaction with between parents and children. Lundborg et al. (2018) investigate parents' educational transmission to children's education and health status using a twin adoption sample from Sweden. Children with more educated parents are more likely to have higher skills, cognitive and non-cognitive skills, and better health than those with less-educated parents. These studies do not account for parents' health problems.

Few studies have examined the relationship between parents' health and children's outcomes. An exception is Choi (2011), who estimates the effects of parents' health on children's educational attainment and labor market behaviors in Russian families. Parents' health problems likely reduce financial and non-financial investment in education and health of children, affect not only education as a short-term outcome but also children's employment status over the long-term achievement. She finds there is a different pattern of the effects on children's education and labor force participation by gender. Parents' poor health reduces a son's years of schooling by about 0.08, but it is not statistically significant. However, a father's illness or severe illness reduces the year of schooling of a daughter by about a year. Also, a married son's labor market behaviors may not be affected by unexpected parents' illness, but parents' illness reduces the chance of labor force participation of a married daughter.

Several studies also have focused on estimating the relationship between economic status and self-rated health in Korea, showing that education and income are pos- 
itively associated with own perceived health conditions (Kim, 2007a,b; Jung et al., 2007; Kim et al., 2013; Yoon, 2016; Kim, 2019). The findings of these studies are consistent with other papers' results, confirming that more education produces higher income. They also show that greater income leads to better health. Jung et al. (2007) extend the analysis to health status inequality induced by the financial crisis in Korea. They find that the illness becomes substantially more likely in the lower-income families than the high-income families. The findings of this study are consistent with the results of Van Doorslaer et al., 1997; Smith, 1999. However, little research on the impacts of parents' unexpected health events when children are in childhood or adolescence has been conducted in Korea.

This paper focuses particular attention on the effects of parents' self-assessed health problems on children's educational success using the Korean Labor and Income Panel Study. We find that a parent's illness, especially in the early childhood period, is strongly associated with a child's education. Because parental education is a determinant of own health status and their children's educational success, this study also estimates the effect of parental health controlling for parental education. A child from a single parent family may have a different experience of parenting quality than those who from a traditional family; thus I account for the household structure as years of single parenting on a child's experienced. Single parenting by either a father or a mother has negative impacts on a child's educational attainment in all childhood periods. The effects of single father parenting are greater than single mother's effects. This suggests that a mother's loss during childhood periods is more important disruption of a child's concentration on schooling activities. However, although parental income is considered the most important determinant of children's schooling, this study does not include parental income in the main model because it is likely to be influenced by the health conditions.

The remainder of this study is organized as follows: Section 2 presents the detailed 
empirical specification. Section 3 describes the Korean Labor and Income Panel Study (KLIPS) dataset, which is used in this study. We show the results in section 4. Section 5 provides the conclusion.

\subsection{Empirical Strategy}

As a first step, I specify an estimating equation for the effects of parental health problems on children's education. The basic OLS model is:

$$
Y_{i}=\alpha_{1}+\beta_{k} H P_{i}^{P_{k}}+\epsilon_{i}, \quad \forall P=F \text { or } M, k=1,2,3,
$$

where $Y_{i}$ is the educational achievement of a child in family $i$, and $H P_{i}^{P_{k}}$ denotes the health status of a father or a mother in family $i$ when a child was in an age range of $k$ that $k=1$ identifies that a child's age was between 6 and 10 years old, and $k=2$ and 3 identify a child's age between 11 and 15, and between 16 and 21 years old, respectively. In other words, $H P_{i}^{P_{k}}$ is an indicator of proportion of time when parents had health problems. They are calculated by years of parent's illness over a number of years with response. A superscript $P$ includes $F$ denoting father, and $M$ denoting mother.

In this paper, we identify the causal relationship between parental illness and two measures of children's educational achievement: college attendance and years of schooling. The coefficient of interest is $\beta$, which indicates the effects of parental illness at each children's age period. Additionally, I add $H P M S^{P_{k}}$, which stands for either missing value of illness of a father or a mother that we replace missing value with the average years of parents' health problem at each children's age period, on the Equation (1). The model is:

$$
Y_{i}=\alpha_{2}+\beta_{k} H P_{i}^{P_{k}}+\theta_{k} H P M S_{i}^{P_{k}}+u_{i}, \forall P=\text { For } M, k=1,2,3 .
$$


In Equation (2), we distinguish the missing group differently to understand what happens with parental illness in the group. Another advantage of including the missing observations is that we can use the entire population that has educational information.

This study also controls single parenting by either a father or a mother, and parents' educational attainment. Children in single parent households would have experienced different parenting than traditional households. More specifically, a one parent household is more likely to have less investment in children's education and less time allocation for caring for children. The effects of parental loss can differentially affect children's education depending on the period at parental loss. $S P$ denotes the single parenting by a father and a mother, respectively in Equation (3). Both $S P_{i}^{F_{k}}$ and $S P_{i}^{M_{k}}$ measure in the same way as the parental health problems that average across years for which data is available.

In addition to the household structure, I add both parents' education to the model because it is an important factor influencing children's education. I fit an additive model that uses single parenting and education of both fathers and mothers along with parental health problems:

$$
\begin{aligned}
Y_{i}=\alpha_{3}+\beta_{k} H P_{i}^{P_{k}}+\rho_{k} S P_{i}^{F_{k}}+\mu_{k} S P_{i}^{M_{k}}+\theta_{k} H P M S_{i}^{P_{k}} \\
\quad+E d u c_{i}^{F} \eta+E d u c_{i}^{M} \xi+X_{i} \tau+e_{i}, \quad \forall P=F \text { or } M, k=1,2,3,
\end{aligned}
$$

where $S P$ denotes the single parenting by a father and a mother, respectively.

$E d u c^{F}$ and $E d u c^{M}$ measure the educational attainment of parents. Parental education consists of dummies for four categories: less than 12th grade, high school, some college, and college. The dummy for high school is the omitted category for both parents. Some college includes those who attend or graduate from a 2 or 3year junior college, and for those who attend a 4-year college but do not graduate. Although I can distinguish parents who pursue graduate curricula, I code them as college graduates in empirical models because of the small number of cases. 
$X_{i}$ captures the number of siblings of children and home address (metropolitan area or not). In the last empirical model, $X_{i}$ additionally includes parental average income. Because parental average income may well be influenced by parents' illness, its inclusion could be bias results if we control the parental income. Prior studies identify a positive association between income and health, and show that higher income can lead to better health (Smith, 1999; Cutler and Lleras-Muney, 2006). However, it may also be the case that parents' poor health can reduce household financial circumstances, which would then it would affect children's education. Therefore, this study does not control parental income in the main analyses.

\subsection{Data}

\subsubsection{Korea Labor and Income Panel Study (KLIPS)}

This study uses the Korea Labor and Income Panel Study (hereafter KLIPS) based on a survey conducted by the Korea Labor Institute, to identify the effects of parental illness on children's education. ${ }^{1}$ KLIPS provides extensive Korean labor market information and income (earnings) of both households and individuals who lived in urban and suburban areas from 1998 to 2018. This is a longitudinal survey and samples 5,000 households with 13,321 individuals aged 15 and older in 16 metropolitan areas in 1998. An additional 1,415 households were included in the survey in 2009 to improve the representativeness of the data, addressing limitations of attrition and concentration of the urban residence.

A variable of interest is the illness of parents while children were young. KLIPS provides individuals' self-reported health conditions since the fourth year of the survey and detailed information related to labor market outcomes, and individuals and family

\footnotetext{
${ }^{1}$ The KLIPS is the first Korean longitudinal survey focusing on labor issues. These data are available on the website of the Korea Labor Institute: http://www.kli.re.kr/klips ${ }_{e} n g /$ index.do
} 
characteristics such as educational level, earnings, income, family background, and demographic characteristics.

In the KLIPS, there are many health-relevant questions; however, most questions are related to the diagnosis of particular illnesses, and such questions are only asked in a single survey. Parents' illness may show different patterns of effects by children's age when the illness occurred. There are two questions consistently have asked since the 4th survey year, the health condition at the current survey year and health condition at the current survey year compared to the prior year. However, because the comparison to a health condition in the last year may be endogenous with the current health condition, this study uses the current health condition of individuals exclusively. The health question consists of five categories: 1. very good, 2. good, 3 . normal, 4. bad, and 5. very bad. I consider persons who responded 4 and 5 in the question as those who have an illness. In some specifications, I also take into account cases of when parents had a severe illness, which is in category 5 .

One advantage of KLIPS is it allows us to infer information about family of origin prior to survey participation of the children. Because the minimum age to participate in the survey is 15 years old, information based on direct interview before participation is not available. However, parents joined the survey either in the first year (1998), or the 12th year of the survey when additional households were added. This enables us to look back at the family background of children before their own participation. For example, with 20-year-old children at the last survey, we have only 6 years' of information based on interviews with them. We still can infer parents' information such as income, health condition, and household structure prior to that although children were not in the survey. Based on such an approach, this study distinguishes children who experienced parents' health problems between 6 and 10 years old, between 11 and 15 years old, and between 16 and 21 years old. This study examines parents' illness effects in their early childhood and adolescence on 
ultimate educational achievement. Household structure, other family characteristics, and parental average income are also available in the same way as parental health conditions.

\subsubsection{Sample Description}

Table 1 provides summary statistics for parental health condition, education, family background, and children's information. The parental health measure is a continuous variable instead of a 0-1 variable. The sample varies observable years of health problem, making the 0-1 variable could provide bias with children's age. Taking average by years we can observe is a more credible way to code than using the 0-1 binary dependent variable. The health problem of parents is a continuous variable, which is the average years of health problem. At least, this does not provide bias, which associates with children's age. Single parenting also is coded in an identical way as parental illness.

The health problems and single parenting of either a father or a mother by a child's age period are not mutually exclusive. Some survey respondents may have not been able to fully capture the parents' health condition since children were 6 years old. There are data missing and non-response for the illness of parents. This study uses the average years of having illness across all years if there is any data available. Then, I replaces the sample mean if all answers regarding current health condition are missing. However, we exclude non-response cases where all information is missing because we cannot use any other information except parental education. After replacing parental health missing with the mean value of time having illness of each parent, we have 4,591 observations for fathers' illness, but we can observe 4,328 of mothers' illness. To exclusively capture the effects of missing cases, we take into account missing cases as including dummies.

As children get older, we can observe a larger number of observations for the 
Table 3.1 Sample Description

\begin{tabular}{|c|c|c|c|c|c|c|c|}
\hline & Mean & Std.Dev. & Proportion & & Mean & Std.Dev. & Proportion \\
\hline Child's Age at last survey (21st) & 26.89 & 5.25 & & Father's Health Problem by Child's Age & & & \\
\hline \multirow[t]{2}{*}{ Child's Gender, Daughter $=1$} & & & 0.47 & Between 6 and 10-Year-Old & 0.05 & 0.15 & 0.09 \\
\hline & & & & Between 11 and 15 -Year-Old & 0.07 & 0.18 & 0.11 \\
\hline Child's Years of Schooling & 14.47 & 1.72 & & Between 16 and 21-Year-Old & 0.08 & 0.22 & 0.17 \\
\hline Less Than 12 th Grade $=9$ yrs & & & 0.02 & Mother's Health Problem by Child's Age & & & \\
\hline High School = 12 yrs & & & 0.20 & Between 6 and 10-Year-Old & 0.06 & 0.16 & 0.10 \\
\hline Some College $=14 \mathrm{yrs}$ & & & 0.30 & Between 11 and 15-Year-Old & 0.07 & 0.19 & 0.13 \\
\hline College $+=16$ yrs & & & 0.48 & Between 16 and 21-Year-Old & 0.10 & 0.24 & 0.18 \\
\hline Child in School Before 20 & & & 0.05 & Father's Severe Health Problem by Child's Age & & & \\
\hline Child in School Between 21 and 25 & & & 0.15 & Between 6 and 10-Year-Old & 0.01 & 0.08 & 0.02 \\
\hline \multirow[t]{2}{*}{ Child in School After 26} & & & 0.03 & Between 11 and 15 -Year-Old & 0.01 & 0.08 & 0.03 \\
\hline & & & & Between 16 and 21-Year-Old & 0.02 & 0.10 & 0.04 \\
\hline 4-year College Attendance & & & 0.52 & Mother's Severe Health Problem by Child's Age & & & \\
\hline 4-year College Graduation & & & 0.48 & Between 6 and 10-Year-Old & 0.02 & 0.09 & 0.03 \\
\hline \multirow[t]{2}{*}{ Number of Siblings } & 1.08 & 0.83 & & Between 11 and 15 -Year-Old & 0.02 & 0.09 & 0.03 \\
\hline & & & & Between 16 and 21-Year-Old & 0.02 & 0.10 & 0.03 \\
\hline \multicolumn{8}{|l|}{ Father's Education: } \\
\hline Less than 12 th grade & & & 0.24 & Single Father by Child's Age & & & \\
\hline High school & & & 0.41 & Between 6 and 10-Year-Old & 0.04 & 0.15 & 0.06 \\
\hline Some college & & & 0.08 & Between 11 and 15 -Year-Old & 0.06 & 0.17 & 0.05 \\
\hline College & & & 0.19 & Between 16 and 2-Year-Old & 0.08 & 0.20 & 0.06 \\
\hline \multirow[t]{2}{*}{ Father's Education Missing (Dummy) } & & & 0.08 & Single Mother by Child's Age & & & \\
\hline & & & & Between 6 and 10-Year-Old & 0.07 & 0.20 & 0.09 \\
\hline Mother's education: & & & & Between 11 and 15 -Year-Old & 0.08 & 0.23 & 0.10 \\
\hline Less than 12 th grade & & & 0.34 & Between 16 and 21-Year-Old & 0.10 & 0.25 & 0.13 \\
\hline High school & & & 0.45 & & & & \\
\hline Some college & & & 0.06 & Parents' Income (Log Income): & & & \\
\hline College & & & 0.10 & Between 6 and 10-Year-Old & 6.21 & 0.66 & \\
\hline \multirow{3}{*}{ Mother's Education Missing (Dummy) } & & & 0.04 & Between 11 and 15 -Year-Old & 6.34 & 0.73 & \\
\hline & & & & Between 16 and 21-Year-Old & 6.40 & 0.74 & \\
\hline & & & No. of I & lividuals $=4,591$ & & & \\
\hline
\end{tabular}

parental health problems and other family characteristics including single parenting. When children were in the late adolescent period (between 16 and 21 years old), $17 \%$ (18\%) of them have experienced a father's (mother's) illness at least one year of the period. Only $3 \%$ of children had experienced a maternal severe illness experience regardless of their age. Proportions of children who experienced paternal severe illness are similar to the proportion of maternal illness.

Single parenting (household structure) also can be identified by children's age, coded for the same age ranges as parents' health problems and parental income: between 6 and 10 years old, between 11 and 15 years old, and between 16 and 21 years old. Along with parental health problems, single parenting by either parent is another important factor influencing children's educational achievement. Because single parenting households can have a different educational environment than traditional two-parent families, children who experienced a parent's absence due to separation, divorce, or death are likely to face fewer educational opportunities than children in 
traditional families.

This study uses two dependent variables: years of schooling and college attendance. Parental illness in childhood or adolescence can influence children's education through reduced financial investment and parenting quality. I consider children's years of final schooling, coded as 9 years (high school dropout and less), 12 years (high school graduate), 14 years (some college, or two or three-year degree), and 16 years (bachelor's degree and above). Children have 14.5 average years of schooling. Over $45 \%$ of children graduated from a four-year college. If children are still in high schools or tertiary schools, I code them either 'Less than 12th grade' or 'Some college.' I make a dummy variable to distinguish individuals who are in school from those who completed education. However, we consider those who are in colleges as entering 4-year colleges, which is another dependent variable.

We limit children's age, 20 to 37-year-old at the last survey year to investigate the effects of parental health. If children who are older than 37 years old are included in the sample, we are not able to identify parental health information during their adolescence. In our sample, the mean age of children is 26.9 years old. However, we restrict children's age from 22 to 37 years old to use years of schooling of children as a dependent variable. With this restriction, the number of observations shrinks to 3,987 for father's illness and 3,776 for mother's illness.

This study also considers four educational levels for parents, coded in the same way as children's education. However, there is a huge educational difference between parents and children. While $40 \%$ of children graduated from college, less than $20 \%$ of fathers and $10 \%$ of mothers completed college. About $50 \%$ of parents graduated from high school in this sample. This is because the educational structure has changed dramatically with substantial economic growth over the last several decades.

In addition to parents' schooling, parental income is also one of the key determinants of children's education. However, when we control for parental income, the 
causal impact of health may be misrepresented because income may be influenced by health. Therefore, we do not include the parental income in the main analyses, but we include it as a control as a robustness check. KLIPS provides detailed income sources of a family such as earnings, financial income, and government and private transfer income. After summing the average income of father and mother, we also calculate the mean parental income by children's age periods: between 6 and 10 years old, between 11 and 15 years old, and between 16 and 21 years old. We exclude parental income from these averages for children's age periods in which the data are missing and where we have zero income, likely non-response.

\subsection{Empirical Results}

Table 2 reports zero-order relationships between parental health problems and children's education. Table 2 does not represent a causal relationship because it does not control for parental education or other family characteristics, and because it includes all parental illnesses in the same equation. However, it still provides an idea of how various measures of parental health are related to children's educational outcomes. Columns (1) to (3) show the estimation results of the parental illness effects on children's college entrance, and columns (4) to (6) show effects on years of schooling. Columns (1) and (2) show the effects of all relevant illnesses and severe illnesses of fathers and mothers regardless of children's age that column (1) provides that the effects of father's health problems and severe health problems at all age periods of children. The effects of father's health problems at children between ages 6 and 10 are statistically significant.

Mother's health problems are significantly associated with a decline in the chance of children's college admission no matter when a mother was sick. Also, the results suggest that parental illness has the strongest effects when children are very young, 
Table 3.2 Parents' Illness Identification Power

\begin{tabular}{|c|c|c|c|c|c|c|}
\hline \multirow[t]{2}{*}{ Dependent Variables: } & \multicolumn{3}{|c|}{ Children's College Attendance } & \multicolumn{3}{|c|}{ Children's Years of Schooling } \\
\hline & $(1)$ & $(2)$ & $(3)$ & (4) & $(5)$ & (6) \\
\hline Father Illness 6-10 & $\begin{array}{c}-0.27^{* * * *} \\
(0.06)\end{array}$ & & $\begin{array}{c}-0.16^{* * *} \\
(0.06)\end{array}$ & $\begin{array}{c}-0.67^{* * *} \\
(0.19)\end{array}$ & & $\begin{array}{c}-0.36^{* *} \\
(0.17)\end{array}$ \\
\hline Father Illness 11-15 & $\begin{array}{l}-0.04 \\
(0.05)\end{array}$ & & $\begin{array}{l}-0.04 \\
(0.05)\end{array}$ & $\begin{array}{l}-0.27 \\
(0.17)\end{array}$ & & $\begin{array}{l}-0.17 \\
(0.16)\end{array}$ \\
\hline Father Illness 16-21 & $\begin{array}{l}-0.04 \\
(0.04)\end{array}$ & & $\begin{array}{l}-0.04 \\
(0.04)\end{array}$ & $\begin{array}{l}-0.12 \\
(0.12)\end{array}$ & & $\begin{array}{c}0.05 \\
(0.12)\end{array}$ \\
\hline Mother Illness 6-10 & & $\begin{array}{c}-0.20 * * * \\
(0.05)\end{array}$ & $\begin{array}{c}-0.24^{* * * *} \\
(0.05)\end{array}$ & & $\begin{array}{c}-0.35^{* *} \\
(0.17)\end{array}$ & $\begin{array}{c}-0.45^{* * *} \\
(0.16)\end{array}$ \\
\hline Mother Illness 11-15 & & $\begin{array}{c}-0.16^{* * *} \\
(0.04)\end{array}$ & $\begin{array}{l}-0.07^{*} \\
(0.04)\end{array}$ & & $\begin{array}{l}-0.15 \\
(0.14)\end{array}$ & $\begin{array}{l}-0.08 \\
(0.12)\end{array}$ \\
\hline Mother Illness 16-21 & & $\begin{array}{c}-0.08^{* *} \\
(0.03)\end{array}$ & $\begin{array}{l}-0.01 \\
(0.03)\end{array}$ & & $\begin{array}{l}-0.21^{*} \\
(0.12)\end{array}$ & $\begin{array}{l}-0.08 \\
(0.10)\end{array}$ \\
\hline Father Serious Illness 6-10 & $\begin{array}{c}-0.30^{* * *} \\
(0.08)\end{array}$ & & $\begin{array}{c}-0.29 * * * \\
(0.08)\end{array}$ & $\begin{array}{l}-0.18 \\
(0.32)\end{array}$ & & $\begin{array}{l}-0.16 \\
(0.32)\end{array}$ \\
\hline Father Serious Illness 11-15 & $\begin{array}{l}-0.09 \\
(0.09)\end{array}$ & & $\begin{array}{l}-0.10 \\
(0.09)\end{array}$ & $\begin{array}{l}-0.40 \\
(0.39)\end{array}$ & & $\begin{array}{l}-0.31 \\
(0.39)\end{array}$ \\
\hline Father Serious Illness 16-21 & $\begin{array}{c}0.02 \\
(0.07)\end{array}$ & & $\begin{array}{c}0.02 \\
(0.07)\end{array}$ & $\begin{array}{l}-0.05 \\
(0.28)\end{array}$ & & $\begin{array}{c}0.09 \\
(0.26)\end{array}$ \\
\hline Mother Serious Illness 6-10 & & $\begin{array}{c}-0.36^{* * *} \\
(0.10)\end{array}$ & $\begin{array}{c}-0.23^{* *} \\
(0.10)\end{array}$ & & $\begin{array}{l}-0.37 \\
(0.28)\end{array}$ & $\begin{array}{l}-0.01 \\
(0.28)\end{array}$ \\
\hline Mother Serious Illness 11-15 & & $\begin{array}{l}-0.07 \\
(0.09)\end{array}$ & $\begin{array}{l}-0.12 \\
(0.09)\end{array}$ & & $\begin{array}{c}-2.10^{* * *} \\
(0.32)\end{array}$ & $\begin{array}{c}-1.46^{* * *} \\
(0.30)\end{array}$ \\
\hline Mother Serious Illness 16-21 & & $\begin{array}{l}-0.02 \\
(0.08)\end{array}$ & $\begin{array}{c}0.01 \\
(0.08)\end{array}$ & & $\begin{array}{c}-0.93^{* * *} \\
(0.30)\end{array}$ & $\begin{array}{c}-0.89^{* * *} \\
(0.26)\end{array}$ \\
\hline Constant & $\begin{array}{c}0.75 \\
(0.01)\end{array}$ & $\begin{array}{c}0.67 \\
(0.01)\end{array}$ & $\begin{array}{c}0.74 \\
(0.01)\end{array}$ & $\begin{array}{l}15.28 \\
(0.03)\end{array}$ & $\begin{array}{r}15.24 \\
(0.02)\end{array}$ & $\begin{array}{l}15.29 \\
(0.03)\end{array}$ \\
\hline $\begin{array}{l}\text { Other Controls } \\
\text { Parental Illness Missing }\end{array}$ & $\mathrm{x}$ & $\mathrm{x}$ & $\mathrm{x}$ & $\mathrm{x}$ & $\mathrm{x}$ & $\mathrm{x}$ \\
\hline $\begin{array}{l}\mathrm{R}^{2} \\
\text { Obs. }\end{array}$ & $\begin{array}{c}0.35 \\
4,591\end{array}$ & $\begin{array}{c}0.11 \\
4,328\end{array}$ & $\begin{array}{c}0.34 \\
4,209\end{array}$ & $\begin{array}{c}0.46 \\
3,987\end{array}$ & $\begin{array}{c}0.29 \\
3,776\end{array}$ & $\begin{array}{c}0.47 \\
3,691\end{array}$ \\
\hline
\end{tabular}

Note: 6-10, 11-15, and 16-21 mean children's age periods between 6 and 10, between 11 and 15, and between 16 and 21 years old when either a father or a mother encounters illness or severe illness.

$* \mathrm{p}<.1,{ }^{*} * \mathrm{p}<.05, * * * \mathrm{p}<.01$.

which are similar to results in column (1) when we control both father's and mother's illness and severe illness in the same model (column (3)). Unlike the effects on college admission, a mother's severe health problems substantially reduce a child's education if a mother was sick when a child was in primary education (between 11 and 15 years old). This pattern also is the same after controlling for both father's and mother's health. 


\subsubsection{The Effects of Parental Illness on Children's College Attendance}

This section examines how parental illness single parenting, and other family background factors influence children's years of schooling. The focus is on how either parents' health problems determine college attendance of children. Tables 3 and 4 report estimates of how the paternal and maternal health problems at particular children's ages affect children's college attendance based on equations (1) to (3). Both tables also show the association between children's education and single parenting by either father or mother. The effects of single parenting are also captured for children's age ranges as are parental health problems.

Columns (1), (4), and (7) in both tables provide an estimate of the association between children's college admission and parental illness. Columns (2), (5), and (8) additionally control the missing group of parent's health to treat this group differently from those who reported health conditions. Lastly, we control for the educational attainment of both parents, the number of siblings of children, location of residency (metropolitan area or not), and children's ages in columns (3), (6), and (9). Parents' education consists of four categories: less than high school, high school, some college, and college. High school is an omitted group for both parents.

Based on the results in Table 3, the father's illness when the child is between 6 and 10 years old has the biggest impact on children's college entrance. Column (1) in Table 3 indicates that a 1 percentage point increases in the level of father's illness when a child was between 6 and 10 years old can reduce the likelihood of college attendance of a child by 0.46 percentage points. Paternal health problems have the same effects if we control for a dummy variable identifying that the paternal health problem measure is missing. We can see this pattern when a father's illness happened at when a child was between 11 and 15 years old and between 16 and 21 years old (in columns (5) and (8)). 
Table 3.3 Paternal Illness Effects on Children's College Attendance

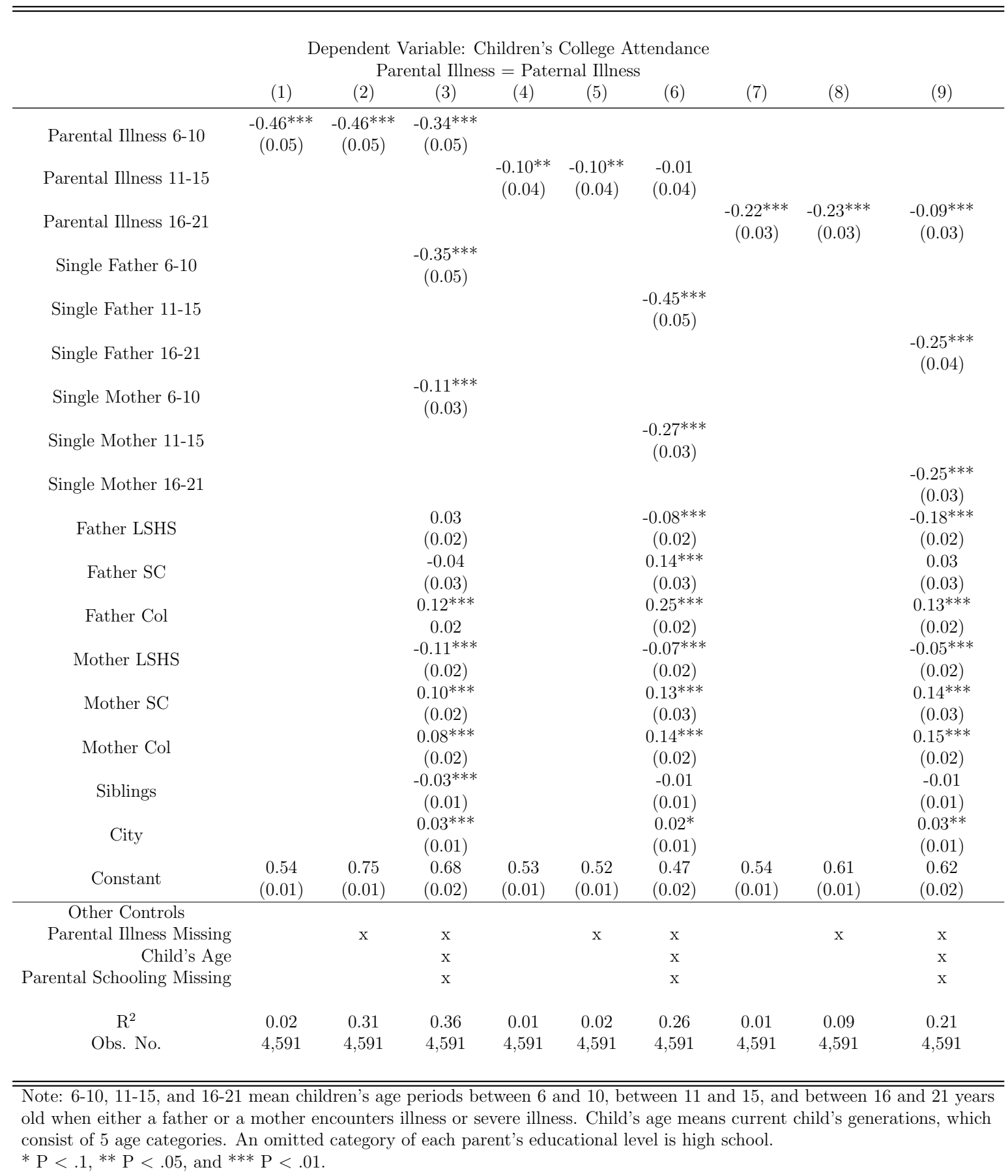




\section{Table 3.4 Maternal Illness Effects on Children's College Attendance}

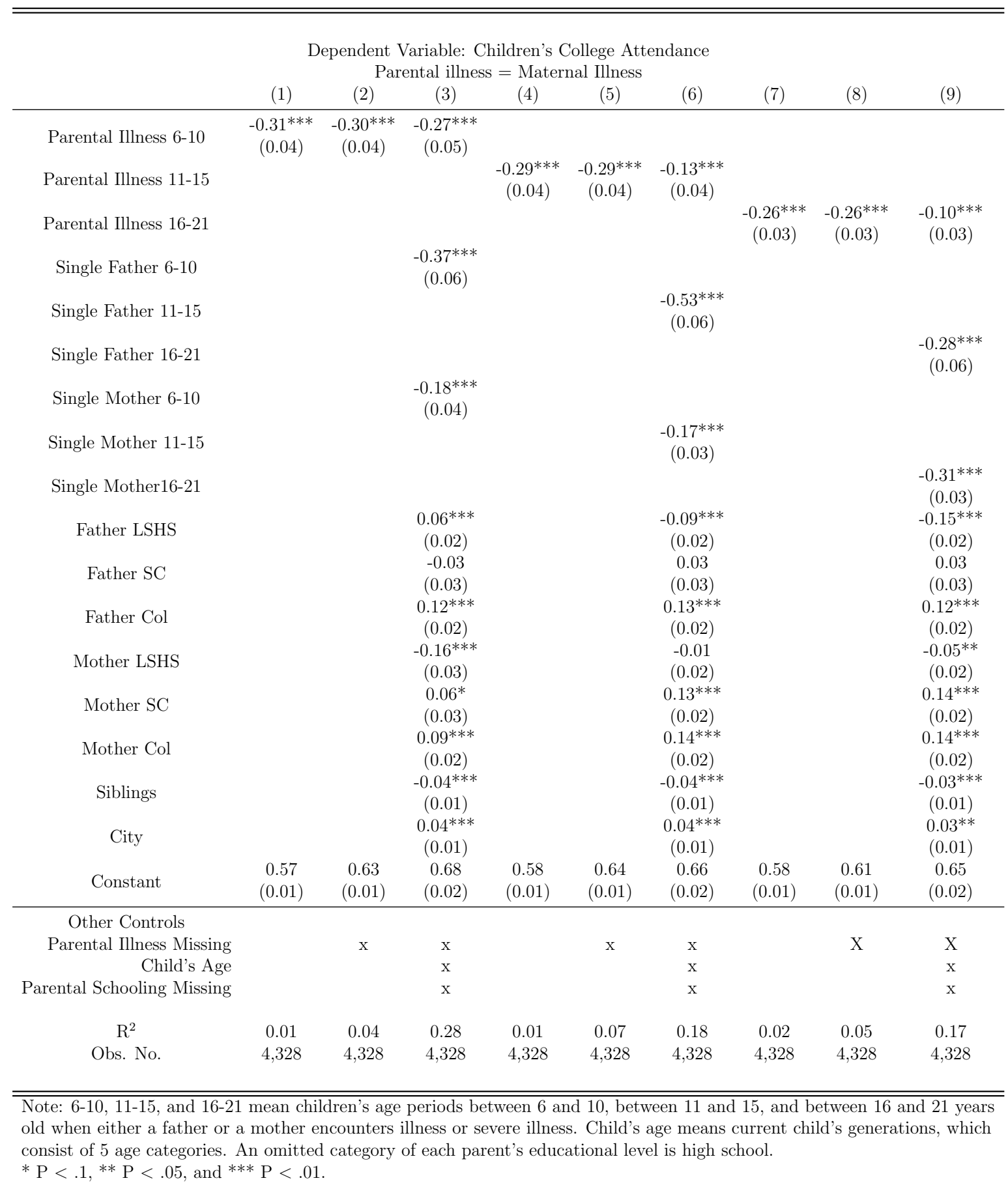


After including parents' education and other characteristics, the coefficient of paternal illness effects decreases to -0.34 from -0.46 . This reflects the association with parents' education, mostly paternal education and single parenting. A child with a single father is less likely to attend college, a 35 percentage point negative effect, compared to other household structures. A single mother reduces the chance of college attendance by 11 percentage points.

Comparing the three age ranges, paternal health problems have the weakest negative impact on a child when the child was between 11 and 15 years old. In Korean age, a child in this age range was most likely to attend a middle school. In other words, a child with a 1 percentage point increment in the likelihood of haing a father with health problems is less likely to enter a college by 0.10 percentage points if the father's illness occurred while the child was attending middle school. In column (6), after controlling for single parenting and other characteristics, however, paternal health problems no longer affect a child's college entrance, as the coefficient decreases to -0.01 , and it is not statistically significant. The effects of single parenting of either a father or a mother are stronger than its effects when a child is aged between 6 and 10-year-old. The effects of both parents' educational levels are consistent over time on children's education. On the other hand, a child's sibling effect is no longer statistically significant.

Columns (7) to (9) in Table 3 report the effects of paternal health problems on children's college attendance when a child was aged between 16 and 21 years of age, the time when most of the children are senior students in middle school or are high school students. A 1 percentage point increase in paternal illness reduces the chance that a child attends college by -0.22 percentage points. After controlling for other variables, its effects decrease to -0.09 . The single parenting of either a father or a mother has the same effects that it reduces the likelihood of a child attending a college by -0.25 percentage points, and it is statistically significant. 
Table 4 shows how a mother's health is associated with the educational success of children. Maternal illness has similar negative effects regardless of children's age, like the father's illness. A child whose a mother was sick is less likely to go to a college by 0.31 percentage points when the child was between 6 and 10 years old. Unlike a father's health problems (column (3) in Table 3), the maternal health problem effects do not decrease dramatically after controlling for other variables. The negative effects decrease to -0.27 from -0.30 . This may be because parental education and illness are not strongly correlated when children are young.

A mother's absence has a much stronger impact on children than a father's absence. When a child is young, a mother spends relatively more time caring for a child. This mother's care at the moment may be crucial for educational success at a later age. This may be the reason why a single father's parenting has much greater negative effects than a single mother's parenting.

However, maternal illness effects drop to -0.13 and -0.10 , respectively with controls for other variables (columns (6) and (9)). This tells us that parental education is more strongly correlated to parental illness at a later age of a child. A mother's absence when a child was between 11 and 15-year-old is still strongly associated with a child's educational success. The effects of father's absence are relatively smaller than a mother's absence when a child was aged between 6 and 10 years and aged between 11 and 15 years. When the child was aged between 16 and 21 years, however, the effects of father's absence become important as a mother's absence by -0.31. Living without a father means that a child can have less chance to get financial support for education because the father's earnings are generally the main source of the household budget in Korea.

Tables 5 and 6 present the effects of both parents' severe illness on a child's college admission; the format is the same as Tables 3 and 4 . The effects of severe paternal health problems are much stronger than the effects of paternal illness, and they are 


\section{Table 3.5 Paternal Severe Illness Effects on Children's College Attendance}

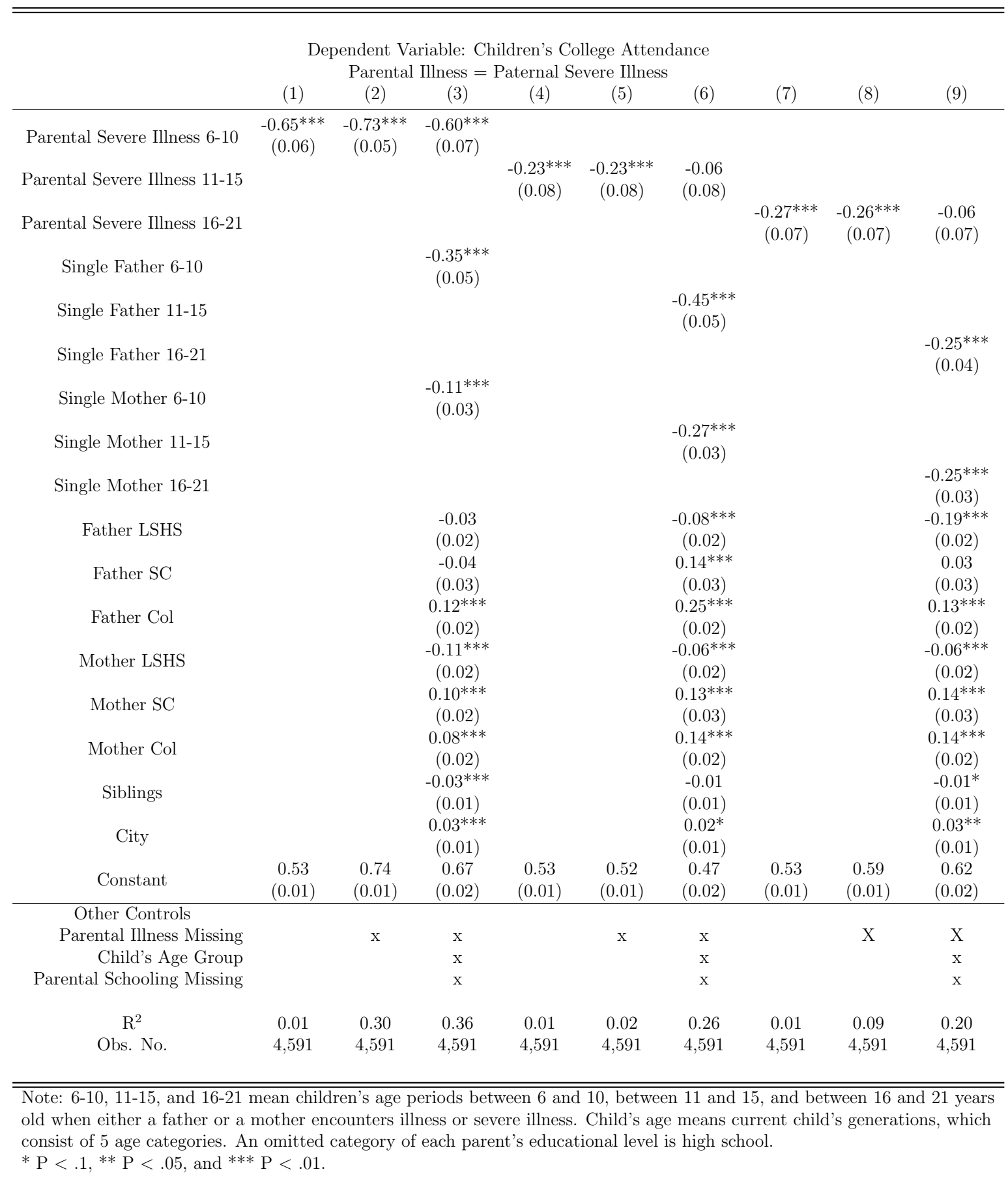




\section{Table 3.6 Maternal Severe Illness Effects on Children's College Attendance}

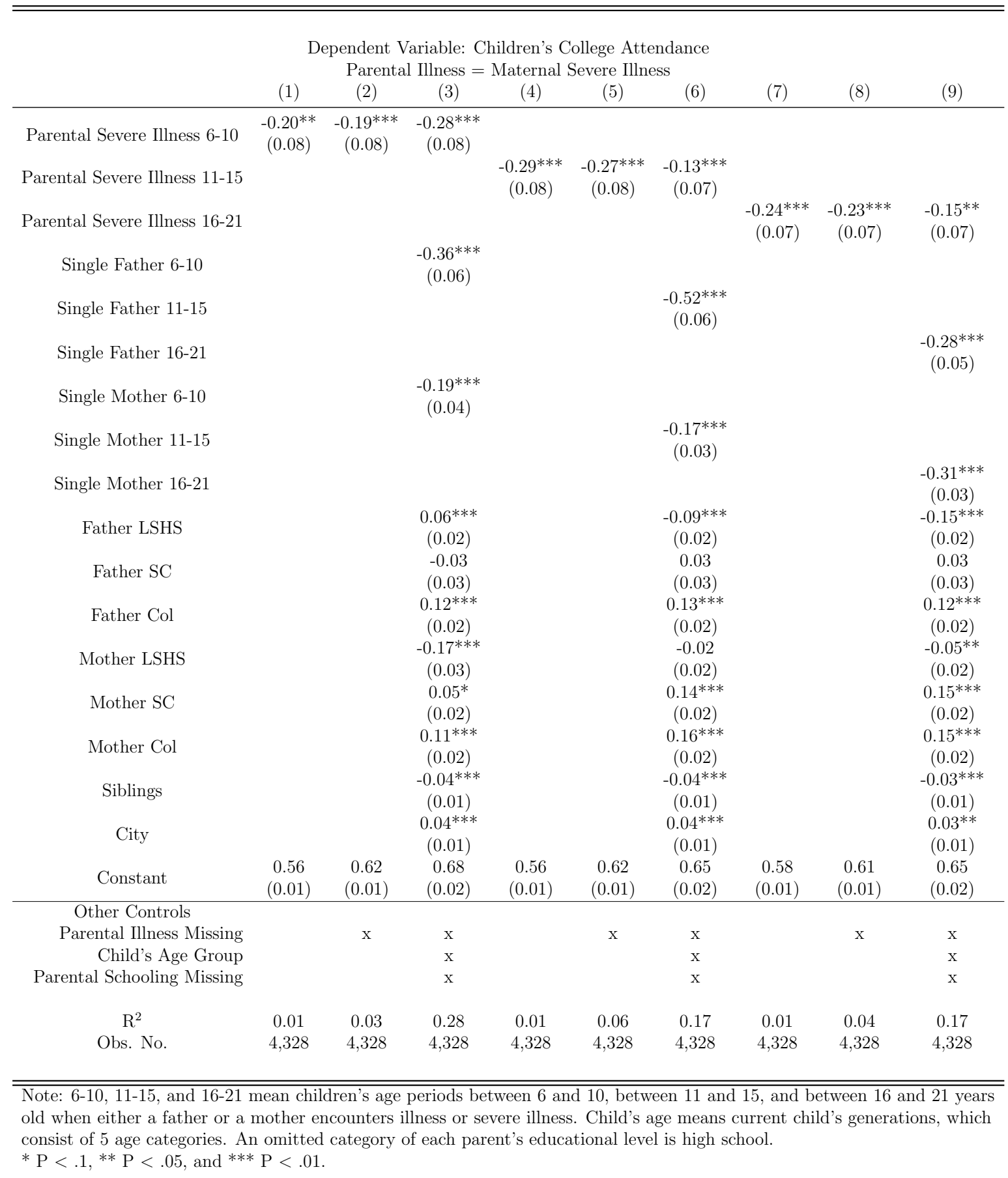


the greatest at the youngest age range of a child. A child whose father was seriously sick when he/she was aged between 6 and 10 years of age is less likely to go to a college by 65 percentage points than one whose father was not severely sick at the same age period. It decreases to 60 percentage points when we control for household structure and parental education, and it is statistically significant. However, the effects substantially drop to -0.06 and are no longer statistically significant at the middle and late age period of children. With controls for parenting structure and parents' education, there is no effect of severe illness of a father at any later points. In addition, the patterns of single parenting of either parent and parental education are similar to the effects of paternal illness.

Although paternal severe illness has much stronger effects than just illness, mother's serious health problems have very similar effects to illness. Maternal severe illness has a different relationship to background factors than simple maternal illness. The coefficient of maternal severe illness increases from -0.19 to -0.28 at the earliest age period of a child when the family background is controlled (columns (2) and (3) in Table 6). This study examines the relationship between severe illness and parental education at the end of this chapter (Table 11) to look at the reverse relation of severe illness, which is positive. In later age periods, however, the effects of severe illness decline when the family background is controlled. A 1 percentage point increase in a mother's severe health problems when a child was aged between 16 and 21-year-old decreases the chance that a child attends a college by about 0.15 percentage points.

\subsubsection{The Effects of Parental Illness on Children's Years of Schooling}

The analysis in this section also focuses on how either parent's health problems are associated with children's years of schooling. Unlike college attendance analysis, this analysis restricts children's age, between 22 to 37-year-old at the last survey year 
because it takes more time to complete education than to begin college. Years of schooling is coded as 10 for less than high school, 12 for high school graduation, 14 for some college, and 16 for college and above. I estimate effects of parent's health problems without controlling other variables in columns (1), (4), and (7) of each table.

Tables 7 to 10 show the results of how either parent's (severe) health problems affect children's years of schooling, respectively. In Table 7, a 1 percentage point increase in father's health problems when a child was aged between 6 and 10-yearold reduces 0.13 years of schooling of a child. After considering single parenting by either parent and other characteristics, the coefficient declines to -1.02, and it is still statistically significant (column (3) in Table 7). If a father was sick for at least one year while a child was between 11 and 15-year-old, it decreases .04 years of schooling of a child, but it is not statistically significant regardless of other variables. A father's illness when a child was aged between 16 and 21 reduces a child's years of schooling by -0.42 with controlling other variables (column (9)).

The pattern of single parenting by either parent is similar to when we look at the effects on college attendance. A mother's absence has greater negative effects on a child's education when a child was relatively young than a father's absence. However, the difference in the effects of one parent's absence is smaller when a child was between 16 and 21-year-old in column (9). If either parent who does not graduate from a high school, years of schooling of a child decreases somewhat, and parents' college degree helps a child obtain more years of schooling than a high school diploma, as we expect.

Table 8 also reports the estimates of the effects of maternal health problems. The pattern of the effects of maternal illness on years of schooling without considering other family background is similar to its effects on college attendance, as reported in Table 4. The effects are very similar regardless of age of child, so having a parent who is ill continuously reduces schooling of a child by about 1 year relative to no illness. The coefficient of maternal illness is -0.95 when a child is between 6 and 10 years 


\section{Table 3.7 Paternal Illness Effects on Children's Years of Schooling}

\begin{tabular}{|c|c|c|c|c|c|c|c|c|c|}
\hline \multicolumn{10}{|c|}{$\begin{array}{c}\text { Dependent Variable: Children's Years of Schooling } \\
\text { Parental Illness = Paternal Illness }\end{array}$} \\
\hline & (1) & (2) & (3) & $(4)$ & $(5)$ & (6) & (7) & $(8)$ & (9) \\
\hline Parental Illness 6-10 & $\begin{array}{c}-1.33^{* * *} \\
(0.21)\end{array}$ & $\begin{array}{c}-1.31^{* * *} \\
(0.20)\end{array}$ & $\begin{array}{c}-1.02^{* * *} \\
(0.19)\end{array}$ & & & & & & \\
\hline Parental Illness 11-15 & & & & $\begin{array}{l}-0.20 \\
(0.15)\end{array}$ & $\begin{array}{l}-0.20 \\
(0.15)\end{array}$ & $\begin{array}{l}-0.18 \\
(0.15)\end{array}$ & & & \\
\hline Parental Illness 16-21 & & & & & & & $\begin{array}{c}-0.71^{* * *} \\
(0.12)\end{array}$ & $\begin{array}{c}-0.77^{* * *} \\
(0.11)\end{array}$ & $\begin{array}{c}-0.42^{* * *} \\
(0.11)\end{array}$ \\
\hline Single Father 6-10 & & & $\begin{array}{c}-1.08^{* * *} \\
(0.21)\end{array}$ & & & & & & \\
\hline Single Father 11-15 & & & & & & $\begin{array}{c}-1.34^{* * *} \\
(0.20)\end{array}$ & & & \\
\hline Single Father 16-21 & & & & & & & & & $\begin{array}{c}-0.53^{* * *} \\
(0.16)\end{array}$ \\
\hline Single Mother 6-10 & & & $\begin{array}{c}-0.55^{* * *} \\
(0.10)\end{array}$ & & & & & & \\
\hline Single Mother 11-15 & & & & & & $\begin{array}{c}-0.93^{* * *} \\
(0.10)\end{array}$ & & & \\
\hline Single Mother 16-21 & & & & & & & & & $\begin{array}{c}-0.33^{* * *} \\
(0.10)\end{array}$ \\
\hline Father LSHS & & & $\begin{array}{l}-0.09 \\
(0.07)\end{array}$ & & & $\begin{array}{c}-0.34^{* * *} \\
(0.07)\end{array}$ & & & $\begin{array}{c}-0.45^{* * *} \\
(0.07)\end{array}$ \\
\hline Father SC & & & $\begin{array}{l}-0.04 \\
(0.08)\end{array}$ & & & $\begin{array}{c}0.51^{* * *} \\
(0.09)\end{array}$ & & & $\begin{array}{c}0.09 \\
(0.08)\end{array}$ \\
\hline Father Col & & & $\begin{array}{c}0.31^{* * *} \\
(0.06)\end{array}$ & & & $\begin{array}{c}0.78^{* * *} \\
(0.08)\end{array}$ & & & $\begin{array}{c}0.29^{* * *} \\
(0.07)\end{array}$ \\
\hline Mother LSHS & & & $\begin{array}{c}0.08 \\
(0.09)\end{array}$ & & & $\begin{array}{l}-0.02 \\
(0.06)\end{array}$ & & & $\begin{array}{c}-0.18^{* * *} \\
(0.06)\end{array}$ \\
\hline Mother SC & & & $\begin{array}{l}-0.01 \\
(0.09)\end{array}$ & & & $\begin{array}{c}0.04 \\
(0.10)\end{array}$ & & & $\begin{array}{c}0.11 \\
(0.08)\end{array}$ \\
\hline Mother Col & & & $\begin{array}{c}0.01 \\
(0.08)\end{array}$ & & & $\begin{array}{c}0.08 \\
(0.09)\end{array}$ & & & $\begin{array}{c}0.16^{* *} \\
(0.08)\end{array}$ \\
\hline Siblings & & & $\begin{array}{c}-0.10^{* * *} \\
(0.03)\end{array}$ & & & $\begin{array}{l}-0.04 \\
(0.03)\end{array}$ & & & $\begin{array}{l}-0.03 \\
(0.03)\end{array}$ \\
\hline City & & & $\begin{array}{c}0.07 \\
(0.04)\end{array}$ & & & $\begin{array}{c}0.02 \\
(0.04)\end{array}$ & & & $\begin{array}{c}0.03 \\
(0.04)\end{array}$ \\
\hline Constant & $\begin{array}{l}14.61 \\
(0.03) \\
\end{array}$ & $\begin{array}{l}15.19 \\
(0.03)\end{array}$ & $\begin{array}{l}14.78 \\
(0.09) \\
\end{array}$ & $\begin{array}{l}14.55 \\
(0.03)\end{array}$ & $\begin{array}{l}14.43 \\
(0.03) \\
\end{array}$ & $\begin{array}{l}14.23 \\
(0.08)\end{array}$ & $\begin{array}{l}14.61 \\
(0.03) \\
\end{array}$ & $\begin{array}{l}14.95 \\
(0.03) \\
\end{array}$ & $\begin{array}{l}15.09 \\
(0.08)\end{array}$ \\
\hline Other Controls & & & & & & & & & \\
\hline $\begin{array}{r}\text { Parental Illness Missing } \\
\text { Child's Age }\end{array}$ & & $\mathrm{x}$ & $\mathrm{x}$ & & $\mathrm{x}$ & $\mathrm{x}$ & & $\mathrm{x}$ & $\mathrm{x}$ \\
\hline Parental Schooling Missing & & & $\begin{array}{l}\mathrm{x} \\
\mathrm{x}\end{array}$ & & & $\begin{array}{l}\mathrm{x} \\
\mathrm{x}\end{array}$ & & & $\begin{array}{l}\mathrm{x} \\
\mathrm{x}\end{array}$ \\
\hline $\mathrm{R}^{2}$ & 0.01 & 0.23 & 0.29 & 0.01 & 0.01 & 0.29 & 0.01 & 0.28 & 0.35 \\
\hline Obs. No. & 3,987 & 3,987 & 3,987 & 3,987 & 3,987 & 3,987 & 3,987 & 3,987 & 3,987 \\
\hline
\end{tabular}


Table 3.8 Maternal Illness Effects on Children's Years of Schooling

\begin{tabular}{|c|c|c|c|c|c|c|c|c|c|}
\hline \multicolumn{10}{|c|}{$\begin{array}{c}\text { Dependent Variable: Children's Years of Schooling } \\
\text { Parental illness = Maternal Illness }\end{array}$} \\
\hline & (1) & $(2)$ & (3) & (4) & (5) & $(6)$ & (7) & (8) & (9) \\
\hline Parental Illness 6-10 & $\begin{array}{c}-1.02^{* * *} \\
(0.17)\end{array}$ & $\begin{array}{c}-1.01^{* * *} \\
(0.17)\end{array}$ & $\begin{array}{c}-0.95^{* * *} \\
(0.17)\end{array}$ & & & & & & \\
\hline Parental Illness 11-15 & & & & $\begin{array}{c}-0.87^{* * *} \\
(0.13)\end{array}$ & $\begin{array}{c}-0.90^{* * *} \\
(0.13)\end{array}$ & $\begin{array}{c}-0.41^{* * *} \\
(0.13)\end{array}$ & & & \\
\hline Parental Illness $16-21$ & & & & & & & $\begin{array}{c}-1.03^{* * *} \\
(0.12)\end{array}$ & $\begin{array}{c}-1.05^{* * *} \\
(0.12)\end{array}$ & $\begin{array}{c}-0.62^{* * *} \\
(0.12)\end{array}$ \\
\hline Single Father 6-10 & & & $\begin{array}{c}-0.93^{* * *} \\
(0.17)\end{array}$ & & & & & & \\
\hline Single Father 11-15 & & & & & & $\begin{array}{c}-1.31^{* * *} \\
(0.19)\end{array}$ & & & \\
\hline Single Father 16-21 & & & & & & & & & $\begin{array}{l}-0.06 \\
(0.14)\end{array}$ \\
\hline Single Mother 6-10 & & & $\begin{array}{c}-0.39^{* * *} \\
(0.14)\end{array}$ & & & & & & \\
\hline Single Mother 11-15 & & & & & & $\begin{array}{c}-0.52^{* * *} \\
(0.12)\end{array}$ & & & \\
\hline Single Mother 16-21 & & & & & & & & & $\begin{array}{c}-0.87^{* * *} \\
(0.12)\end{array}$ \\
\hline Father LSHS & & & $\begin{array}{c}0.08 \\
(0.08)\end{array}$ & & & $\begin{array}{c}-0.32 * * * \\
(0.07)\end{array}$ & & & $\begin{array}{c}-0.31^{* * *} \\
(0.07)\end{array}$ \\
\hline Father SC & & & $\begin{array}{l}-0.06 \\
(0.08)\end{array}$ & & & $\begin{array}{c}0.08 \\
(0.08)\end{array}$ & & & $\begin{array}{c}0.06 \\
(0.08)\end{array}$ \\
\hline Father Col & & & $\begin{array}{c}0.25^{* * *} \\
(0.07)\end{array}$ & & & $\begin{array}{c}0.32^{* * *} \\
(0.07)\end{array}$ & & & $\begin{array}{c}0.25^{* * *} \\
(0.07)\end{array}$ \\
\hline Mother LSHS & & & $\begin{array}{c}-0.20^{* *} \\
(0.10)\end{array}$ & & & $\begin{array}{c}-0.16^{* *} \\
(0.08)\end{array}$ & & & $\begin{array}{c}-0.24^{* * *} \\
(0.07)\end{array}$ \\
\hline Mother SC & & & $\begin{array}{l}-0.17 \\
(0.12)\end{array}$ & & & $\begin{array}{c}0.09 \\
(0.10)\end{array}$ & & & $\begin{array}{c}0.12 \\
(0.09)\end{array}$ \\
\hline Mother Col & & & $\begin{array}{c}0.04 \\
(0.09)\end{array}$ & & & $\begin{array}{c}0.11 \\
(0.09)\end{array}$ & & & $\begin{array}{l}0.17^{* *} \\
(0.08)\end{array}$ \\
\hline Siblings & & & $\begin{array}{c}-0.15^{* * * *} \\
(0.03)\end{array}$ & & & $\begin{array}{c}-0.13^{* * *} \\
(0.03)\end{array}$ & & & $\begin{array}{c}-0.07^{* *} \\
(0.03)\end{array}$ \\
\hline City & & & $\begin{array}{c}0.11^{* *} \\
(0.05)\end{array}$ & & & $\begin{array}{c}0.10^{* *} \\
(0.05)\end{array}$ & & & $\begin{array}{l}0.08^{*} \\
(0.05)\end{array}$ \\
\hline Constant & $\begin{array}{l}14.73 \\
(0.03) \\
\end{array}$ & $\begin{array}{l}14.96 \\
(0.03) \\
\end{array}$ & $\begin{array}{l}14.82 \\
(0.09) \\
\end{array}$ & $\begin{array}{l}14.73 \\
(0.03) \\
\end{array}$ & $\begin{array}{l}15.02 \\
(0.03)\end{array}$ & $\begin{array}{l}14.85 \\
(0.08) \\
\end{array}$ & $\begin{array}{l}14.78 \\
(0.03) \\
\end{array}$ & $\begin{array}{l}14.97 \\
(0.03)\end{array}$ & $\begin{array}{l}15.12 \\
(0.08)\end{array}$ \\
\hline Other Controls & & & & & & & & & \\
\hline Parental Illness Missing & & $\mathrm{x}$ & $\mathrm{x}$ & & $\mathrm{x}$ & $\mathrm{x}$ & & $\mathrm{x}$ & $\mathrm{x}$ \\
\hline Child's Age & & & $\mathrm{x}$ & & & $\mathrm{x}$ & & & $\mathrm{x}$ \\
\hline Parental Schooling Missing & & & $\mathrm{x}$ & & & $\mathrm{x}$ & & & $\mathrm{x}$ \\
\hline $\mathrm{R} \hat{2}$ & 0.01 & 0.06 & 0.22 & 0.01 & 0.13 & 0.21 & 0.03 & 0.19 & 0.26 \\
\hline Obs. No. & 3,776 & 3,776 & 3,776 & 3,776 & 3,776 & 3,776 & 3,776 & 3,776 & 3,776 \\
\hline
\end{tabular}


old even after controlling for household structure and family characteristics. When a child was between 16 and 21 years old, a 1 percent increment of mother's health problems decreases about 0.006 years of schooling of a child.

The effects of a parent's absence are different from when predicting college attendance. A 1 percentage point increase in a mother's absence in age periods of a child's age between 6 and 10 and age between 11 and 15 reduces about 0.01 or more years of schooling and statistically significant. If a mother's absence occurred when the child was between 16 and 21-year-old, the coefficient surprisingly decrease to .06 years of schooling, and it is not statistically significant. The effects of a father's absence are relatively weaker than a mother's absence when a child was between 6 and 15 years old. On the other hand, its effect at a later stage of a child is substantially greater than a mother's absence that coefficient is -0.87 . This pattern indicates father's role becomes more crucial for a child's educational success as the child ages.

Tables 9 and 10 predict a child's years of schooling using the measure of parental severe health problems. The paternal severe illness effects are similar to those predicting college attendance. When considering other variables, a percentage point increment of a father's severe illness at the younger age of a child decreases years of schooling by about 0.015 . Although father's severe illness reduces a child's years of schooling when a child was between aged 11 and 15 years and between aged 16 and 21 years, but they are not statistically significant (columns (6) and (9) in Table 9). This pattern also is similar to when predicting college attendance. We may be able to say that a father's education and his severe health problems when the child is old are not strongly correlated.

According to Table 10, mother's severe health problems are more strongly associated with children's education than a father's severe illness. A 1 percentage point increase in severe health problems of a mother would reduce about 0.035 years of schooling of a child if it happened when a child was before 16 years old. In later ages 


\section{Table 3.9 Paternal Severe Illness Effects on Children's Years of Schooling}

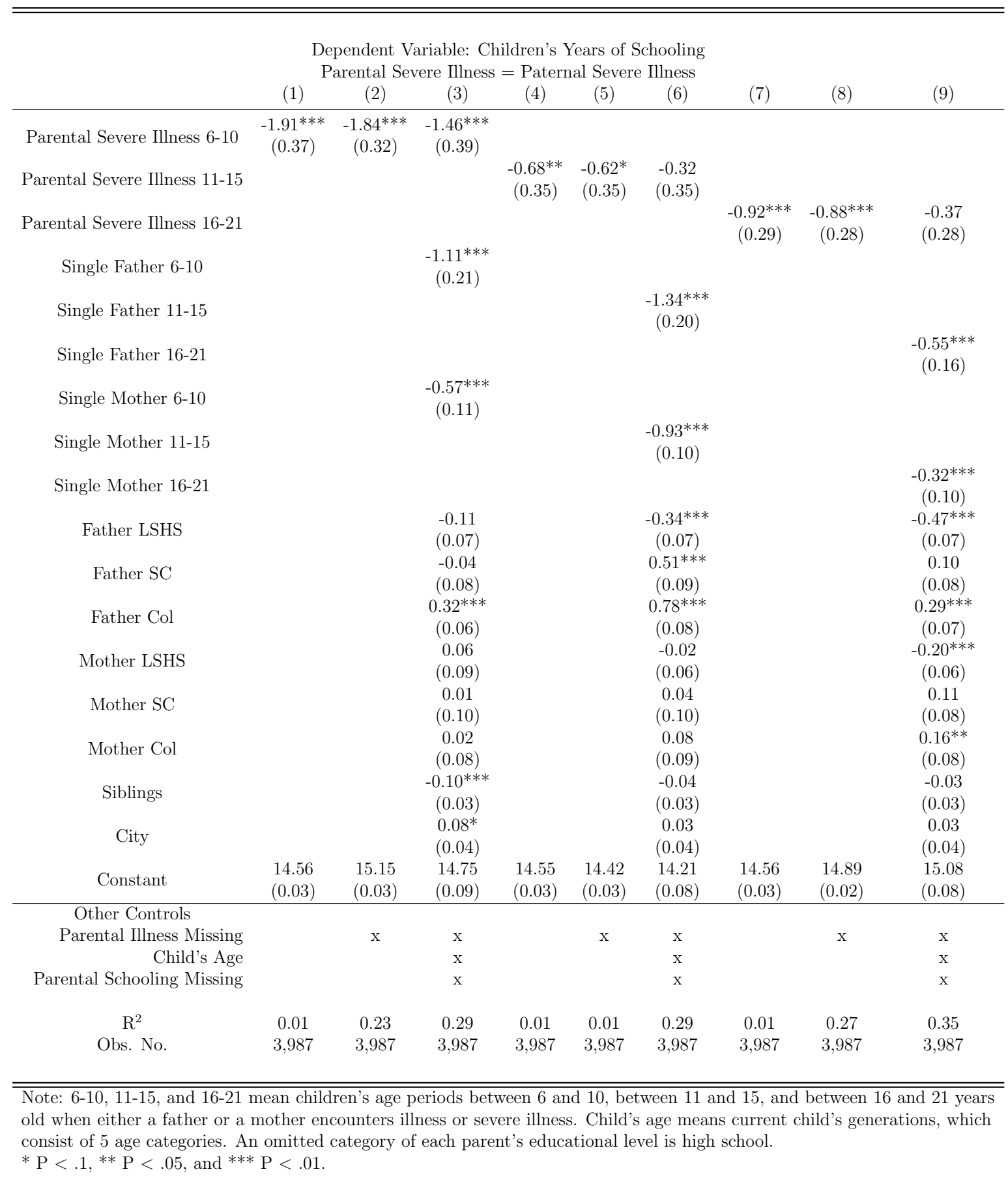




\section{Table 3.10 Maternal Severe Illness Effects on Children's Years of Schooling}

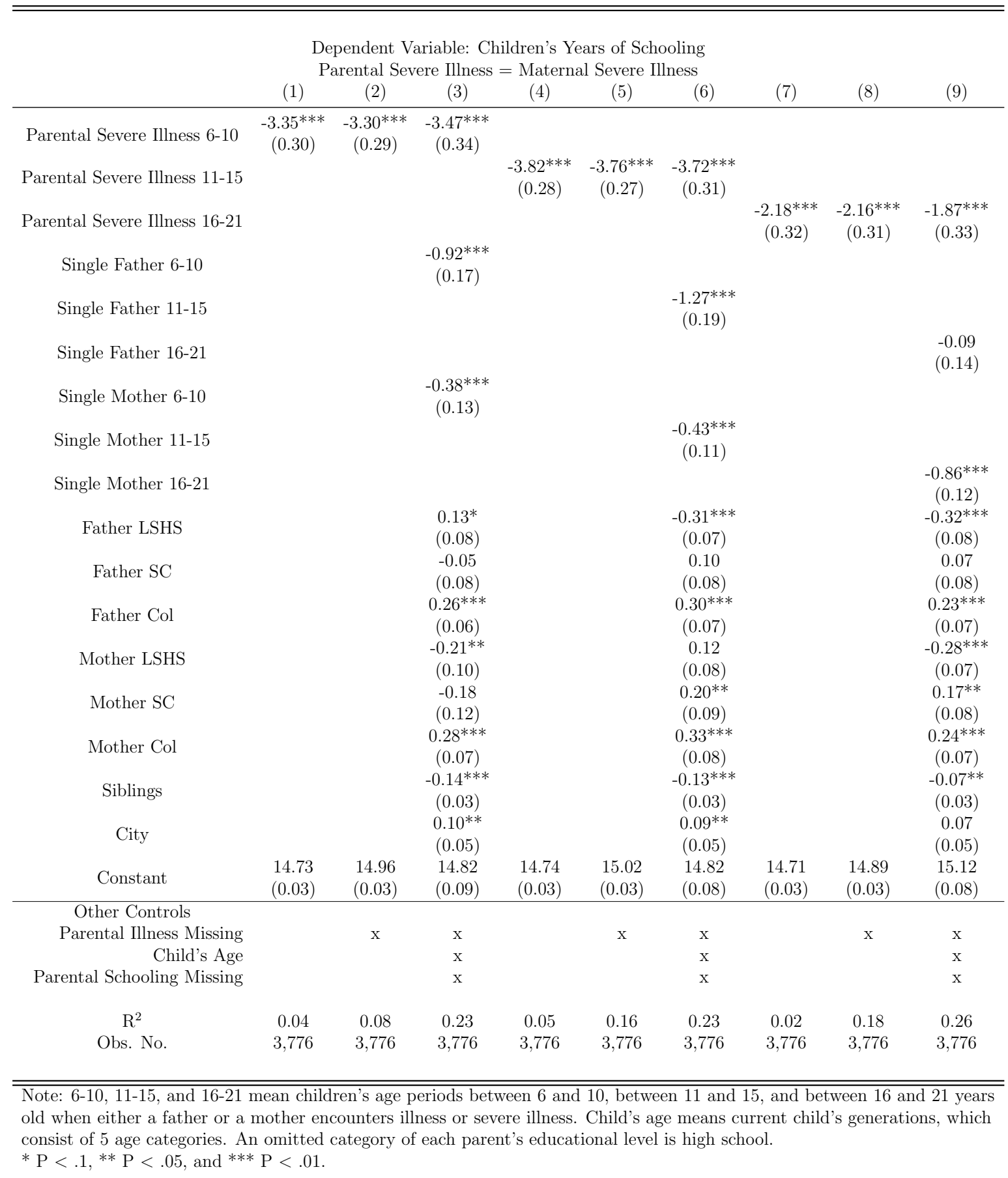


of a child, it has slightly lower effects, reducing schooling by about .02 years, but this is still greater than the effects for father's illness. When predicting college attendance of a child, a mother's severe illness also has a different pattern than a mother's illness. The effects become stronger controlling family background, an increase in the coefficient from -3.30 to -3.47 (columns (2) and (3) in Table 10). To see if there is a different relationship between parental education and severe illness at early ages of a child from the relationship at the later ages of the child, this study examines the correlation matrix in Table 11.

There are abundant theoretical and empirical studies identifying the positive association between education and health condition (Leigh, 1983, Feinstein et al., 2006, Groot and Van Den Brink, 2007, and Cutler and Lleras-Muney, 2006). Education can affect own health in direct and indirect ways. People with more education are more likely to have a greater income than those with less education and are likely to select a less risky occupations. More educated people also may have more knowledge regarding behaviors to improve health, such as pre-medical care, and may be more cautious doing perilous tasks. For these reasons, education is strongly associated with own health conditions.

However, a coefficient of a mother's severe health problems is more strongly associated with a child's educational success even after considering parents' education attainment, household structure, and other family characteristics, according to columns (2) and (3) in Tables (6) and (10). This means that a mother's severe illness may be positively associated with her education. Thus, Table 11 reports the results of the correlation between a parent's health problem and education. Father's illness and severe illness have a similar negative correlations with education. However, as we expected, the correlation between a mother's severe illness and her education is positive in panel $\mathrm{D}$, while other correlations are negative. The results in Table 11 explain why the association of a mother's severe health problems becomes stronger 
Table 3.11 Correlation Between Father's Illness and Education

\begin{tabular}{|c|c|c|c|}
\hline \multicolumn{4}{|c|}{ Panel A: Correlation Between Father's Illness and Education } \\
\hline \multirow[b]{3}{*}{ Paternal Education } & \multicolumn{3}{|c|}{ Father's Illness at Children's Age periods } \\
\hline & Between 6 - 10 & Between 11 - 15 & Between 16-21 \\
\hline & -0.09 & -0.13 & -0.19 \\
\hline \multicolumn{4}{|c|}{ Panel B: Correlation Between Father's Severe Illness and Education } \\
\hline \multirow[b]{3}{*}{ Paternal Education } & \multicolumn{3}{|c|}{ Father's Severe Illness at Children's Age periods } \\
\hline & Between $6-10$ & Between 11 - 15 & Between 16-21 \\
\hline & -0.03 & -0.07 & -0.11 \\
\hline \multicolumn{4}{|c|}{ Panel C: Correlation Between Mother's Illness and Education } \\
\hline \multirow[b]{3}{*}{ Maternal Education } & \multicolumn{3}{|c|}{ Mother's Illness at Children's Age periods } \\
\hline & Between $6-10$ & Between $11-15$ & Between 16-21 \\
\hline & -0.13 & -0.17 & -0.22 \\
\hline \multicolumn{4}{|c|}{ Panel D: Correlation Between Mother's Severe Illness and Education } \\
\hline & \multicolumn{3}{|c|}{ Mother's Illness at Children's Age periods } \\
\hline & Between 6 - 10 & Between 11 - 15 & Between 16-21 \\
\hline Mother's Education & 0.11 & 0.09 & 0.01 \\
\hline \multicolumn{4}{|c|}{$\begin{array}{l}\text { Note: The age periods } 6-10,11-15 \text {, and } 16-21 \text { mean children's age periods between } \\
6 \text { and } 10 \text {, between } 11 \text { and } 15 \text {, and between } 16 \text { and } 21 \text {-year-old when either a father } \\
\text { or a mother encounters illness or severe illness. Parental education is measured by } \\
\text { years of schooling, which is translated to } 10 \text { years for less than high school, } 12 \\
\text { years for high school, } 14 \text { years for some college, and } 16 \text { years for college and above }\end{array}$} \\
\hline
\end{tabular}

after controlling for her education.

\subsubsection{The Effects of Parental Illness with Controlling for Parental Income}

This section investigates the effects of parental (severe) illness when additionally including parental income. Parental income is calculated by summing up earnings, capital gains, real estate gains, private and public transfer income, and other 


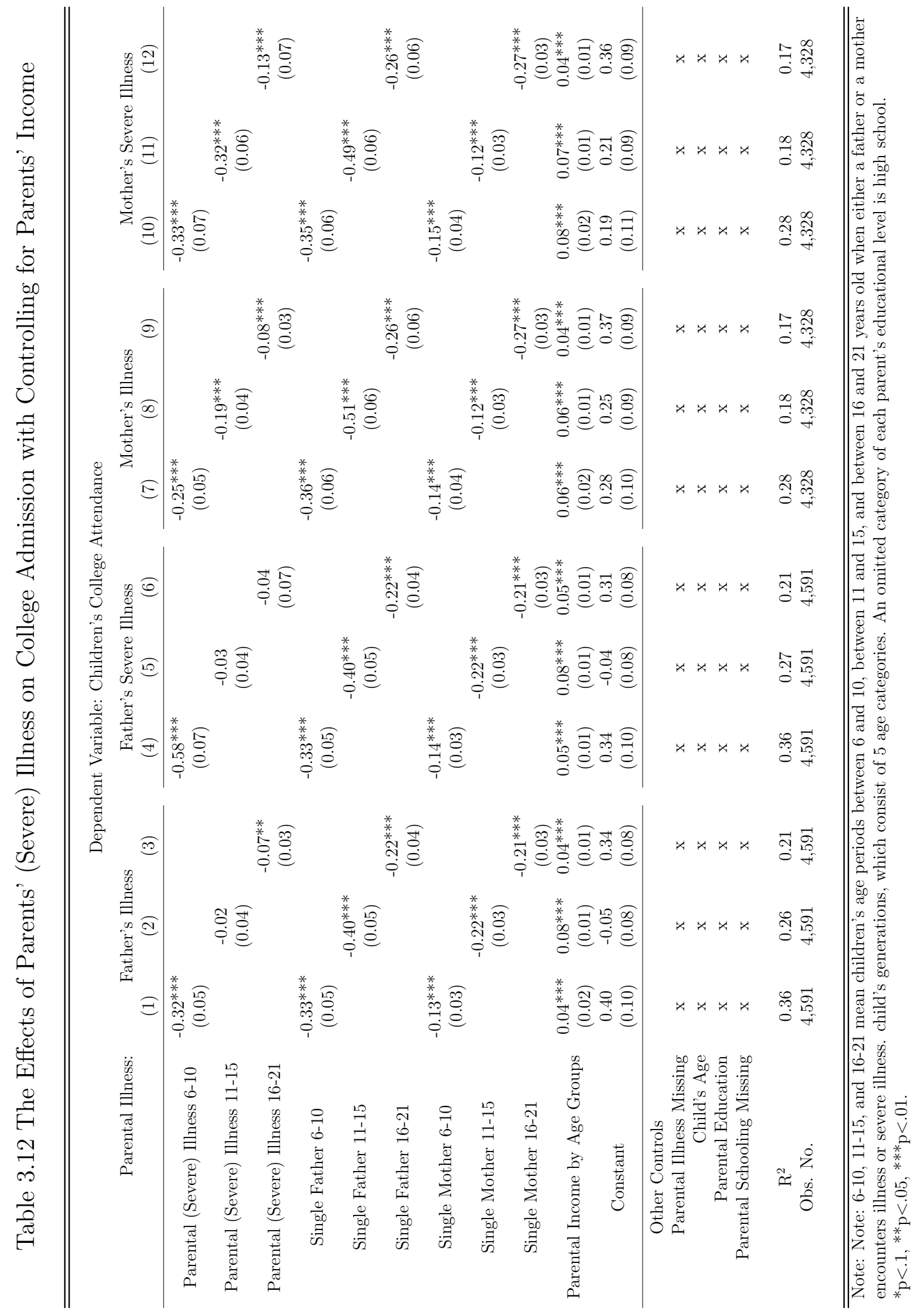




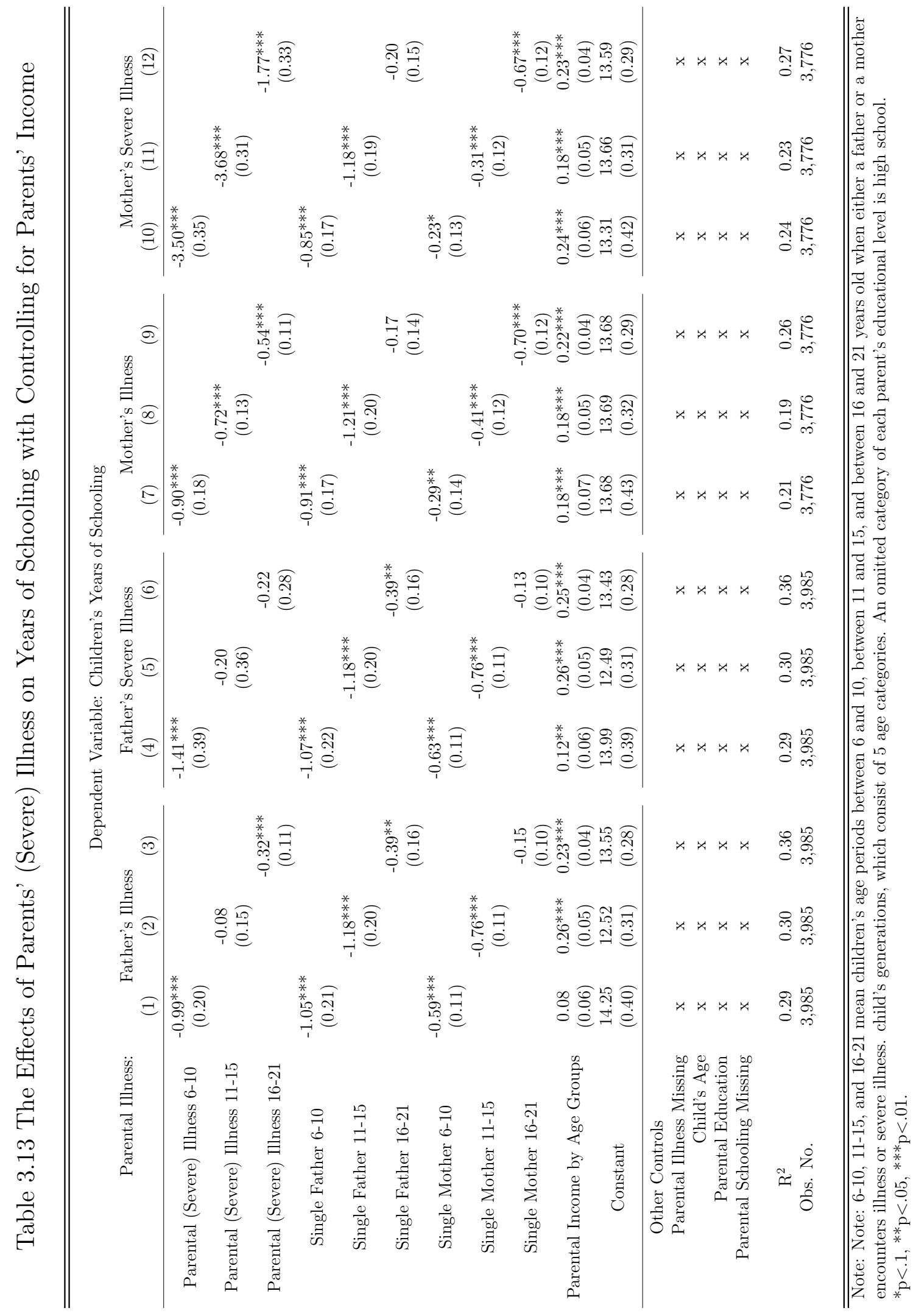


miscellaneous income. We also measure average parental income for periods when children were between ages 6 and 10, between ages 11 and 15, and between ages 16 and 21. As we mention above, although parental income is a crucial factor in determining children's educational success, if the analysis includes parental income, the results may not capture the full causal effect of health because income may well be affected by health problems.

Tables 12 and 13 show the estimates, including single parenting, parents' education, and other characteristics. The estimates are very similar to Tables 4 to 10. After controlling for parental income, the effects of parental (severe) illness on the college attendance of a child are almost identical to the results without including parents' income. The estimates of single parenting by either a parent also have very similar patterns. According to Tables 12 and 13, parental income at each age of children is positively associated with a child's educational achievement as expected. However, the association is relatively weaker than other variables of interest: parents' (severe) illness and single parenting. In other words, parents' (severe) illness is a more essential determinant of a child's education than parental income.

\subsection{Discussion and Conclusion}

Parents' health conditions can substantially reduce their children's educational achievement through lowering parenting quality. If one parent is sick when a child is in childhood, it decreases financial investment in children's education. Another parent also is not able to spend time caring for children who have particular needs. The purpose of this study is to estimate the effects of parents' health at each age period

of childhood (between ages 6 and 10, between ages 11 and 15, and between ages 16 and 21) on children's educational achievement.

This study investigates empirically how parents' health problems are related to 
their children's education. A parent's health problem reduces children's educational achievement, which is measured here as the chance of going to college or having more years of schooling. The effects of a parent's health problem substantially decrease after controlling for both parents' education, single parenting, and other characteristics. As many studies note, this is because a parent's illness is negatively associated with the parent's education (Leigh, 1983, Feinstein et al., 2006, Groot and Van Den Brink, 2007, and Cutler and Lleras-Muney, 2006). Also, parental education predicts children's educational attainment, which means that children with more educated parents are likely to obtain greater education. A parent's more severe health problem has a stronger relationship with educational success.

Korea has a relatively well organized public health insurance. Lower-income families, however, may not be able to afford medical payments even after adjustment by the public insurance. In addition, public health insurance cannot cover all kinds of illnesses. Also, there are many policies to support children in single-parent families. However, children whose parents have illnesses are the target of fewer direct policies than children with single parents although children with parents who have severe health problems might experience similar difficulties to children in single-parent families.

Our findings can imply possible policies that may be able to support children's education. When parents suffer from (severe) illness, the illness leads to deficit in the budget for the family. A smaller family budget may reduce the children's education due to a decline in the family's financial investment. Also, parental health problems may cause parents to spend less time with children because another parent takes care of a sick spouse. The time spent with children makes an important contribution to the educational environment of children. Since this study investigates the causal relationship between parents' health and children's educational achievement, this study proposes policies aimed at supporting children's educational opportunity by helping 
children who have sick parents.

One implementable policy is to provide educational scholarships to children whose parents undergo a financial deficit due to medical expenditures. Such a scholarship can help maintain the educational opportunity for children when parents face medical expenses. The scholarship would allow children to maintain the level of schooling when faced parental health problems. Another possible policy would be providing support for after-school curricula to children in lower-income families who have an illness of either parent. In the case of children in early childhood (before entering elementary school), government possibly would operate educational institutions to care for the children. The ultimate benefit of such the support for children who have sick parents would be to maintain children's educational attainment.

We are not able to identify the effects of Korea's public health insurance and relevant health policies. Health insurance may help households that have a sick parent by covering some unexpected medical expenses. It also may reduce the likelihood that parents curtail investment in their children's education. For countries with less developed health insurance systems, the effects of parental illness may well be greater than those we observe in Korea. 


\section{Bibliography}

Acemoglu, Daron (2002) "Technical change, inequality, and the labor market," Journal of economic literature, 40 (1), 7-72.

Adda, Jérôme, Anders Bjorklund, and Helena Holmlund (2011) "The role of mothers and fathers in providing skills: Evidence from parental deaths."

Autor, David H, Lawrence F Katz, and Melissa S Kearney (2006) "The polarization of the US labor market," AEA Papers and Proceedings, 96 (2), 189-194.

Bazzoli, Gloria J (1985) "The early retirement decision: new empirical evidence on the influence of health," Journal of Human Resources, 214-234.

Becker, Gary S, Scott Duke Kominers, Kevin M Murphy, and Jörg L Spenkuch (2018) "A theory of intergenerational mobility," Journal of Political Economy, 126 (S1), S7-S25.

Becker, Gary S and Nigel Tomes (1979) "An Equilibrium theory of the distribution of income and intergenerational mobility," Journal of Political Economy, 87 (6), $1153-1189$.

_ (1986) "Human capital and the rise and fall of families," Journal of Labor Economics, 4 (3, Part 2), S1-S39.

Behrman, Jere R and Mark R Rosenzweig (2002) "Does increasing women's schooling raise the schooling of the next generation?" American Economic Review, 92 (1), 323-334.

Bingley, Paul, Kaare Christensen, and Vibeke Myrup Jensen (2009) "Parental schooling and child development: Learning from twin parents," Danish National Centre for Social Research Social Policy and Welfare Services Working Paper 07:2009.

Björklund, Anders and Markus Jäntti (1997) "Intergenerational income mobility in Sweden compared to the United States," The American Economic Review, 87 (5), 1009-1018. 
Björklund, Anders, Mikael Lindahl, and Erik Plug (2006) "The origins of intergenerational associations: Lessons from Swedish adoption data," The Quarterly Journal of Economics, 121 (3), 999-1028.

Black, Sandra E. and Paul J. Devereux (2011) "Chapter 16 - Recent Developments in Intergenerational Mobility," 4 Part B of Handbook of Labor Economics, 1487 1541: Elsevier.

Black, Sandra E, Paul J Devereux, and Kjell G Salvanes (2005) "Why the apple doesn't fall far: Understanding intergenerational transmission of human capital," American Economic Review, 95 (1), 437-449.

Blanden, Jo, Alissa Goodman, Paul Gregg, and Stephen Machin (2004) "Changes in intergenerational mobility in Britain," Generational Income Mobility in North America and Europe, 122-46.

Blanden, Jo, Paul Gregg, and Lindsey Macmillan (2007) "Accounting for intergenerational income persistence: Noncognitive skills, ability and education," The Economic Journal, 117 (519), C43-C60.

Burtless, Gary (1987) "Occupational effects on the health and work capacity of older men," Work, health, and income among the elderly, 103-41.

Cameron, Adrian Colin and Pravin K Trivedi (2010) Microeconometrics using stata, revised edition, 5: Stata press College Station, TX.

Carneiro, Pedro, Costas Meghir, and Matthias Parey (2013) "Maternal education, home environments, and the development of children and adolescents," Journal of the European Economic Association, 11 (suppl_1), 123-160.

Chen, Stacey H, Yen-Chien Chen, and Jin-Tan Liu (2009) "The impact of unexpected maternal death on education: First evidence from three national administrative data links," American Economic Review, 99 (2), 149-53.

Chetty, Raj, Nathaniel Hendren, Patrick Kline, and Emmanuel Saez (2014a) "Where is the land of opportunity? The geography of intergenerational mobility in the United States," The Quarterly Journal of Economics, 129 (4), 1553-1623.

Chetty, Raj, Nathaniel Hendren, Patrick Kline, Emmanuel Saez, and Nicholas Turner (2014b) "Is the United States still a land of opportunity? Recent trends in intergenerational mobility," American Economic Review, 104 (5), 141-47.

Choi, HwaJung (2011) "Parents' health and adult children's subsequent working status: A perspective of intergenerational transfer and time allocation," Journal of Family and Economic Issues, 32 (3), 493-507.

Connolly, Marie, Miles Corak, and Catherine Haeck (2019) "Intergenerational mobility between and within Canada and the United States," Journal of Labor Economics, 37 (S2), S595-S641. 
Conti, Valentina and Joanna Kopinska (2018) "The role of parental cognitive ageing in the intergenerational mobility of cognitive abilities," Labour Economics, 51, 38-47.

Corak, Miles (2001) "Death and divorce: The long-term consequences of parental loss on adolescents," Journal of Labor Economics, 19 (3), 682-715.

(2006) "Do poor children become poor adults? Lessons from a cross-country comparison of generational earnings mobility," in Dynamics of Inequality and Poverty, 13, 143-188: Emerald Group Publishing Limited, Bingley.

(2013a) "Income inequality, equality of opportunity, and intergenerational mobility," Journal of Economic Perspectives, 27 (3), 79-102.

(2013b) "Inequality from generation to generation: The United States in comparison," 1, 107-126: ABC-CLIO Santa Barbara, CA.

Currie, Janet and Brigitte C Madrian (1999) "Health, health insurance and the labor market," Handbook of labor economics, 3, 3309-3416.

Cutler, David M and Adriana Lleras-Muney (2006) "Education and health: evaluating theories and evidence," Technical report, National bureau of economic research.

De Haan, Monique (2011) "The effect of parents' schooling on child's schooling: A nonparametric bounds analysis," Journal of Labor Economics, 29 (4), 859-892.

Dearden, Lorraine, Stephen Machin, and Howard Reed (1997) "Intergenerational mobility in Britain," The Economic Journal, 47-66.

Ministry of Education, Science and Technology (1973) Statistical yearbook of education: [in Korean] Seoul, Korea: Ministry of Education, Republic of Korea.

(2008) "2008 Brief Statistics on Korean Education,": Seoul, Korea: Ministry of Education, Republic of Korea.

Ettner, Susan L, Richard G Frank, and Ronald C Kessler (1997) "The impact of psychiatric disorders on labor market outcomes," ILR Review, 51 (1), 64-81.

Feinstein, Leon, Ricardo Sabates, Tashweka M Anderson, Annik Sorhaindo, and Cathie Hammond (2006) "What are the effects of education on health," in Measuring the effects of education on health and civic engagement: Proceedings of the Copenhagen symposium, 171-354, Organisation for Economic Co-operation and Development Paris.

Gertler, Paul, David I Levine, and Minnie Ames (2004) "Schooling and parental death," Review of Economics and Statistics, 86 (1), 211-225.

Giustinelli, Pamela (2011) "Non-parametric bounds on quantiles under monotonicity assumptions: with an application to the Italian education returns," Journal of Applied Econometrics, 26 (5), 783-824. 
Gollu, Gultekin (2015) Essays in Health Economics Ph.D. dissertation, The University of Wisconsin-Madison.

Gonzalez, Libertad (2005) "Nonparametric bounds on the returns to language skills," Journal of Applied Econometrics, 20 (6), 771-795.

Gould, Eric D, Avi Simhon, and Bruce A Weinberg (2020) "Does parental quality matter? Evidence on the transmission of human capital using variation in parental influence from death, divorce, and family size," Journal of Labor Economics, 38 (2), 569-610.

Grönqvist, Erik, Björn Öckert, and Jonas Vlachos (2017) "The intergenerational transmission of cognitive and noncognitive abilities," Journal of Human Resources, $52(4), 887-918$.

Groot, Wim and Henriëtte Maassen Van Den Brink (2007) "The health effects of education," Economics of Education Review, 26 (2), 186-200.

Grossman, Michael (1972) "On the concept of health capital and the demand for health," Journal of Political economy, 80 (2), 223-255.

Grossman, Michael and Robert Kaestner (1997) Effects of Education on Health, 69124: University of Michigan Press.

Gundersen, Craig, Brent Kreider, and John Pepper (2012) "The impact of the National School Lunch Program on child health: A nonparametric bounds analysis," Journal of Econometrics, 166 (1), 79-91.

Haveman, Robert and Barbara Wolfe (1995) "The determinants of children's attainments: A review of methods and findings," Journal of Economic Literature, 33 (4), $1829-1878$.

Hof, Stefanie (2014) "Does private tutoring work? The effectiveness of private tutoring: A nonparametric bounds analysis," Education Economics, 22 (4), 347-366.

Holmlund, Helena, Mikael Lindahl, and Erik Plug (2011) "The causal effect of parents' schooling on children's schooling: A comparison of estimation methods," Journal of Economic Literature, 49 (3), 615-51.

Huber, Martin, Lukas Laffers, and Giovanni Mellace (2017) "Sharp IV bounds on average treatment effects on the treated and other populations under endogeneity and noncompliance," Journal of Applied Econometrics, 32 (1), 56-79.

Iannelli, Cristina (2002) "Parental Education and Young People's Educational and Labour Market Outcomes: A Comparison across Europe," MZES Working Papers 45, MZES. 
Jung, Youn, Ju-Hwan Oh, and Young-Tae Cho (2007) "Differential effects of family income on self-rated health by age: analysis of Seoul citizens health indicators survey 2001, 2005 (in Korean)," Journal of Preventive Medicine and Public Health, 40 (5), 381-387.

Jyung, Chyulyoung (1997) "Current status and new directions for vocational high schools," [in Korean] The Journal of Vocational Education Research, 16 (1), 1-29.

Kalil, Ariel, Magne Mogstad, Mari Rege, and Mark E Votruba (2016) "Father presence and the intergenerational transmission of educational attainment," Journal of Human Resources, 51 (4), 869-899.

Kang, Changhui (2011) "Family size and educational investments in children: Evidence from private tutoring expenditures in South Korea," Oxford Bulletin of Economics and Statistics, 73 (1), 59-78.

Kang, Euntaek (2014) "A study on the intergenerational mobility of migration to the Seoul metropolitan area," [in Korean] Journal of Korea Real Estate, 32(1) (1), $75-92$.

Kikuchi, Nobuyoshi (2017) "Intergenerational transmission of education in Japan: Nonparametric bounds analysis with multiple treatments," ISER Discussion Paper No. 1011.

Kim, Hisam (2009) "An Analysis of intergenerational economic mobility in Korea," [in Korean] Korea Development Institute. 18.

Kim, J, Y Song, and E Paek (2013) "Education and self-rated health: The links through labor-market status and economic status, (in Korean)," Korean Journal of Sociology, 47 (2), 211-239.

Kim, Jinsook (2007a) "Relationship between job satisfaction and self-rated health status among salaried Workers in Korea," Quarterly Journal of Labor Policy, 7 (4), $143-164$.

Kim, Jinyoung (2007b) "The relationship between socioeconomic status and health in Korea-focusing on age variations, (in Korean)," Korean Journal of Sociology, 41 (3), 127-153.

(2019) "Education and Health: Comparison between the Mediating Effect of Income and That of Personal Control, (in Korean)," Health and Social Science, 51 (1), 133-151.

Kim, Soobin (2017) "Intergenerational earnings mobility in Korea," IZA Journal of Development and Migration, 7, 21. 
Koenker, Roger and Gilbert Bassett Jr (1978) "Regression quantiles," Econometrica, $33-50$.

Kreider, Brent and John V Pepper (2007) "Disability and employment: Reevaluating the evidence in light of reporting errors," Journal of the American Statistical Association, 102 (478), 432-441.

Lechner, Michael (1999) "Nonparametric bounds on employment and income effects of continuous vocational training in East Germany," The Econometrics Journal, 2 (1), 1-28.

Lee, Chulin and Gary Solon (2009) "Trends in intergenerational income mobility," The Review of Economics and Statistics, 91 (4), 766-772.

Lee, Jungmin (2008) "Sibling size and investment in children's education: An Asian instrument," Journal of Population Economics, 21 (4), 855-875.

Lee, Yong Suk (2014) "Exams, districts, and intergenerational mobility: Evidence from South Korea," Labour Economics, 29, 62-71.

Leigh, J Paul (1983) "Direct and indirect effects of education on health," Social Science $\mathscr{E}$ Medicine, 17 (4), 227-234.

Lemieux, Thomas (2006) The "Mincer Equation" thirty years after schooling, experience, and earnings, 127-145, Boston, MA: Springer US.

Lundborg, Petter, Martin Nordin, and Dan Olof Rooth (2018) "The intergenerational transmission of human capital: the role of skills and health," Journal of Population Economics, 31 (4), 1035-1065.

Ma, Kangrae and Okyu Kwon (2013) "A study on intergenerational mobility of housing asset," [in Korean] Housing Studies Review, 21 (2), 169-188.

Manski, Charles F (1989) "Anatomy of the selection problem," Journal of Human Resources, 24(3) (3), 343-360.

Manski, Charles F. (1990) "Nonparametric Bounds on Treatment Effects," The American Economic Review, 80 (2), 319-323.

Manski, Charles F (1997) "Monotone treatment response," Econometrica, 65(6) (6), 1311-1334.

Manski, Charles F. and John V. Pepper (2000) "Monotone instrumental variables: With an application to the returns to schooling," Econometrica, 68(4) (4), 9971010 .

(2009) "More on monotone instrumental variables," The Econometrics Journal, 12 (s1), S200-S216. 
Maurin, Eric and Sandra McNally (2008) "Vive la revolution! Long-term educational returns of 1968 to the angry students," Journal of Labor Economics, 26 (1), 1-33.

Mazumder, Bhashkar (2005) "Fortunate sons: New estimates of intergenerational mobility in the United States using social security earnings data," Review of Economics and Statistics, 87 (2), 235-255.

Mazumder, Bhashkar and David I Levine (2002) "Choosing the right parents: Changes in the intergenerational transmission of inequality between 1980 and the early 1990s," FRB Chicago Working Paper.

Meadows, Sarah O, Sara S McLanahan, and Jeanne Brooks-Gunn (2007) "Parental depression and anxiety and early childhood behavior problems across family types," Journal of Marriage and Family, 69 (5), 1162-1177.

Mogstad, Magne (2017) "The human capital approach to intergenerational mobility," Journal of Political Economy, 125 (6), 1862-1868.

Mullahy, John and Jody Sindelar (1996) "Employment, unemployment, and problem drinking," Journal of health economics, 15 (4), 409-434.

Nam, K (2008) “The effect of parents' education level on children's education level and occupational status," The Journal of Economics and Finance of Education, $17,61-92$.

Nicoletti, Cheti and John F Ermisch (2008) "Intergenerational Earnings Mobility: Changes across Cohorts in Britain," The BE Journal of Economic Analysis 8 Policy, 7, 777-826.

Okumura, Tsunao and Emiko Usui (2014) "Concave-monotone treatment response and monotone treatment selection: With an application to the returns to schooling," Quantitative Economics, 5 (1), 175-194.

Olivetti, Claudia and M Daniele Paserman (2015) "In the name of the son (and the daughter): Intergenerational mobility in the United States, 1850-1940," American Economic Review, 105 (8), 2695-2724.

Oreopoulos, Philip, Marianne E Page, and Ann Huff Stevens (2006) "The intergenerational effects of compulsory schooling," Journal of Labor Economics, 24 (4), $729-760$.

Parsons, Donald O (1982) "The male labour force participation decision: health, reported health, and economic incentives," Economica, 49 (193), 81-91.

Pepper, John V (2000) "The intergenerational transmission of welfare receipt: A nonparametric bounds analysis," Review of Economics and Statistics, 82 (3), 472488. 
Phang, Hanam and G Kim (2001) "Change and inheritance: The structure and process of social status achievement in Korea," [in Korean] Korean Journal of Sociology, 35 (3), 1-30.

Restuccia, Diego and Carlos Urrutia (2004) "Intergenerational persistence of earnings: The role of early and college education," American Economic Review, 94 (5), 13541378.

Richey, Jeremiah and Kiho Jeong (2014) "Intergenerational economic mobility in Korea using a quantile regression analysis," [in Korean] Journal of the Korean Data and Information Science Society, 25 (4), 715-725.

Sacerdote, Bruce (2007) "How large are the effects from changes in family environment? A study of Korean American adoptees," The Quarterly Journal of Economics, 122 (1), 119-157.

Sickles, Robin C and Paul Taubman (1986) "An analysis of the health and retirement status of the elderly," Econometrica: Journal of the Econometric Society, 13391356.

Smith, James P (1999) "Healthy bodies and thick wallets: the dual relation between health and economic status," Journal of Economic perspectives, 13 (2), 145-166.

Solon, Gary (1992) "Intergenerational income mobility in the United States," The American Economic Review, 393-408.

- (1999) "Intergenerational mobility in the labor market," in Handbook of Labor Economics, 3, 1761-1800: New York: Elsevier.

Stern, Steven (1989) "Measuring the effect of disability on labor force participation," Journal of Human Resources, 361-395.

Ueda, Atsuko (2013) "Intergenerational mobility of earnings in South Korea," Journal of Asian Economics, 27, 33-41.

Van Doorslaer, Eddy, Adam Wagstaff, Han Bleichrodt, Samuel Calonge, Ulf-G Gerdtham, Michael Gerfin, Jose Geurts, Lorna Gross, Unto Häkkinen, Robert E Leu et al. (1997) "Income-related inequalities in health: some international comparisons," Journal of health economics, 16 (1), 93-112.

Wagstaff, Adam (1986) "The demand for health: some new empirical evidence," Journal of Health economics, 5 (3), 195-233.

Yoon, Byoung-Jun (2016) "Relationship of Socioeconomic Status and Health Behaviors with Self-rated Health Status (in Korean)," The Journal of Korean Society for School \& Community Health Education, 17 (3), 71-85. 


\section{VITA}

Joonhong Ahn was born and raised in Seoul, South Korea. He received his Bachelor's degree in Economics from Dongguk University, Seoul, South Korea in 2012. Then, he also earned a master's degree in Economics under the supervision of Dr. Hyungtaek Ahn at Dongguk University in 2013.

He began his Ph.D. program in Economics at the University of Missouri, Columbia in the fall of 2015. While at the University of Missouri, he was advised by Dr. Mueser, and his primary area of specialization is labor economics particularly focusing on intergenerational transmission of socioeconomic status in Korea. His secondary interests are health economics, policy evaluation, and applied econometrics. During the Ph.D. study, he was a graduate teaching assistant from the fall of 2016 to the spring of 2021. He also participated in Missouri Applied Data Analytics Training Program in the summer of 2019 and the Missouri Adult Education and Literacy Program in the summer of 2021 as a research assistant. 